\author{
UNIVERSIDADE DE SÃO PAULO \\ FACULDADE DE ECONOMIA, ADMINISTRAÇÃO E CONTABILIDADE \\ DEPARTAMENTO DE ECONOMIA \\ PROGRAMA DE PÓS-GRADUAÇÃO EM ECONOMIA
}

\title{
Maturidade da Dívida Pública e Modelos DSGE
}

\author{
Paulo de Carvalho Lins
}

Orientador: Prof. Dr. Márcio Issao Nakane

São Paulo - Brasil

2016 
Prof. Dr. Marco Antonio Zago

Reitor da Universidade de São Paulo

Prof. Dr. Adalberto Américo Fischmann

Diretor da Faculdade de Economia, Administração e Contabilidade

Prof. Dr. Hélio Nogueira da Cruz

Chefe do Departamento de Economia

Prof. Dr. Márcio Issao Nakane

Coordenador do Programa de Pós-Graduação em Economia 


\section{PAULO DE CARVALHO LINS}

\section{Maturidade da Dívida Pública e Modelos DSGE}

Dissertação apresentada ao Departamento de Economia da Faculdade de Economia, Administração e Contabilidade da Universidade de São Paulo como requisito parcial para a obtenção do título de Mestre em Ciências.

Orientador: Prof. Dr. Márcio Issao Nakane

Versão Corrigida

(versão original disponível na Biblioteca da Faculdade de Economia, Administração e Contabilidade)

São Paulo - Brasil

2016 


\section{FICHA CATALOGRÁFICA}

\section{Elaborada pela Seção de Processamento Técnico do SBD/FEA/USP}

\section{Lins, Paulo de Carvalho}

Maturidade da dívida pública e modelos DSGE / Paulo de CarValho Lins. - São Paulo, 2016.

$115 \mathrm{p}$.

Dissertação (Mestrado) - Universidade de São Paulo, 2016.

Orientador: Márcio Issao Nakane

1. Política monetária 2. Dívida pública 3. Política fiscal 4. Letras financeiras do tesouro I. Universidade de São Paulo. Faculdade de Economia, Administração e Contabilidade. II. Título.

$$
\text { CDD - } 332.46
$$


Para Haroldo, Isabel, Ana e Gabriel 



\section{Agradecimentos}

À minha família, agradeço o apoio constante. Especialmente, agradeço ao meu Pai por seus conselhos em momentos críticos e à minha Mãe pelo seu carinho imensurável. À minha irmã, agradeço por ser minha melhor amiga.

Ao professor Márcio Nakane, agradeço pela orientação e dedicação. Foram inúmeras as vezes que cheguei na sua sala sem rumo e você me colocou na rota certa. Sua orientação foi fundamental na minha formação de pesquisador.

Aos meus professores do mestrado, agradeço a dedicação e o empenho na minha formação. Ao professor Mauro Rodrigues, ao professor Pedro Duarte e ao professor Fábio Kanczuk, agradeço a participação e os comentários durante a qualificação e durante a avaliação de progresso.

Aos colegas do IPE-USP, agradeço as inúmeras conversas na salinha do café. Tenho certeza que fiz grandes amigos que levarei pela vida. Agradeço especialmente ao Gian, cuja ajuda e comentários foram essências durante todo o trabalho, e ao Matheus Assaf, que leu atentamente esta dissertação.

Aos amigos de São Paulo, agradeço por ter tornado esse período um momento especial na minha vida. Não posso deixar de mencionar todos com quem dividi apartamento e que me fizeram sentir tendo realmente uma casa na cidade: Dito, Bill, Rafa, Assaf, Matheus e Mouse.

Aos amigos de Belo Horizonte, pelo carinho de tantos anos. As constantes visitas ajudaram a diminuir bastante a distância entre as cidades.

À CAPES, pelo apoio financeiro durante o mestrado.

Ao pessoal do Bradesco, por me receberem e me ajudarem a compreender como funciona o mercado de títulos brasileiro. 



\section{Resumo}

Este trabalho analisa qual o impacto da maturidade da dívida pública no comportamento da economia e na execução da política monetária. Para isso, desenvolveu-se três modelos DSGE. O primeiro é feito apenas para padronizar a notação e para apresentar resultados comuns aos outros dois modelos. No segundo modelo, a maturidade da dívida é introduzida usando uma estrutura recursiva. Analisando as funções de resposta a impulso, conclui-se que a maturidade da dívida pública não possui impacto na dinâmica da economia. Para testar a hipótese de que as Letras Financeiras do Tesouro enfraquecem a política monetária (PASTORE, 1996), generalizou-se a estrutura do modelo para permitir a existência de um título com remuneração semelhante a um título pós-fixado. A única diferença encontrada foi que a taxa de juros de longo prazo passou a responder a mudanças da taxa de juros básica. No último modelo, os agentes enfrentam uma probabilidade de morrer a la Blanchard (1985) e as dívidas de longo prazo são modeladas como perpetuidade com cupons com decaimento exponencial. A maturidade da dívida pública impacta, exclusivamente, na tributação, no estoque da dívida e no preço do título de longo prazo, mas a magnitude da diferença é mínima.

Palavras-chaves: Política Monetária, Dívida Pública, Política Fiscal, Letras Financeiras do Tesouro 



\begin{abstract}
This paper analyzes the impact of the public debt maturity in the behavior of the economy and in the monetary policy implementation. It has developed three DSGE models. The first is a model for standardizing the notation and to present common results to the other two models. In the second model, the debt maturity is introduced using a recursive structure. Analyzing impulse response functions, it is concluded that the public debt maturity has no impact on the model dynamics. To test the hypothesis that the Letras Financeiras do Tesouro weakens the monetary policy (PASTORE, 1996), the model structure was generalized to allow the existence of a bond with payment similar to a pos-fixed bonds. The only difference was that the long-term interest rates began to respond to changes in the basic interest rate. In the latter model, the agents face a probability of dying a la Blanchard (1985) and long-term debt is modeled as perpetuity with exponential decay coupons. The public debt maturity impacts exclusively on taxation, the debt stock and the price of long-term debt, but the magnitude of the difference is minimal.
\end{abstract}

Key-words: Monetary Policy, Public Debt, Fiscal Policy, Letras Financeiras do Tesouro 



\section{Lista de ilustrações}

Figura 1 - Função de resposta a impulso do modelo canônico quando ocorre um choque na taxa de juros básica . . . . . . . . . . . . . . 42

Figura 2 - Função de resposta a impulso do modelo canônico quando ocorre um

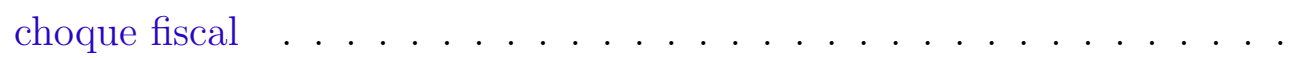

Figura 3 - Função de resposta a impulso para o modelo com maturidade recursiva quando ocorre um choque na taxa de juros básica . . . . . . . . . . 53

Figura 4 - Função de resposta a impulso para o modelo com maturidade recursiva quando ocorre um choque na taxa de juros básica . . . . . . . . . . . . 54

Figura 5 - Função de resposta a impulso para o modelo com maturidade recursiva quando ocorre um choque fiscal . . . . . . . . . . . . .

Figura 6 - Funções de resposta a impulso para o modelo modificado quando ocorre um choque na taxa de juros básica . . . . . . . . . . . . .

Figura 7 - Funções de resposta a impulso para o modelo modificado quando ocorre um choque na taxa de juros básica . . . . . . . . . . . . .

Figura 8 - Funções de resposta a impulso para duas calibrações do modelo modificado quando ocorre um choque na taxa de juros básica . . . . . . . . .

Figura 9 - Funções de resposta a impulso para o modelo modificado quando ocorre



Figura 10 - Funções de resposta a impulso para duas calibrações do modelo modificado quando ocorre um choque fiscal . . . . . . . . . . . . . .

Figura 11 - Comparação entre funções de resposta a impulso do modelo com maturidade recursiva sem e com tributação distorciva quando ocorre um choque na taxa básica de juros . . . . . . . . . . . . .

Figura 12 - Comparação entre funções de resposta a impulso do modelo com maturidade recursiva sem e com tributação distorciva quando ocorre um

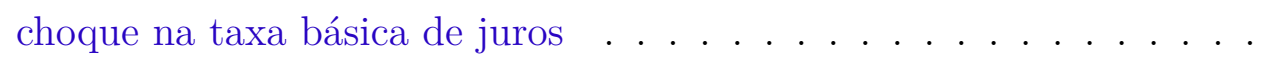


Figura 13 - Comparação entre funções de resposta a impulso do modelo com maturidade recursiva sem e com tributação distorciva quando ocorre um choque fiscal . . . . . . . . . . . . . . . . 70

Figura 14 - Comparação entre funções de resposta a impulso a um choque na taxa básica de juros do modelo modificado sem e com tributação distorciva . 72

Figura 15 - Comparação entre funções de resposta a impulso a um choque na taxa básica de juros do modelo modificado sem e com tributação distorciva .

Figura 16 - Funções de resposta a impulso a um choque na taxa básica de juros para duas calibrações do modelo modificado com tributação distorciva

Figura 17 - Comparação entre funções de resposta a impulso do modelo modificado sem e com tributação distorciva quando ocorre um choque fiscal . . . . 75

Figura 18 - Funções de resposta a impulso do modelo com tributação distorciva após um choque na taxa básica de juros para diferentes maturidades $\quad 77$

Figura 19 - Funções de resposta a impulso do modelo com tributação distorciva após um choque fiscal para diferentes maturidades . . . . . . . . . . . 79

Figura 20 - Comparação entre funções de resposta a impulso do modelo com maturidade recursiva, com tributação distorciva e com e sem agentes não ricardianos ........................ 82

Figura 21 - Comparação entre funções de resposta a impulso após a ocorrência de um choque fiscal do modelo com maturidade recursiva, com tributação distorciva e com e sem agentes não ricardianos . . . . . . . . . . . . . . 84

Figura 22 - Funções de resposta a impulso para o modelo com Perpetual Youth quando ocorre um choque na taxa de juros básica . . . . . . . . . . 95

Figura 23 - Steady-State para diferentes $\rho \ldots \ldots \ldots$. . . . . . . . . 96

Figura 24 - Funções de resposta a impulso para o modelo com Perpetual Youth quando ocorre um choque fiscal . . . . . . . . . . . . . . . 97

Figura 25 - Funções de resposta a impulso para três calibrações do modelo com Perpetual Youth e com tributação distorciva quando ocorre um choque na taxa de juros básica . . . . . . . . . . . . . . . . . . . . . . . 99 
Figura 26 - Funções de resposta a impulso para três calibrações do modelo com Perpetual Youth e com tributação distorciva quando ocorre um choque fiscal . . . . . . . . . . . . . . . . . . . . . . 101 



\section{Sumário}

1 Introdução. . . . . . . . . . . . . . . . . . 19

1.1 Literatura Teórica Relacionada . . . . . . . . . . . . . . . . . . 20

1.2 A Discussão Sobre a Taxa de Juros Nacional . . . . . . . . . . . . . . . . . 27

2 Modelo Canônico . . . . . . . . . . . . . . . . . . . . . . 33

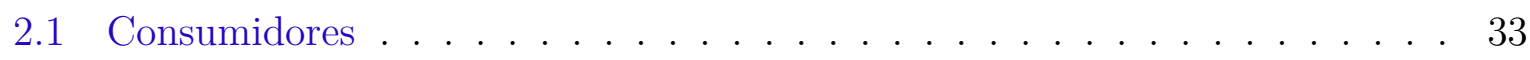

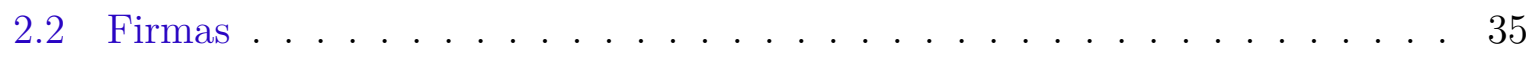

2.3 Autoridade Fiscal e Monetária . . . . . . . . . . . . . . . . . . . . 38

2.4 Equilíbrio . . . . . . . . . . . . . . . . . . . . . . . 39

2.5 Calibração e Simulação . . . . . . . . . . . . . . . . . . . . . . 40

2.6 Conclusão . . . . . . . . . . . . . . . . . . . . . . . . . . . 44

3 Modelo com Maturidade Recursiva . . . . . . . . . . . . . . 45

3.1 Modelo de Krause e Moyen . . . . . . . . . . . . . . . . . . . . . . . 45

3.1 .1 Condições de Ótimo do Consumidor . . . . . . . . . . . . . . . . . 46

3.1 .2 Equações da Firma . . . . . . . . . . . . . . . . . . . . . . . . . . . 49

3.1 .3 Autoridade Fiscal e Monetária . . . . . . . . . . . . . . . . . 50

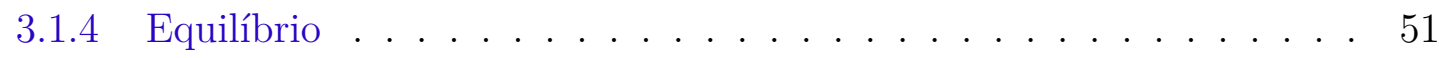

3.1 .5 Calibração e Simulação . . . . . . . . . . . . . . . . . . . . . . 51

3.1.6 Relação entre Taxas de Juros . . . . . . . . . . . . . . . . . 56

3.2 Modificação do Modelo . . . . . . . . . . . . . . . . . 56

3.2 .1 Consumidor . . . . . . . . . . . . . . . . . . . 58

3.2 .2 Resto do Modelo e Equilíbrio . . . . . . . . . . . . . . . 60

3.2 .3 Calibrações . . . . . . . . . . . . . . . . . . . 61

3.3 Imposto Distorcivo . . . . . . . . . . . . . . . . . . 67

3.4 Agentes Não Ricardianos . . . . . . . . . . . . . . . . . . . . . . . 80

3.4 .1 Agregação . . . . . . . . . . . . . . . . . . . . 80

3.4 .2 Calibração e Simulação . . . . . . . . . . . . . . . . . . . . . 81

3.5 Conclusão . . . . . . . . . . . . . . . . . . . . 85

4 Modelo com Perpetual Youth . . . . . . . . . . . . . . . . . . . 87 
4.1 Lado da Demanda . . . . . . . . . . . . . . . . . . . . . . 87

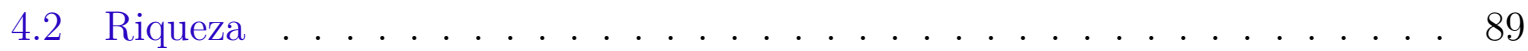

4.3 Agregação . . . . . . . . . . . . . . . . . . . . . 89

4.4 Firma ............................... 90

4.5 Autoridade Fiscal e Monetária . . . . . . . . . . . . . . . . . . . . . . 91

4.6 Equilíbrio . . . . . . . . . . . . . . . . . . . . . . . . 92

4.7 Calibração e Simulação . . . . . . . . . . . . . . . . . . . . . . . . . 93

4.8 Imposto Distorcivo . . . . . . . . . . . . . . . . . . . . . . . . . . . . . 98

4.8 .1 Simulação . . . . . . . . . . . . . . . . . . . . . . . . . 98

4.9 Conclusão . . . . . . . . . . . . . . . . . . . . . . . . . . . . 102

5 Conclusão . . . . . . . . . . . . . . . . . . . . . 103

Referências ............................ 105

$\begin{array}{ll}\text { Apêndices } & 109\end{array}$

APÊNDICE A Modelo com Maturidade Recursiva . . . . . . . . . . . 111

A.1 Calculo das Equações de Ótimo do Modelo Modificado . . . . . . . . . . . 111

APÊNDICE B Modelo com perpetual youth . . . . . . . . . . . . . 115

B.1 Consumo Agregado . . . . . . . . . . . . . . . . . . . 115 


\section{Introdução}

A partir do artigo de Pastore (1996), uma discussão na literatura nacional se iniciou questionando qual o papel da estrutura da dívida pública na transmissão da política monetária. O argumento seria que a existência de um título pós-fixado - nacionalmente chamado de Letras Financeiras do Tesouro Nacional (LFTs) - enfraqueceria a eficácia da política monetária ao obstruir o canal riqueza pelo qual essa é transmitida. Diversos autores $^{1}$ já apresentaram considerações sobre o assunto, mas não se sabe de nenhum trabalho que analisou esse argumento usando um modelo DSGE (Dynamic Stochastic General Equilibrium). Este trabalho procura suprimir essa lacuna na literatura nacional ${ }^{2}$.

A proporção de LFTs no estoque da dívida brasileira já foi mais elevada, sendo que, em abril de 2003, ela atingiu quase 70\%. Ainda assim, a proporção se mostra relevante e não ignorável, correspondendo a 27,5\% em abril de 2016. Além disso, a proporção apresenta uma trajetória crescente, sendo $30 \%$ maior do que a do ano passado - comparação de abril de 2016 com abril de 2015 .

Inicialmente, procurar-se-á modificar um modelo DSGE canônico para que esse apresente uma estrutura de maturidade da dívida pública. Na literatura, foram encontradas duas formas de modelar títulos de longo prazo, uma proposta por Woodford (2001) e outra proposta por Krause e Moyen (2016). As duas propostas serão exploradas neste trabalho, esta no capítulo 3 e aquela no capítulo 4.

Nos dois modelos a serem desenvolvidos, a primeira análise será entender de que maneira mudanças no parâmetro que controla a maturidade influencia na dinâmica da economia. Na literatura econômica, diversos autores já analisaram o papel da maturidade da dívida pública na economia. Lucas e Stokey (1983) mostram como dívida contingente de diferentes maturidades pode resolver o problema de inconsistência intertemporal de uma política de tributação ótima. Angeletos (2002) e Buera e Nicolini (2004) mostram que, modificando a maturidade da dívida pública, pode-se garantir a alocação do planejador

1 Exemplos são Arida (2006), Resende (2006), Carneiro (2006) e Loyo (2006)

2 Alfaro e Kanczuk (2010) e Divino e Silva Junior (2013) analisam a escolha entre títulos nominais e títulos indexados a inflação. Ambos fazem considerações sobre o caso brasileiro. 
central usando apenas títulos não contingentes. Leeper e Zhou (2013), Krause e Moyen (2016) e Eusepi e Preston (2014) estudam a possibilidade de se usar a inflação para diminuir o fardo real da dívida e como diferenças na maturidade impactam nessa possibilidade. Faraglia et al. (2013) analisam como o governo usa inflação para atingir uma dívida sustentável e como variações da maturidade da dívida pública modificam essa estratégia. Espera-se com este trabalho contribuir para essa literatura.

Barro (1999) argumenta que, em modelos em que há impostos lump-sum, certeza quanto ao futuro, mercados de capitais perfeitos e agentes que vivem infinitamente, vale a Equivalência Ricardiana, o que torna a adição de novos títulos redundante. Por isso, no modelo do capítulo 3, utilizar-se-ão impostos distorcivos no mercado de trabalho e agentes rule-of-thumb e, no modelo do capítulo 4, utilizar-se-ão impostos distorcivos no mercado de trabalho e agentes que enfrentam uma probabilidade de morrer a la Blanchard (1985).

Vale ressaltar que o problema das LFTs só será analisado no capítulo 3, já que a estrutura de maturidade proposta por Krause e Moyen (2016) é a única flexível suficiente para permitir a existência de um título com remuneração semelhante a de um título pós-fixado.

No restante deste capítulo, apresentar-se-á em mais detalhes a literatura com a qual este trabalho dialoga. No capítulo 2, apresentar-se-á o modelo DSGE canônico de forma a padronizar a notação e a apresentar resultados comuns aos modelos que serão desenvolvidos nos próximos capítulos. No capítulo 3, a maturidade da dívida é introduzida ao modelo canônico usando a maneira proposta por Krause e Moyen (2016). No capítulo 4, a maturidade é introduzida da maneira proposta por Woodford (2001). O capítulo 5 conclui este trabalho.

\subsection{Literatura Teórica Relacionada}

A literatura que aborda o papel da dívida pública no funcionamento econômico é extensa e, de nenhuma maneira, essa revisão tem o objetivo de esgotar o assunto. Nesta 
seção, procurar-se-á apresentar alguns trabalhos com os quais este dialoga ${ }^{3}$.

Partindo das contribuição de Ramsey (1927), uma literatura se desenvolveu para analisar qual deve ser uma política de tributação ótima e qual deve ser o papel da dívida pública. Lucas e Stokey (1983) escreveram um artigo seminal sobre como a maturidade da dívida pública pode resolver o problema de inconsistência temporal de uma política de tributação ótima. Supõem que o governo consegue emitir dívida pública contingente ao estado da natureza e com diversas maturidades. Se o governo, no período $t_{0}$, conseguir se comprometer com uma política de tributação ótima, a dívida pública é irrelevante. Se o governo não conseguir se comprometer intertemporalmente e não for preciso honrar suas obrigações da dívida, ele tem o incentivo a desviar dessa. Como os agentes são racionais, ele não conseguirá emitir dívida. Contudo, se ele não se comprometer com as alíquotas futuras, mas se comprometer com os encargos das dívidas emitidas, o governo consegue, modificando a maturidade, induzir seu sucessor a seguir a política ótima. No modelo, a função da dívida é suavizar intertemporalmente a tributação distorciva.

Judd (1985) e Chamley (1986) também usam um modelo a la Ramsey e procuram estudar qual é a taxação ótima do capital. Ao se aproximar do Steady-State, a taxação deve ser zero. Chamley (1986) ainda encontra que a função da dívida é acomodar choques e suavizar a taxação distorciva. Nos modelos desenvolvidos nos próximos capítulos, a dívida varia para acomodar o choque fiscal.

Aiyagari et al. (2002) modificam a economia formulada por Lucas e Stokey (1983) para permitir apenas um título nominal de um período. Os autores encontram a restrição de implementabilidade do artigo original, mas precisam impor restrições adicionais (restrições estocásticas para que o débito seja sem risco). Com mercados completos, os autores conseguem um resultado semelhante ao de Lucas, mas, supondo mercados incompletos e um limite ad hoc ao endividamento governamental, o resultado se assemelha ao encontrado por Barro (1979) - as taxas são um passeio aleatório para qualquer processo estocástico representando os gastos do governo. Sem esse limite, o comportamento pode divergir

3 Autores clássicos, como Modigliani (1961) e Diamond (1965) já discutiam os efeitos da dívida pública na economia. Roley (1979) propõe um modelo para discutir gestão da dívida pública. 
bastante e a tributação vai para zero.

Angeletos (2002) foca apenas na capacidade de a dívida pública suavizar a tributação e ignora o problema de consistência intertemporal da política ótima. O autor amplia os resultados encontrados por Lucas e Stokey (1983), mostrando que toda alocação de Arrow-Debreu e toda política de tributação ótima são implementáveis (ou pode ser arbitrariamente bem aproximada) com dívida não contingente de diferentes maturidades. Uma condição necessária é que a variação estocástica da estrutura a termo da taxa de juros deve corresponder contemporaneamente à variação no valor presente do superávit. A maturidade ótima, conforme definição do autor, é aquela que permite um seguro perfeito contra flutuações exógenas e permite ao governo manter uma tributação invariante.

Buera e Nicolini (2004) também usam a estrutura de Lucas e Stokey (1983) e também procuram mostrar que a estrutura de maturidade da dívida pública reproduz a alocação ótima de tributação de uma economia com dívida contingente. Se apenas dívida não contingente estiver à disposição do governo, a alocação ótima de mercados completos pode ser reproduzida emitindo dívida de diferentes maturidades. Avaliando quantitativamente o modelo, os autores encontram que a quantidade de dívida emitida deve ser demasiadamente grande, chegando a centenas de vezes o tamanho do produto.

Faraglia, Marcet e Scott (2010) chamam de abordagem de mercados completos para a gestão da dívida pública (complete market approach to debt management) o resultado de que variações na curva de juros podem ser usadas pelo governo para minimizar taxações distorcivas - resultado comum a Angeletos (2002) e Buera e Nicolini (2004) observada. Os autores afirmam que os resultados são incongruentes com a prática. Além da necessidade de o governo manter posição irrealista de dívida pública, os autores encontram que, adicionando capital ao modelo, a posição do governo em dívida se torna extremamente volátil. Custos de transação e informação imperfeita quanto à estrutura do modelo podem mudar o resultado e, em certos casos, tornar ótimo ao governo ignorar a estrutura ótima de maturidade e levá-lo a manter a restrição orçamentária respeitada em todos os períodos.

Faraglia et al. (2013) expandem o trabalho anterior para analisar como o governo 
usa inflação para atingir uma dívida sustentável e como variações da maturidade da dívida pública modificam essa estratégia. Em uma economia com política fiscal e monetária coordenadas, o nível e a maturidade da dívida possuem impacto limitado na inflação. A política ótima é estabilizar a dívida com aumentos de tributação. Se a política monetária e a política fiscal não são coordenadas e a taxa básica de juros segue uma regra de Taylor, a inflação possui um maior papel em estabilizar a dívida pública.

Neste trabalho, não se preocupou com o problema de inconsistência intertemporal da política de tributação ótima e nem é o objetivo mostrar se, quando o governo só tem acesso a títulos não contingentes, mudanças na maturidade podem reproduzir a alocação de tributação ótima de uma economia caso títulos contingentes estivessem disponíveis. Assim como a literatura de tributação ótima, foi encontrado na dívida o papel de amortecer choques.

Outro ramo da literatura analisa o argumento, fundamental para que mudanças no estoque de dívida pública causem efeitos reais, de que títulos públicos do governo são percebidos como riqueza pelos consumidores. Barro (1974) analisa quais hipóteses teóricas devem ser feitas para a validade do argumento ${ }^{4}$. Ele analisa três cenários, um em que os agentes têm vida finita - modelo de overlapping generations, um em que o mercado de capital é incompleto e outro em que o governo possui controle de emissão de ativos líquidos. No primeiro cenário, caso haja uma transferência intergeracional, não haverá efeito riqueza. No segundo, o efeito será positivo apenas se o governo for mais eficiente em "carregar" poupança que o setor privado e, no terceiro, apenas se o governo agir como um monopolista na emissão de liquidez. Barro conclui que nenhum caso teórico analisado convence que dívida pública deva ser percebida como riqueza. Buchanan (1976) chama atenção ao fato do problema analisado por Barro já ter sido previamente abordado, sendo conhecido por Equivalência Ricardiana.

O modelo canônico apresentado no capítulo 2 respeita a Equivalência Ricardiana e, quando essa vale, a adição de um novo título público é redundante. Nos modelos dos

4 O autor atenta que a dívida só será percebida como riqueza se seu valor ao ser emitida exceder o custo futuro de ser paga via taxação. 
capítulos 3 e 4 foram introduzidos elementos com o objetivo de escapar da Equivalência Ricardiana. Mais especificamente, no modelo do capítulo 3, utilizou-se impostos distorcivos no mercado de trabalho e agentes rule-of-thumb e, no modelo do capítulo 4, utilizou-se impostos distorcivos no mercado de trabalho e agentes que enfrentam uma probabilidade de morrer a la Blanchard (1985).

Supondo que a Equivalência Ricardiana seja válida, Barro (1979) desenvolve uma teoria para explicar o comportamento ótimo da dívida pública federal. O modelo de Barro necessita que os déficits do governo variem para manter constante a taxação esperada. A teoria implica que a taxa de crescimento da dívida seja independente da razão dívida-renda e não seja afetada pelo nível de gastos do governo. Além disso, as taxas de tributação devem ser independentes de qualquer variável defasada.

Uma extensa literatura empírica se desenvolveu procurando descobrir se os dados validavam ou não a equivalência ricardiana. Mais especificamente, essa literatura empírica está preocupada se uma política fiscal possui ou não efeitos reais de curto prazo. Perotti (2007) faz uma ampla revisão da literatura e procura estudar a robustez dos resultados, tentando conciliar as duas abordagens mais comuns na literatura, a abordagem narrativa e a abordagem de vetores autorregressivos estruturais (SVAR). Ele encontra evidências robustas para os EUA e outros países de uma resposta positiva do consumo e do produto a um choque de gasto governamentais. Em uma revisão mais recente, Ramey (2011) argumenta que a maior parte dos trabalhos encontra o multiplicador fiscal dado um aumento temporário nos gastos do governo não acompanhado por um aumento de taxas distorcivas está, provavelmente, entre 0,8 e 1,5. Houve um crescimento de métodos usados para a identificação dos choques, mas Ramey argumenta que mecanismos de transmissão dos choques ainda não são consenso e devem ser mais estudados ${ }^{5}$.

Woodford (2013) revisa diversas formas alternativas de introduzir formação de expectativas em modelos dinâmicos, distanciando-se do benchmark de expectativas racionais. Esse distanciamento modifica diversos resultados da teoria monetária e da fiscal, sendo a

$5 \quad$ A literatura de política fiscal em modelos DSGE se preocupa principalmente em entender a transmissão dos choques fiscais para o consumo, principalmente quanto ao seu sentido e magnitude. Exemplos são Galí, López-Salido e Vallés (2007) e Monacelli e Perotti (2008). 
implicação para a equivalência ricardiana a mais importante para este trabalho. O autor atenta para o fato de que, em diversas análises em que as expectativas dos agentes são formadas via expectativas racionais, a dinâmica de modelos com agentes representativos e com política fiscal ricardiana ${ }^{6}$ são indiferentes à adição de um novo título do governo. Não existe mais efeito riqueza na variação da dívida pública, já que qualquer mudança no estoque da dívida é instantaneamente compensada por uma mudança no caminho futuro esperado do resultado primário do governo. Nesse caso, a demanda agregada é independente da trajetória da dívida pública e dos impostos coletados. Caso outras formas de formação de expectativas sejam permitidas, a composição da dívida passa a importar.

A recente prática de políticas monetárias não convencionais, com o consequente alargamento do balanço dos Bancos Centrais e diminuição da maturidade da dívida pública em economias desenvolvidas, trouxe a atenção da literatura para os efeitos da composição da dívida pública na transmissão monetária e para a possibilidade de usar-se a inflação para diminuir o endividamento público ${ }^{7}$. Hilscher, Raviv e Reis (2014) utilizam um método próprio baseado na construção de uma distribuição de probabilidade de inflação usando preços de opções para estimar quantitativamente o quanto da dívida pública real pode ser corroída ao se ter uma inflação acima do esperado. Os autores concluem que é improvável que a inflação seja capaz de diminuir o peso da dívida pública americana, mas, se for combinada com repressão financeira que aumente a maturidade da dívida, o efeito pode ser significativo.

Três artigos recentes analisam a influência da composição da dívida pública na economia americana utilizando modelos DSGE. O primeiro, Leeper e Zhou (2013), utiliza uma abordagem quadrática linear, desenvolvida por Benigno e Woodford (2004), para

$\overline{6}$ Conforme definida por Woodford (2001):

$$
\frac{W_{t}^{s}}{P_{t}}=\sum_{T=t}^{\infty} \beta^{T-t} E_{t} \frac{U_{c}\left(y_{T}, m_{T}\right)}{U_{c}\left(y_{t}, m_{t}\right)}\left[s_{T}+\frac{i_{T}}{1+i_{T}} \frac{M_{T}^{s}}{P_{T}}\right]
$$

sendo $s_{t} \equiv T_{t} / P_{t}-g_{t}$ o superávit primário do governo. Essa condição diz que o valor real do passivos líquidos do governo deve ser iguai ao valor presente esperado do superávit do governo, corrigido pelos juros economizados pelo governo na parte do passivo que os agentes decidem manter em papel moeda.

7 Para uma análise histórica da composição da dívida pública americana no pós guerra, ver Hall e Sargent (2010). Os autores argumentam que, historicamente, o crescimento, e não a inflação, foi o responsável pela diminuição da dívida real. 
resolver o modelo. Os autores estudam como a composição da dívida pública afeta a implementação de política monetária e fiscal ótimas na presença de impostos distorcivos e preços rígidos. Mais especificamente, como a inflação pode ser usada como forma de diminuir os encargos reais da dívida pública. Os autores encontram que inovações na inflação corrente e na futura possuem papel na diminuição dos encargos da dívida, sendo que a importância aumenta quanto maior a maturidade. Inflação é importante na absorção de choques fiscais, principalmente em economias com altos níveis de endividamento.

Já Krause e Moyen (2016) e Eusepi e Preston (2014) usam informação imperfeita, mais especificamente técnicas de learning. Krause e Moyen (2016) analisam se um aumento da meta de inflação tem capacidade de diminuir a dívida real. Os autores constroem um modelo Novo Keynesiano adicionando um título de longo prazo que permite calibrar a maturidade da dívida pública e permitindo que os agentes observem imperfeitamente a meta de inflação. Os autores concluem que apenas mudanças permanentes na meta têm impacto na dívida real, sendo mais fácil diminuir a dívida quando sua maturidade é maior. Tecnicamente, os agentes do modelo inferem a meta de inflação do Banco Central através de um filtro de Kalman. Eusepi e Preston (2014) propõem um modelo que explica os fundamentos fiscais ${ }^{8}$ da inflação baseando a análise em informação incompleta e learning. A existência de informação incompleta quebra a equivalência ricardiana, fazendo a maturidade e a composição da dívida pública importar para a dinâmica da inflação, ou seja, o lado fiscal restringe a política monetária. Os caminhos da dívida pública, da arrecadação e da inflação passam a estar conectados. Como resultado, os autores encontram que países muito endividados precisam de uma política monetária agressiva para ancorar as expectativas.

O modelo desenvolvido no capítulo 3 é baseado no modelo de Krause e Moyen (2016), mas o objetivo não é estudar a capacidade da inflação diminuir o fardo real da dívida pública, mas sim se mudanças no parâmetro de maturidade possuem efeito real na economia. Não se usará modelos com informação imperfeita.

8 Os autores afirmam que sua teoria é diferente da Fiscal Theory of Price Level. Para esta, veja Christiano e Fitzgerald (2000) e Woodford (2001). 


\subsection{A Discussão Sobre a Taxa de Juros Nacional}

A elevada taxa de juros real brasileira é um problema que intriga estudiosos da economia nacional. Esperava-se que, após a estabilização inflacionária e adoção do sistema de metas de inflação, as taxas de juros convergiriam para um valor encontrado em outros países emergentes. Diversas explicações e soluções já foram apresentadas. Favero e Giavazzi (2002) decompõem os componentes da taxa de juros de longo prazo e constroem uma estrutura a termo do prêmio de risco. Os autores concluem que as altas taxas não são consequência da trajetória esperada da taxa de juros básica, mas sim devido ao termo de risco. Esse reflete a preocupação com a sustentabilidade da dívida pública e a ausência institucional da independência do Banco Central.

Arida, Bacha e Lara Resende (2005) apontam a alta incerteza jurídica nacional, que impede o surgimento de um mercado de crédito de longo prazo no país, e a baixa conversibilidade da moeda como as principais causas. Os autores também atentam para o fato de que, ao tentar solucionar o problema paliativamente, o governo aumentou as intervenções estatais, aumentando as restrições à conversibilidade da moeda, alongando artificialmente a maturidade - isso é, forçando o mercado a comprar títulos mais longos e, consequentemente, este cobrando taxas mais altas, aumentando as taxas de poupança forçada e criando taxações distorcivas. Essas medidas só elevariam o risco jurisdicional nacional, amplificando o problema da elevada taxa de juros.

Gonçalves, Holland e Spacov (2007) testam a hipótese de Arida, Bacha e Lara Resende (2005) em um painel com 50 países, e não encontram evidências que a suportem. A taxa de inflação e razão dívida pública total-PIB são estatisticamente significativas em explicar a taxa de juros de curto prazo, diferente de proxys para incerteza jurídica e para incoversibilidade da moeda. Os autores atentam para o fato de não terem uma medida sem ruído do caráter anti-credor e anti-poupador que Arida, Bacha e Lara Resende (2005) dizem ser importante para explicar a taxa de juros real nacional. Além disso, os autores não controlam para alongamentos artificiais da maturidade da dívida pública, para taxas de poupança forçada e para taxação distorciva. 
Muinhos e Nakane (2006) procuram medir a taxa de juros real de países emergentes utilizando diferentes métodos e explicar porque o Brasil apresenta taxa de juros tão alta e tão diferente do comportamento de seu pares. Comparando a taxa bruta e líquida de retorno do capital no Brasil, os autores acreditam que há indícios de que riscos institucionais podem explicar a alta taxa de juros. Estimando um painel para 17 países emergentes, os autores encontram que a razão dívida pública-PIB explica pouco da taxa de juros real e que o índice $\mathrm{EMBI}^{9}$ é uma variável explicativa melhor. Mesmo controlando por esta, o efeito fixo ainda é relevante para explicar o juros brasileiro, o que indica que há mais elementos além do prêmio de risco para explicar a taxa brasileira. Os autores também encontram que o prêmio de risco inflacionário no Brasil é maior que o encontrado no Chile, na Colômbia e no México.

Segura-Ubiergo (2012), em um estudo mais recente usando dados em painel para 15 países emergentes que adotam metas de inflação ${ }^{10}$, observou que o Brasil conseguiu baixar o nível da taxa de juros real melhorando os fundamentos macroeconômicos (menor volatilidade da inflação, melhora fiscal e melhor posição externa) e adotando o sistema de metas de inflação. Para o autor, para continuar a convergência da taxa de juros para níveis encontrados em outros emergentes, o país precisa aumentar o nível de poupança. Mas, mesmo com o aumento da poupança, o país ainda apresentaria taxa de juros real acima da média dos emergentes, o que aponta para a necessidade de se entender outras especificidades da economia nacional que possam estar impactando.

Já Pastore (1996) argumenta que a existência de um título pós fixado, as Letras Financeiras do Tesouro (LFTs), diminuem a eficácia da política monetária nacional principalmente por obstruírem o canal de riqueza da política monetária ${ }^{11}$. O autor analisa dois regimes monetários em um modelo IS/LM, um em que o financiamento do déficit é feito com títulos perpétuos pré fixados e outro em que o financiamento é feito com títulos perpétuos indexados à taxa básica de juros ${ }^{12}$. No primeiro regime, alterações na taxa de

$9 \quad$ J.P.Morgan Emerging Markets Bond Index Global

10 A amostra do autor vai de 1980 a 2009.

11 Para uma visão geral sobre canais de transmissão monetários, ver Mishkin (1995) e Bernanke e Gertler (1995). Para o caso brasileiro, ver Minella e Souza-Sobrinho (2009).

12 "Perpetuidades indexadas" na nomenclatura de Simonsen (1991). 
juros impactam no estoque de riqueza, mas não alteram o fluxo de pagamento, ou seja, há um efeito riqueza e não há um efeito renda. No segundo, as alterações de juros não produzem efeito no valor do estoque, mas alteram o fluxo futuro de pagamentos, ou seja, há efeito renda e não há efeito riqueza. Um detalhe do modelo é a presença do estoque de riqueza na função de consumo agregado, fazendo o aumento dos juros no primeiro regime mais contracionista do que no segundo.

Não se sabe de nenhum trabalho que tenha analisado o argumento de Pastore utilizando um modelo DSGE. No capítulo 3, o modelo de Krause e Moyen (2016) é modificado para permitir um título pós-fixado e, dessa maneira, espera-se contribuir para a literatura nacional ao ser o primeiro trabalho a analisar o efeito da existência de um título pós-fixado em um modelo DSGE.

As LFTs surgiram no contexto de uma economia fragilizada pelo longo período de inflação elevada ocorrido na década de 80 no Brasil. Antes do Plano Cruzado, as instituições financeiras trabalhavam com descasamento de prazos entre passivos e ativos e com altas taxas de alavancagem permitidas pela legislação. Como, no período, a inflação possuía grande variabilidade, quando as instituições acertavam suas expectativas, lucravam com a alavancagem. Quando erravam, por exemplo, esperando um nível menor de inflação, a mudança dos juros causava grandes perdas, o que era um risco para a estabilidade do sistema. Nessas ocasiões o Banco Central precisava intervir e recomprar os títulos (ARIDA, 2006). Com o Plano Cruzado, formou-se a expectativa de que a inflação estava controlada e, consequentemente, as instituições financeiras apostaram na queda dos juros e alavancaram seus passivos. Com os primeiros sinais de pressão inflacionária, ficou claro que os juros teriam de ser elevados após o descongelamento de preços e em uma magnitude que provocaria perdas elevadas para os intermediários financeiros (RESENDE, 2006) . Como solução do problema, foram criadas em maio de 1986 as LFTs - na época, Letras do Banco Central (LBCs) - um título com indexação financeira diária e prazos de até um ano. Na prática, foi criado um título que refletia a remuneração dos passivos dos intermediários financeiros, o que acabava com o problema do descasamento da remuneração entre ativos e passivos dos intermediários financeiros, facilitava a condução da política monetária e 
reduzia o custo de rolagem da dívida.

Carneiro (2006) analisa o papel das LFTs em dois fenômenos prejudiciais à normalidade financeira: juros elevados persistentes e incertezas nos vértices longos da estrutura a termo da taxa de juros. Segundo o autor, a oferta de LFTs se justifica por preferências e conveniências do Tesouro, principalmente por diminuir o custo e risco de rolagem do emissor. Já a demanda se justifica por ser lastro para depósitos referenciados e pela necessidade de adequação às exigências quanto aos prazos dos passivos.

Alguns autores reconhecem o impacto negativo que as LFTs têm na política monetária nacional, mas acham que o argumento é exagerado. Loyo (2006) argumenta que o efeito riqueza não tem, aparentemente, tanta importância quantitativa quanto aparenta. O autor cita o estudo de Lettau e Ludvigson (2001) que mostra que o consumo responde de forma diferente a mudanças transitórias ou permanentes no estoque de riqueza. Mesmo os autores não identificando mudanças causadas pela política monetária, Loyo acredita que elas se comportariam como transitórias. Outro estudo citado pelo autor foi o elaborado por Ludvigson, Steindel e Lettau (2002) que, usando um VAR, encontram uma pequena importância do efeito riqueza na transmissão de política monetária. Loyo também conjectura que o efeito riqueza é mais fraco no Brasil do que nos EUA, principalmente devido à menor razão riqueza-PIB, devido à riqueza mais concentrada e devido ao mercado imobiliário pouco desenvolvido. A riqueza financeira brasileira é composta por títulos de renda fixa, títulos em que a equivalência ricardiana tende a ser mais presente. Segundo Loyo, muito do impacto de uma elevação da taxa de juros na economia americana provem de mudanças no equity premium.

Carvalho, Goldfajn e Pames (2006) analisam a velocidade adequada para a substituição de LFTs e avaliam os custos e benefícios da substituição, sem fazer uma análise de qual deveria ser a composição ótima da dívida. Os autores usam uma equação básica da dinâmica da dívida que considera o efeito dos diversos indexadores da dívida líquida do setor público brasileiro.

Dois trabalhos estudam a composição ótima da dívida pública para a economia 
nacional. Ambos estudam apenas a escolha entre títulos indexados a inflação e títulos nominais, mas não estudam o caso das LFTs. Alfaro e Kanczuk (2010) utilizam um modelo de equilíbrio geral para determinar a estrutura ótima de títulos indexados e não indexados dado um nível de endividamento governamental. Título contingente (não indexado) é usado para reduzir intertemporalmente as distorções da tributação, mas criam o incentivo para o governo fazer um default via inflação. Os agentes reconhecem esse risco e cobram taxas de juros mais altas para o governo se financiar. Já os títulos não contingentes são considerados títulos indexados. Com o modelo calibrado para a economia brasileira, os autores encontram que é ótimo se financiar com uma dívida 100\% indexada - o custo de inflação é superior ao custo de suavização de taxação. Fazendo um exercício em que a economia tem de ser financiada com uma mínima quantidade de dívida nominal, o ótimo passa a ser se financiar com nenhuma dívida indexada.

Divino e Silva Junior (2013) introduzem em um modelo DSGE títulos públicos indexados à inflação e analisam quais são os impactos na dinâmica de variáveis macroeconômicas e na interação com a política monetária. Os autores encontram que uma maior indexação é acompanhada de um nível mais elevado de bem-estar - já que as famílias desejam se proteger de variações de preços. Os autores também concluem que, olhando pela perspectiva da autoridade monetária, é melhor uma dívida pública não indexada, devido a maior facilidade de se controlar a inflação. Já olhando da perspectiva da autoridade fiscal, dívida indexada é preferível, pois suaviza a necessidade de se aumentar impostos. 



\section{Modelo Canônico}

O modelo aqui apresentado contém os elementos básicos de um modelo DSGE e será usado como base para os próximos capítulos. Segue-se nesse capítulo a formulação apresentada por Galí (2008), um modelo com competição imperfeita no mercado de bens e rigidez de preços a la Calvo (1983).

Este capítulo é introdutório e é usado principalmente para padronizar notação e apresentar alguns resultados comuns aos dois próximos capítulos.

\subsection{Consumidores}

Os consumidores são caracterizados por um contínuo de agentes que maximizam intertemporalmente:

$$
E_{0} \sum_{t=0}^{\infty} \beta^{t} U\left(C_{t}, N_{t}\right)
$$

sendo:

$$
U\left(C_{t}, N_{t}\right)=\frac{C_{t}^{1-\sigma}}{1-\sigma}-\frac{N_{t}^{1+\varphi}}{1+\varphi}
$$

onde $\sigma$ é a elasticidade intertemporal de substituição, $\varphi$ é o inverso da elasticidade de trabalho de Frisch, $N_{t}$ é o número de horas de trabalho ofertadas e $C_{t}$ é uma cesta de bens definida como:

$$
C_{t} \equiv\left(\int_{0}^{1} C_{t}(i)^{1-\frac{1}{\epsilon}} d i\right)^{\frac{\epsilon}{\epsilon-1}}
$$

sendo $C_{t}(i)$ a quantidade de bem $i$ consumida pelas famílias no período $t$ e $\epsilon$ é o parâmetro de substituição.

A restrição intertemporal das famílias, a cada período de tempo, é dada por:

$$
\int_{0}^{1} P_{t}(i) C_{t}(i) d i+Q_{t} B_{t} \leq B_{t-1}+W_{t} N_{t}-T_{t}
$$

sendo $P_{t}(i)$ o preço do bem $i, Q_{t}$ o preço do título de um período $B_{t}, W_{t}$ o salário nominal e $T_{t}$ um imposto lump-sum. $C_{t}(i)$ e $N_{t}$ são a quantidade de bem $i$ e o número de horas de trabalho ofertada respectivamente. 
É possível mostrar que $\int_{0}^{1} P_{t}(i) C_{t}(i) d i=P_{t} C_{t}{ }^{1}$. A nova restrição orçamentária passa a ter a forma:

$$
P_{t} C_{t}+Q_{t} B_{t} \leq B_{t-1}+W_{t} N_{t}-T_{t}
$$

Iterando para frente a restrição orçamentária, encontra-se a condição de non-ponzi game, $\lim _{T \rightarrow \infty} Q_{t, t+T} B_{t+T}=0$, sendo $Q_{t, t+T} \equiv \prod_{i=0}^{T} Q_{t, t+i}$. O problema do consumidor pode então ser formulado como um problema de maximização da função de utilidade sujeita à restrição orçamentária e à condição de non-ponzi game.

As equações de ótimo encontradas são:

$$
\begin{gathered}
Q_{t}=\beta E_{t}\left\{\left(\frac{C_{t+1}}{C_{t}}\right)^{-\sigma} \frac{P_{t}}{P_{t+1}}\right\} \\
\frac{W_{t}}{P_{t}}=C_{t}^{\sigma} N_{t}^{\varphi}
\end{gathered}
$$

respectivamente a condição de Euler do consumo e a equação de oferta de trabalho.

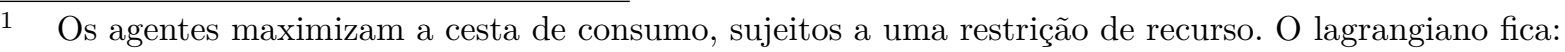

$$
\mathcal{L}=\left(\int_{0}^{1} C_{t}(i)^{1-\frac{1}{\epsilon}} d i\right)^{\frac{\epsilon}{\epsilon-1}}-\lambda_{t}\left(\int_{0}^{1} P_{t}(i) C_{t}(i) d i-Z_{t}\right)
$$

A condição de primeira ordem é:

$$
C_{t}(i)^{-\frac{1}{\epsilon}} C_{t}^{\frac{1}{\epsilon}}=\lambda P_{t}(i)
$$

para todo $i \in[0,1]$. Dividindo a condição de primeira ordem para o bem $i$ pela condição para o bem $j$ :

$$
C_{t}(i)=C_{t}\left(\frac{P_{t}(i)}{P_{t}(j)}\right)^{-\epsilon}
$$

Substituindo na restrição de recursos e usando a definição de preços agregados, $P_{t} \equiv\left(\int_{0}^{1} P_{t}(i)^{1-\epsilon} d i\right)^{\frac{1}{1-\epsilon}}$, encontra-se:

$$
C_{t}(i)=\left[\frac{P_{t}(i)}{P_{t}}\right]^{-\epsilon} \frac{Z_{t}}{P_{t}}
$$

para todo $i \in[0,1]$. Substituindo agora na definição de consumo agregado, tem-se:

$$
C_{t} P_{t}=Z_{t}
$$

e, por definição, $\int_{0}^{1} P_{t}(i) C_{t}(i) d i=Z_{t}$. 


\subsection{Firmas}

O problema de ótimo da firma segue a literatura, sendo os preços rígidos a la Calvo (1983). Existe um contínuo de firmas, $i \in[0,1]$, que produzem diferentes bens, $Y_{t}(i)$, mas com a mesma função de produção:

$$
Y_{t}(i)=A_{t} N_{t}(i)
$$

sendo $A_{t}$ um parâmetro exógeno de produtividade comum a todas as firmas e $N_{t}(i)$ a quantidade de horas usada para produzir o bem $i$. Todas as firmas estão sujeitas a uma demanda de produtos dada por $C_{t}(i)=\left(P_{t}(i) / P_{t}\right)^{-\epsilon} C_{t}$ e elas tomam o índice de preços, $P_{t}$, e a cesta de consumo, $C_{t}$, como dados. A cada período, uma parcela $1-\theta$ das firmas pode reajustar os preços, independentemente de quando foi o último ajuste. Nessa modelagem, a duração média dos contratos de preço é dada por $(1-\theta)^{-1}$

A dinâmica de preços agregados pode ser derivada partindo da equação de agregação de preços, $P_{t} \equiv\left(\int_{0}^{1} P_{t}(i)^{1-\epsilon} d i\right)^{\frac{1}{1-\epsilon}}$ :

$$
\begin{aligned}
P_{t} & =\left[\int_{s(i) c[0,1]} P_{t-1}(i)^{1-\epsilon} d i+(1-\theta)\left(P_{t}^{*}\right)^{1-\epsilon}\right]^{\frac{1}{1-\epsilon}} \\
P_{t} & =\left[\theta P_{t-1}^{1-\epsilon}+(1-\theta)\left(P_{t}^{*}\right)^{1-\epsilon}\right]^{\frac{1}{1-\epsilon}} \\
1 & =\theta\left(\frac{P_{t-1}}{P_{t}}\right)^{1-\epsilon}+(1-\theta)\left(\frac{P_{t}^{*}}{P_{t}}\right)^{1-\epsilon}
\end{aligned}
$$

sendo $P_{t}^{*}$ o preço escolhido em $t$ pelas firmas que podem reajustar seu preço nesse período. Durante todo este trabalho, a forma usada para a equação da dinâmica de preços será:

$$
1=\theta \pi_{t}^{\epsilon-1}+(1-\theta)\left(\frac{P_{t}^{*}}{P_{t}}\right)^{1-\epsilon}
$$

sendo $\pi_{t} \equiv P_{t} / P_{t-1}$.

A firma escolhe o preço $P_{t}^{*}$ no período $t$ de forma a maximizar o lucro esperado em valor presente considerando que não terá a oportunidade de redefinir seu preço. Isso é, maximiza:

$$
\max _{P^{*}} \sum_{k=0}^{\infty} \theta^{k} E_{t}\left\{Q_{t, t+k}\left(P_{t}^{*} Y_{t+k \mid t}-\Psi_{t+k}\left(Y_{t+k \mid t}\right)\right)\right\}
$$


sujeito à restrição de demanda:

$$
Y_{t+k \mid t}=\left(\frac{P_{t}^{*}}{P_{t+k}}\right)^{-\epsilon} C_{t+k}
$$

sendo $Q_{t, t+k} \equiv \beta^{k}\left(C_{t+k} / C_{t}\right)^{-\sigma}\left(P_{t} / P_{t+k}\right)$ o fator de desconto estocástico, $\Psi_{t}$ a função custo e $Y_{t+k \mid t}$ o produto de uma firma no período $t+k$ que ajustou preços no período $t$.

A condição de primeira ordem dessa firma é:

$$
E_{t} \sum_{k=0}^{\infty} \theta^{k} Q_{t, t+k} Y_{t+k \mid t}\left(P_{t}^{*}-\mu M C_{t+k}\right)=0
$$

sendo o custo marginal nominal da firma definido como $M C_{t+k} \equiv \Psi_{t+k}\left(Y_{t+k \mid t}\right)^{\prime}$ e $\mu$ a taxa de mark-up, $\mu \equiv \epsilon / \epsilon-1$. Dividindo a equação anterior por $P_{t+k}$, tem-se:

$$
E_{t} \sum_{k=0}^{\infty} \theta^{k} Q_{t, t+k}\left(\frac{P_{t}^{*}}{P_{t+k}}\right)^{-\epsilon} C_{t+k}\left(\frac{P_{t}^{*}}{P_{t+k}}-\mu m c_{t+k}\right)=0
$$

O custo marginal real da firma é definido como $m c_{t+k} \equiv M C_{t+k} / P_{t+k}$.

Como optou-se por escrever o modelo em nível e não log linearizar, é preciso escrever a relação de ótimo recursivamente por meio de equações auxiliares. Schmitt-Grohé e Uribe (2007) e Krause e Moyen (2016) são exemplos de artigos que utilizam esse método. As equações auxiliares definidas foram:

$$
\begin{gathered}
x_{1, t} \equiv E_{t} \sum_{k=0}^{\infty} \theta^{k} Q_{t, t+k}\left(\frac{P_{t}^{*}}{P_{t+k}}\right)^{1-\epsilon} C_{t+k} \\
x_{2, t} \equiv E_{t} \sum_{k=0}^{\infty} \theta^{k} Q_{t, t+k}\left(\frac{P_{t}^{*}}{P_{t+k}}\right)^{-\epsilon} C_{t+k} m c_{t+k}=0
\end{gathered}
$$

o que resulta na condição:

$$
x_{1, t}=\mu x_{2, t}
$$


Escrevendo $x_{2, t}$ recursivamente $\left(x_{1, t}\right.$ é análogo):

$$
\begin{aligned}
x_{2, t} & \equiv E_{t} \sum_{k=0}^{\infty} \theta^{k} Q_{t, t+k}\left(\frac{P_{t}^{*}}{P_{t+k}}\right)^{-\epsilon} C_{t+k} m c_{t+k} \\
& =\left(\frac{P_{t}^{*}}{P_{t}}\right)^{-\epsilon} C_{t} m c_{t}+\theta E_{t} Q_{t, t+1}\left(\frac{P_{t}^{*}}{P_{t+1}^{*}}\right)^{-\epsilon} x_{2, t+1} \\
& =\left(\frac{P_{t}^{*}}{P_{t}}\right)^{-\epsilon} C_{t} m c_{t}+\beta \theta E_{t} \frac{\lambda_{t+1}}{\lambda_{t}}\left(\frac{P_{t}^{*}}{P_{t}}\right)^{-\epsilon}\left(\frac{P_{t+1}}{P_{t+1}^{*}}\right)^{-\epsilon} \pi_{t+1}^{\epsilon} x_{2, t+1} \\
& =\left(\frac{P_{t}^{*}}{P_{t}}\right)^{-\epsilon}\left[C_{t} m c_{t}+\beta \theta E_{t} \frac{\lambda_{t+1}}{\lambda_{t}}\left(\frac{P_{t+1}^{*}}{P_{t+1}}\right)^{\epsilon} \pi_{t+1}^{\epsilon} x_{2, t+1}\right]
\end{aligned}
$$

em que $Q_{t, t+k} \equiv \beta^{k}\left(\lambda_{t+k} / \lambda_{t}\right)\left(P_{t} / P_{t+k}\right)$ e $\lambda=C_{t}^{-\sigma}$.

Logo, tem-se as equações auxiliares (2.4) e (2.5) na forma recursiva.

$$
\begin{aligned}
& x_{1, t}=\left(\frac{P_{t}^{*}}{P_{t}}\right)^{1-\epsilon}\left[C_{t}+\beta \theta E_{t} \frac{\lambda_{t+1}}{\lambda_{t}}\left(\frac{P_{t+1}^{*}}{P_{t+1}}\right)^{\epsilon-1} \pi_{t+1}^{\epsilon-1} x_{1, t+1}\right] \\
& x_{2, t}=\left(\frac{P_{t}^{*}}{P_{t}}\right)^{-\epsilon}\left[C_{t} m c_{t}+\beta \theta E_{t} \frac{\lambda_{t+1}}{\lambda_{t}}\left(\frac{P_{t+1}^{*}}{P_{t+1}}\right)^{\epsilon} \pi_{t+1}^{\epsilon} x_{2, t+1}\right]
\end{aligned}
$$

As fórmulas funcionais encontradas acima são idênticas às encontradas por SchmittGrohé e Uribe (2007). Com mais manipulações algébricas, pode-se chegar às equações utilizadas por Krause e Moyen (2016), as equações que foram utilizadas neste trabalho. Definindo:

$$
\begin{gathered}
Z_{1, t} \equiv x_{1, t}\left(\frac{P_{t}^{*}}{P_{t}}\right)^{\epsilon-1} \frac{1}{\lambda_{t}} \\
Z_{2, t} \equiv x_{2, t}\left(\frac{P_{t}^{*}}{P_{t}}\right)^{\epsilon} \frac{1}{\lambda_{t}}
\end{gathered}
$$

Reescrevendo a equação (2.4) com a nova definição, tem-se:

$$
\frac{Z_{1, t}}{\left(\frac{P_{t}^{*}}{P_{t}}\right)^{\epsilon-1} \frac{1}{\lambda_{t}}}=\left(\frac{P_{t}^{*}}{P_{t}}\right)^{1-\epsilon}\left[C_{t}+\beta \theta E_{t} \frac{\lambda_{t+1}}{\lambda_{t}}\left(\frac{P_{t+1}^{*}}{P_{t+1}}\right)^{\epsilon-1} \pi_{t+1}^{\epsilon-1} \frac{Z_{1, t+1}}{\left(\frac{P_{t+1}^{*}}{P_{t+1}}\right)^{\epsilon-1} \frac{1}{\lambda_{t+1}}}\right]
$$

Rearranjando os termos:

$$
Z_{1, t}=\lambda_{t} C_{t}+\beta \theta E_{t} \pi_{t+1}^{\epsilon-1} Z_{1, t+1}
$$


Por último, usando a definição de multiplicador de Lagrange $\lambda=C_{t}^{-\sigma 2}$ :

$$
Z_{1, t}=C_{t}^{1-\sigma}+\beta \theta E_{t} \pi_{t+1}^{\epsilon-1} Z_{1, t+1}
$$

Analogamente, pode-se mostrar que a equação (2.5) é:

$$
Z_{2, t}=C_{t}^{1-\sigma} m c_{t}+\beta \theta E_{t} \pi_{t+1}^{\epsilon} Z_{2, t+1}
$$

A equação (2.6) pode ser escrita como:

$$
Z_{1, t}\left(\frac{P_{t}^{*}}{P_{t}}\right)^{1-\epsilon}=\mu Z_{2, t}\left(\frac{P_{t}^{*}}{P_{t}}\right)^{-\epsilon}
$$

ou, rearranjando os termos:

$$
\frac{P_{t}^{*}}{P_{t}}=\mu \frac{Z_{2, t}}{Z_{1, t}}
$$

Para completar, o custo marginal no modelo, dado que não há restrição no mercado de trabalho, é igual a:

$$
m c_{t}=\frac{W_{t}}{P_{t} A_{t}}
$$

\subsection{Autoridade Fiscal e Monetária}

Para completar o modelo, é necessário adicionar uma regra fiscal e uma regra monetária. Na literatura de modelos DSGE estudando política fiscal, Schmitt-Grohé e Uribe (2007) propõem uma regra fiscal da forma:

$$
\tau_{t}-\bar{\tau}=\rho_{\tau}\left(b_{t-1}-\bar{b}\right)
$$

sendo $\tau_{t}$ uma de imposto distorcivo no mercado de trabalho, $\bar{\tau}$ seu valor de Steady-State, $b_{t}$ o estoque de dívida real, $\bar{b}$ o seu valor de Steady-State e $\rho_{\tau}$ o coeficiente de resposta da tributação à variações na dívida pública. A política fiscal responde a desvios na dívida pública. 
Já Krause e Moyen (2016) usam uma regra fiscal da forma:

$$
\tau_{t}-\bar{\tau}=\rho_{\tau}\left(\tau_{t-1}-\bar{\tau}\right)+\phi_{b}\left(b_{t}^{L}-\bar{b}^{L}\right)
$$

sendo $b_{t}^{L}$ o estoque de dívida real de longo prazo e $\bar{b}^{L}$ o seu valor de Steady-State. Nessa regra, a política fiscal responde a desvios na dívida pública real, além de possuir um coeficiente auto regressivo.

Neste trabalho, decidiu-se usar uma regra fiscal da forma:

$$
T_{t}-\bar{T}=\rho_{T}\left(T_{t-1}-\bar{T}\right)+\phi_{b}\left(b_{t}-\bar{b}\right)+s_{t}
$$

onde $T_{t}$ é uma transferência lump-sum, $\bar{T}$ é o valor de Steady-State de alíquota de imposto lump-sum, $b_{t}$ é o nível de endividamento real, dado por $B_{t} / P_{t}, \bar{b}$ é o valor de Steady-State do endividamento real e $s_{t}$ é um choque fiscal com desvio padrão $\sigma_{s}$.

Também é necessário adicionar a restrição orçamentária do governo:

$$
T_{t}+Q_{t} \frac{B_{t}}{P_{t}}=\frac{B_{t}}{P_{t}}+g
$$

onde $g$ é uma constante de gasto público.

Por último, para acabar de caracterizar o governo, a regra de política monetária é:

$$
R_{t}=\left(1-\rho_{R}\right) \bar{R}+\rho_{R} R_{t-1}+\phi_{\pi}\left(\pi_{t}-1\right)+v_{t}
$$

onde $R_{t}$ é a taxa de juros nominal controlada pela autoridade monetária e definida como $Q_{t} \equiv 1 / R_{t}, \bar{R}$ é o valor de Steady-State, $\pi_{t}$ é a taxa de inflação e $v_{t}$ é um choque estocástico com desvio padrão $\sigma_{v}$.

\subsection{Equilíbrio}

A demanda agregada de bens exige que o produto seja igual ao consumo das famílias mais o consumo do governo:

$$
Y_{t}=C_{t}+g
$$

A função de produção de cada firma é $Y_{t}(i)=A N_{t}(i)$. Usando a condição de market 
clearing do mercado de trabalho, $N_{t}=\int_{0}^{1} N_{t}(i) d i$, e a demanda individual de cada firma, $Y_{t}(i)=\left(P_{t}(i) / P_{t}\right)^{-\epsilon} Y_{t}$, tem-se:

$$
\begin{aligned}
& \int_{0}^{1} Y_{t}(i) d i=A \int_{0}^{1} N_{t}(i) d i \\
& Y_{t} \int_{0}^{1}\left(\frac{P_{t}(i)}{P_{t}}\right)^{-\epsilon} d i=A N_{t}
\end{aligned}
$$

Definindo $\Delta_{p, t} \equiv \int_{0}^{1}\left[P_{t}(i) / P_{t}\right]^{-\epsilon}$ como o coeficiente de dispersão de preços, chega-se à equação:

$$
\Delta_{p, t} Y_{t}=A N_{t}
$$

sendo o movimento de $\Delta_{p, t}$ dado por:

$$
\Delta_{p, t}=\theta \pi_{t}^{\epsilon} \Delta_{p, t-1}+(1-\theta)\left[\frac{P_{t}^{*}}{P_{t}}\right]^{-\epsilon}
$$

O equilíbrio do modelo é determinado pelos processos estacionários $Q_{t}, C_{t}, \pi_{t}$, $W_{t} / P_{t}, N_{t}, P_{t}^{*} / P_{t}, Z_{1, t}, Z_{2, t}, m c_{t}, T_{t}, B_{t} / P_{t}, Y_{t}$ e $\Delta_{p, t}$ satisfazendo as relações (2.1), (2.2), (2.3), (2.9), (2.7), (2.8), (2.10), (2.11), (2.12), (2.13), (2.14), (2.15) e (2.16) e pelos processos estocásticos $v_{t}$ e $s_{t}$.

\subsection{Calibração e Simulação}

O modelo canônico foi calibrado usando parâmetros comumente usados na literatura brasileira de modelos de equilíbrio geral e um período representa um trimestre. Castro et al. (2015) apresentam o modelo de equilíbrio geral usado pelo Banco Central do Brasil (Bacen) para realizar análises econômicas. Usando as estimativas dos autores como base, o coeficiente de desconto intertemporal, $\beta$, é igual a 0,989, a elasticidade de substituição intertemporal, $\sigma$, é igual a 1,3, a elasticidade da oferta de trabalho de Frisch, $\varphi$, é igual a 1 , a resposta da tributação a desvios da dívida, $\phi_{b}$, é igual a 0,02, o coeficiente de Taylor, $\phi_{\pi}$, é igual a 2,43, o coeficiente auto-regressivo da regra fiscal, $\rho_{T}$, é igual a 0,8 e o coeficiente auto-regressivo da regra monetária, $\rho_{R}$, é igual a 0,79. Além disso, os autores estimam os desvios padrão dos choques monetário e fiscal, $\sigma_{v}$ e $\sigma_{s}$, sendo este igual a 1,73 e aquele a 
0,32 .

Castro et al. (2015) estimam o coeficiente de substituição para vários mercados. Como neste trabalho, tem-se apenas um mercado, o coeficiente de substituição, $\epsilon$, e a proporção de firmas reajustando preços, $\theta$, foram retirados de Krause e Moyen (2016). O primeiro é igual a 6 - de forma que o mark-up seja $20 \%$ - e o segundo foi calibrado em $2 / 3$ - de forma que a duração média de um contrato de preço dure três quartos.

No cálculo dos valores de Steady-State, a razão governo-produto, $S_{g}$, foi calibrada para ser igual a $22,20 \%$ e a razão dívida-produto, $S_{b}$, foi calibrada para ser igual a $36,81 \%$. Em ambas razões, usou-se os valores das Contas Nacionais divulgadas pelo IBGE. O valor de $g$ usado foi 0,24 . A tabela 1 resume os parâmetros utilizados neste trabalho.

Tabela 1 - Calibração básica para o modelo canônico

\begin{tabular}{|c|c|c|c|}
\hline Simbolo & Valores & Descrição & Fonte \\
\hline \multicolumn{4}{|c|}{ Razões } \\
\hline$S_{g}$ & $22,20 \%$ & Razão Governo-Produto & IBGE \\
\hline$S_{b}$ & $36,81 \%$ & Razão Dívida-Produto & IBGE \\
\hline \multicolumn{4}{|c|}{ Parâmetros de Preferências e de Tecnologia } \\
\hline$\beta$ & 0,989 & Coeficiente de desconto intertemporal & Castro et al. (2015) \\
\hline$\sigma$ & 1,3 & Elasticidade de substituição intertemporal & Castro et al. (2015) \\
\hline$\varphi$ & 1 & Elasticidade da oferta de trabalho de Frisch & Castro et al. (2015) \\
\hline$\epsilon$ & 6 & Mark-up de $20 \%$ & Krause e Moyen (2016) \\
\hline \multicolumn{4}{|c|}{ Parâmetros de Rigidez } \\
\hline$\theta$ & 0,67 & Proporção de firmas reajustando preços & Krause e Moyen (2016) \\
\hline \multicolumn{4}{|c|}{ Parâmetros da Regra Fiscal, da Monetária e da Restrição Orçamentária do Governo } \\
\hline$\phi_{b}$ & 0,02 & Resposta da tributação a desvios da dívida & Castro et al. (2015) \\
\hline$\phi_{\pi}$ & 2,43 & Coeficiente de Taylor & Castro et al. (2015) \\
\hline$\rho_{T}$ & 0,8 & Coeficiente auto-regressivo da regra fiscal & Castro et al. (2015) \\
\hline$\rho_{R}$ & 0,79 & Coeficiente auto-regressivo da regra monetária & Castro et al. (2015) \\
\hline$g$ & 0,24 & Gastos do governo & IBGE \\
\hline \multicolumn{4}{|c|}{ Coeficientes dos Choques Exógenos } \\
\hline$\sigma_{v}$ & 0,32 & Desvio padrão do choque monetário $\left(v_{t}\right)$ & Castro et al. (2015) \\
\hline$\sigma_{s}$ & 1,73 & Desvio padrão do choque monetário $\left(s_{t}\right)$ & Castro et al. (2015) \\
\hline
\end{tabular}

Fonte: Elaboração própria.

Para simular, foi usado o programa Dynare. Dynare é um programa executável via 
MATLAB e é usado para resolver várias classes de modelos econômicos, entre elas, modelos DSGE. As equações do modelo foram introduzidas no programa em nível e, inicialmente, pediu-se uma aproximação de segunda ordem. Infelizmente, não é possível calcular as funções de resposta a impulso quando o modelo sofre uma aproximação de segunda ordem. Elas se mostram explosivas após a ocorrência de um choque de um desvio padrão na taxa de juros. Logo, para calcular as funções de resposta a impulso, foi realizada uma aproximação de primeira ordem.

Figura 1 - Função de resposta a impulso do modelo canônico quando ocorre um choque na taxa de juros básica
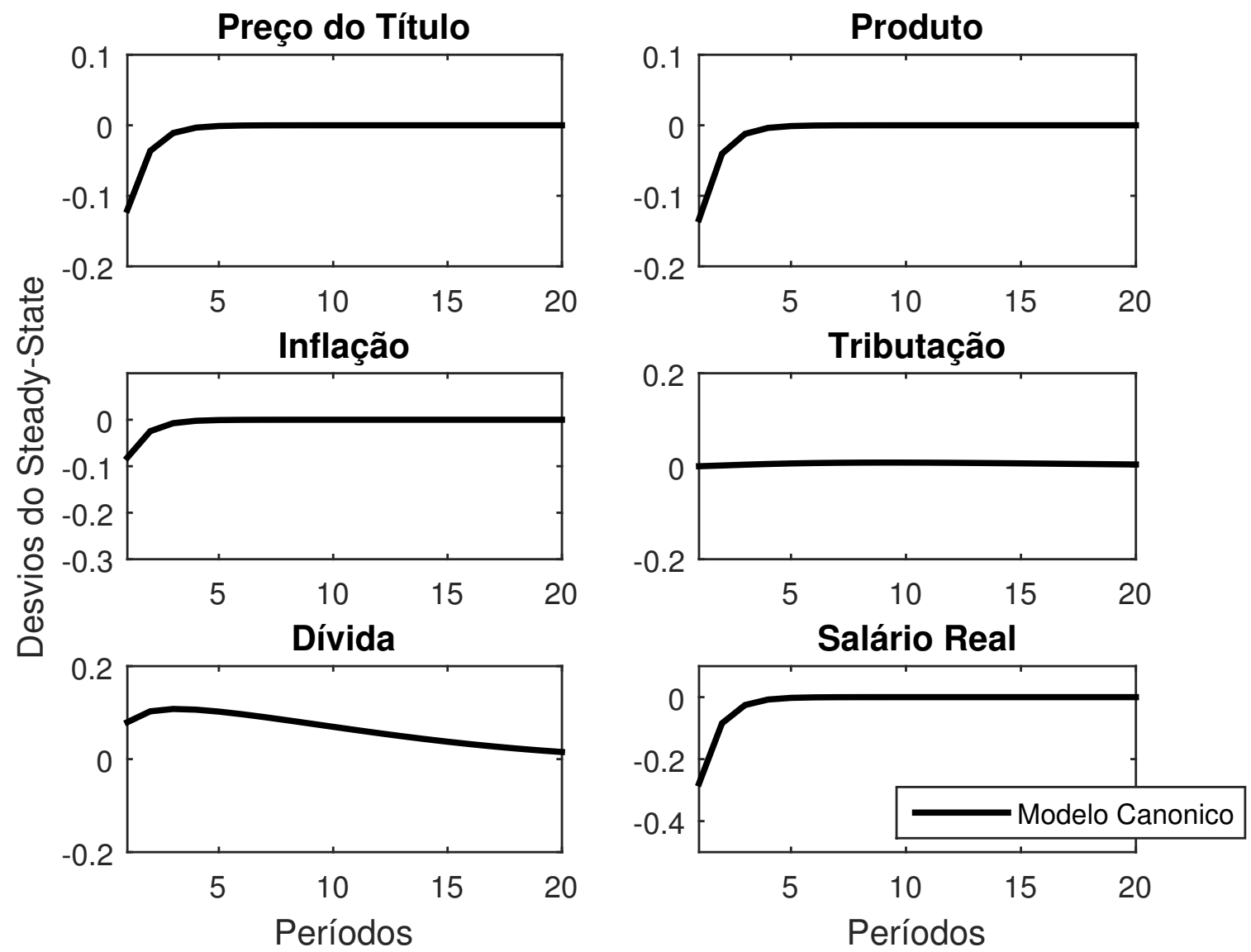

Elaboração própria

A figura 1 apresenta as funções de resposta a impulso para o modelo canônico após a ocorrência de um choque positivo na taxa básica de juros. As funções possuem o sentido esperado, ou seja, um choque positivo na taxa de juros possui impacto negativo na taxa 
de inflação, no preço do título de curto prazo, no produto e no salário real. O valor do estoque da dívida aumenta, mas, devido ao baixo coeficiente de resposta da tributação a desvios da dívida pública, a tributação permanece inalterada.

Figura 2 - Função de resposta a impulso do modelo canônico quando ocorre um choque fiscal
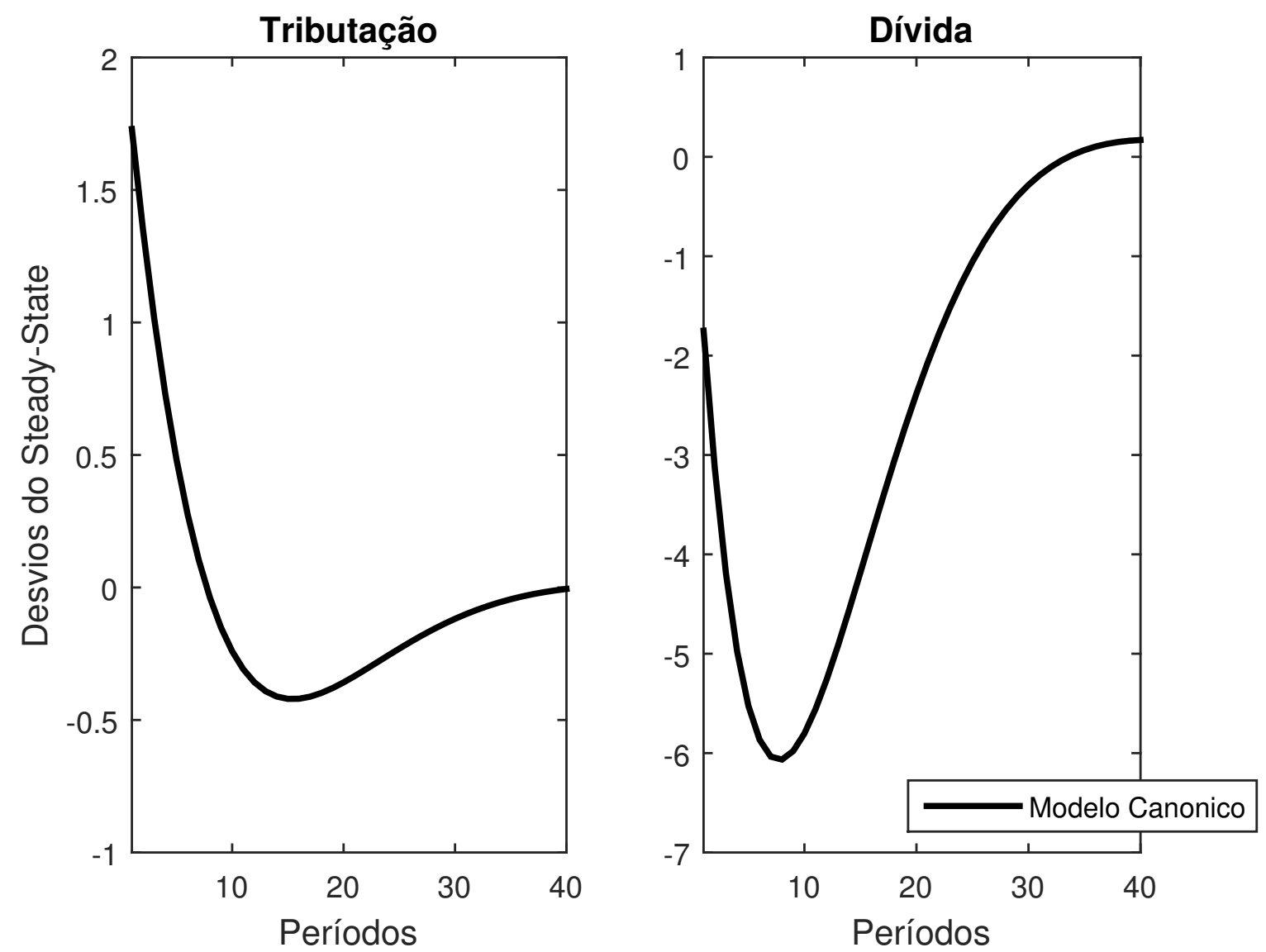

Elaboração própria

A figura 2 apresenta as funções de resposta a impulso para o modelo canônico após a ocorrência de um choque fiscal positivo (aumento de tributação). Quando esse ocorre, a tributação aumenta exatamente igual ao tamanho do choque e o estoque da dívida diminui de valor. Nos momentos que sucedem ao choque, a tributação diminui e o estoque da dívida aumenta até ambos retornarem ao nível de Steady-State. É oportuno observar que esse resultado deixa claro que, neste modelo, a política fiscal obedece a Equivalência Ricardiana e que, portanto, o efeito do choque fiscal sobre as demais variáveis do modelo é 
nulo.

\subsection{Conclusão}

Nesta seção, o modelo DSGE canônico que será usado como base para os próximos capítulos foi apresentado. O comportamento do modelo após a ocorrência de um choque monetário é o esperado, tendo todas as funções de resposta a impulso apresentando o sentido correto: um choque positivo de um desvio padrão na taxa básica de juros controlada pela autoridade monetária possui impacto negativo na taxa de inflação, no preço do título de curto prazo, no produto e no salário real e possui um impacto positivo, mas pequeno no valor do estoque da dívida. O impacto na tributação é nulo.

Quando ocorre um choque fiscal positivo de um desvio padrão, fica claro que o modelo respeita a Equivalência Ricardiana. Tributação aumenta exatamente igual ao tamanho do choque e o estoque da dívida diminui de valor. O impacto nas variáveis reais, como produto e salário real, é nulo. Esse resultado confirma as conjecturas que Barro (1999) fez ${ }^{3}$ e novos elementos devem ser introduzidos ao modelo para se analisar qual o espaço da gestão da dívida pública no modelo.

No modelo do capítulo 3, impostos distorcivos no mercado de trabalho e agentes rule of thumb serão introduzidos. No modelo do capítulo 4, serão introduzidos impostos distorcivos no mercado de trabalho e agentes que enfrentam uma probabilidade de morrer a la Blanchard (1985).

3 O autor argumenta que modelos com impostos lump-sum, com certeza quanto ao futuro, com mercados de capitais perfeitos e com agentes que vivem infinitamente obedecem a Equivalência Ricardiana e neles a adição de novos títulos é redundante. 


\section{Modelo com Maturidade Recursiva}

Neste capítulo, será usada a forma de modelar maturidade da dívida pública de Krause e Moyen (2016). Na seção 3.1, será apresentado um modelo bastante semelhante ao original desenvolvido pelos autores. A diferença mais marcante é a ausência do estoque de moeda no modelo, sendo que essa entrava originalmente na função utilidade do agente representativo.

Usando a existência das LFTs no Brasil como motivação, procurou-se modificar a estrutura da dívida pública do modelo da seção 3.1 para permitir a existência de um título pós-fixado. Acrescentou-se um título de longo prazo remunerado pela taxa de juros básica da economia, esta controlada pela autoridade monetária. Essa modificação será apresentada na seção 3.2. Outras modificações ao modelo serão introduzidas na seção 3.3 e 3.4. A seção 3.5 conclui o capítulo.

\subsection{Modelo de Krause e Moyen}

No modelo de Krause e Moyen (2016), a dívida pública possui uma estrutura recursiva de maturidade. A cada período, $\alpha$ títulos maturam. A equação de movimento dos títulos de longo prazo, $B_{t}^{L}$, é dada por:

$$
B_{t}^{L}=(1-\alpha) B_{t-1}^{L}+B_{t}^{L, n}
$$

sendo $B_{t}^{L, n}$ a quantidade de títulos recém emitidos e $(1-\alpha) B_{t-1}^{L}$ a quantidade de títulos de longo prazo que não maturaram.

A taxa de juros dos títulos emitidos no período $t$ é dada por $i_{t}^{L, n}$ e a taxa média dos títulos de longo prazo é dada por $i_{t}^{L}$. Definine-se a taxa de juros média de longo prazo como uma média ponderada:

$$
i_{t}^{L}=\frac{B_{t}^{L, n}}{B_{t}^{L}} i_{t}^{L, n}+(1-\alpha) \frac{B_{t-1}^{L, n}}{B_{t}^{L}} i_{t-1}^{L, n}+(1-\alpha)^{2} \frac{B_{t-2}^{L, n}}{B_{t}^{L}} i_{t-2}^{L, n}+\ldots
$$

O peso da taxa de juros de um título previamente emitido, $i_{t-i}^{L, n}$, na taxa de juros média de longo prazo, $i_{t}^{L}$, depende da fração desses títulos que ainda resta no estoque total de 
títulos de longo prazo, sendo essa fração representada por $(1-\alpha)^{i} B_{t-i}^{L, n} / B_{t}^{L}$. Ou seja, quanto mais recente o título emitido, maior o peso da sua taxa de juros de emissão na taxa de juros média de longo prazo.

Pode-se simplificar a equação, escrevendo-a na forma recursiva:

$$
B_{t}^{L} i_{t}^{L}=(1-\alpha) B_{t-1}^{L} i_{t-1}^{L}+B_{t}^{L, n} i_{t}^{L, n}
$$

\subsubsection{Condições de Ótimo do Consumidor}

O problema do consumidor é maximizar sua utilidade sujeito à restrição orçamentária, à equação de movimento do estoque de títulos, (3.1), e à equação que determina a taxa média de juros dos títulos de longo prazo, (3.2). Ou seja, os agentes maximizam o valor presente da utilidade intertemporal,

$$
\max E_{0} \sum_{t=0}^{\infty} \beta^{t}\left(\frac{C_{t}^{1-\sigma}}{1-\sigma}-\frac{N_{t}^{1+\varphi}}{1+\varphi}\right)
$$

sendo $C_{t}$ um índice de consumo e $N_{t}$ a quantidade de horas de trabalho ofertada, respeitando as equações:

$$
\begin{aligned}
& \frac{B_{t}}{P_{t}}+\frac{B_{t}^{L, n}}{P_{t}}+C_{t}=\left(1+i_{t-1}\right) \frac{B_{t-1}}{P_{t}}+\left(\alpha+i_{t-1}^{L}\right) \frac{B_{t-1}^{L}}{P_{t}}+\frac{W_{t}}{P_{t}} N_{t}+Z_{t}+T_{t} \\
& B_{t}^{L}=(1-\alpha) B_{t-1}^{L}+B_{t}^{L, n} \\
& B_{t}^{L} i_{t}^{L}=B_{t}^{L, n} i_{t}^{L, n}+(1-\alpha) B_{t-1}^{L} i_{t-1}^{L}
\end{aligned}
$$

Na restrição orçamentária, $P_{t}$ é o índice de preços, $i_{t}$ é a taxa básica de juros da economia, $B_{t}$ é o título público de um período, $W_{t}$ é o salário nominal, $Z_{t}$ é uma transferência das firmas e $T_{t}$ é um imposto lump-sum. As variáveis $B_{t}^{L, n}, B_{t}^{L}, i_{t}^{L, n}$ e $i_{t}^{L}$ já foram definidas e são, respectivamente, a quantidade de títulos de longo prazo recém emitidos, a quantidade de títulos de longo prazo, a taxa de juros de emissão dos títulos de longo prazo e a taxa de juros média de longo prazo.

Assim como no modelo do capítulo 2, o índice de consumo, $C_{t}$, é definido como uma cesta de bens composta por um contínuo de bens, $C_{t}(i) \in[0,1]$. A agregação é feita por $C_{t} \equiv\left(\int_{0}^{1} C_{t}(i)^{1-1 / \epsilon} d i\right)^{\epsilon / \epsilon-1}$, sendo $\epsilon$ a elasticidade de substituição entre os bens $C_{t}(i)$. 
O agregador de preços é $P_{t} \equiv\left(\int_{0}^{1} P_{t}(i)^{1-\epsilon} d i\right)^{1 / 1-\epsilon}$.

A maneira mais fácil de resolver é substituindo a segunda restrição nas outras equações. O problema de maximização fica:

$$
\begin{gathered}
\max E_{0} \sum_{t=0}^{\infty} \beta^{t}\left(\frac{C_{t}^{1-\sigma}}{1-\sigma}-\frac{N_{t}^{1+\varphi}}{1+\varphi}\right) \\
\text { s.a. } \frac{B_{t}}{P_{t}}+\frac{B_{t}^{L}-(1-\alpha) B_{t-1}^{L}}{P_{t}}+C_{t}=\left(1+i_{t-1}\right) \frac{B_{t-1}}{P_{t}}+\left(\alpha+i_{t-1}^{L}\right) \frac{B_{t-1}^{L}}{P_{t}} \\
+\frac{W_{t}}{P_{t}} N_{t}+Z_{t}+T_{t} \\
B_{t}^{L} i_{t}^{L}=\left(B_{t}^{L}-(1-\alpha) B_{t-1}^{L}\right) i_{t}^{L, n}+(1-\alpha) B_{t-1}^{L} i_{t-1}^{L}
\end{gathered}
$$

Krause e Moyen (2016) argumentam que os consumidores tomam a taxa de emissão dos novos títulos de longo prazo como dada, já que é o mercado que a determina. Já a taxa média de juros de longo prazo, $i_{t}^{L}$, depende da quantidade de títulos recém emitidos relativos à quantidade de títulos de longo prazo que o agente escolhe manter. Logo, a taxa média de juros deve ser levada em consideração ao resolver o problema de ótimo do consumidor. O resultado da maximização do lagrangiano ${ }^{1}$ por $C_{t}, N_{t}, B_{t}, B_{t}^{L}$ e $i_{t}^{L}$ é respectivamente:

$$
\begin{aligned}
\frac{\partial \mathcal{L}}{\partial C_{t}} & =C_{t}^{-\sigma}-\lambda_{t}=0 \\
\frac{\partial \mathcal{L}}{\partial N_{t}} & =-N_{t}^{\varphi}+\lambda_{t} \frac{W_{t}}{P_{t}}=0 \\
\frac{\partial \mathcal{L}}{\partial B_{t}} & =-\frac{\lambda_{t}}{P_{t}}+E_{t} \frac{\lambda_{t+1}}{P_{t+1}}\left(1+i_{t}\right)=0 \\
\frac{\partial \mathcal{L}}{\partial B_{t}^{L}} & =-\frac{\lambda_{t}}{P_{t}}+\beta E_{t} \frac{\lambda_{t+1}}{P_{t+1}}(1-\alpha)+\beta E_{t} \frac{\lambda_{t+1}}{P_{t+1}}\left(\alpha+i_{t}^{L}\right)-\mu_{t} i_{t}^{L} \\
& +\beta E_{t} \mu_{t+1}(1-\alpha) i_{t}^{L}+\mu_{t} i_{t}^{L, n}-\beta E_{t} \mu_{t+1}(1-\alpha) i_{t+1}^{L, n}=0 \\
\frac{\partial \mathcal{L}}{\partial i_{t}^{L}} & =\beta E_{t} \frac{\lambda_{t+1}}{P_{t+1}} B_{t}^{L}-\mu_{t} B_{t}^{L}+\beta E_{t} \mu_{t+1} B_{t}^{L}(1-\alpha)=0
\end{aligned}
$$

sendo $\lambda_{t}$ e $\mu_{t}$ dois multiplicadores de Lagrange.

Das condições de primeira ordem, encontra-se uma equação para a oferta de trabalho 
e uma equação de Euler para o título de um período, $B_{t}$ :

$$
\begin{gathered}
N_{t}^{\varphi} C_{t}^{\sigma}=\frac{W_{t}}{P_{t}} \\
1=E_{t} \beta\left\{\left(\frac{C_{t}}{C_{t+1}}\right)^{-\sigma} \frac{P_{t}}{P_{t+1}}\right\}\left(1+i_{t}\right)
\end{gathered}
$$

Observe que as equações (3.3) e (3.4) são iguais às (2.1) e (2.2) no modelo canônico do capítulo 2. Agora, deve-se encontrar a equação de Euler para os outros títulos do modelo. Simplificando a derivada parcial $\partial \mathcal{L} / \partial i_{t}^{L}$, encontra-se:

$$
\mu_{t}=\beta E_{t} \frac{\lambda_{t+1}}{P_{t+1}}+\beta E_{t} \mu_{t+1}(1-\alpha)
$$

Simplificando a derivada parcial $\partial \mathcal{L} / \partial B_{t}^{L}$ e substituindo $\mu_{t}$ pela equação anterior ${ }^{2}$, o resultado é a equação de Euler para o título de longo prazo:

$$
1=\beta E_{t}\left[\frac{\lambda_{t+1}}{P_{t+1}} \frac{P_{t}}{\lambda_{t}}\left(1+i_{t}^{L, n}\right)-\beta \frac{P_{t}}{\lambda_{t}} \mu_{t+1}(1-\alpha) \Delta i_{t+1}^{L, n}\right]
$$

Para encontrar as equações de Euler usadas pelos autores, deve-se normalizar os multiplicadores de Lagrange. A normalização será feita dividindo o multiplicador $\mu_{t+i}$ por $\lambda_{t+i} / P_{t+i}$. As equações de Euler após a transformação são idênticas às encontradas por Krause e Moyen (2016):

$$
\mu_{t}=\beta E_{t}\left\{\left(\frac{C_{t}}{C_{t+1}}\right)^{-\sigma} \frac{P_{t}}{P_{t+1}}\left[1-\mu_{t+1}(1-\alpha)\right]\right\}
$$

2 Contas detalhadas:

$$
\begin{gathered}
-\frac{\lambda_{t}}{P_{t}}+\beta E_{t} \frac{\lambda_{t+1}}{P_{t+1}}\left(1+i_{t}^{L}\right)-\mu_{t}\left(i_{t}^{L}-i_{t}^{L, n}\right)+\beta E_{t} \mu_{t+1}(1-\alpha)\left[i_{t}^{L}-i_{t+1}^{L, n}\right]=0 \\
-\frac{\lambda_{t}}{P_{t}}+\beta E_{t} \frac{\lambda_{t+1}}{P_{t+1}}\left(1+i_{t}^{L}\right)-\left[\beta E_{t} \frac{\lambda_{t+1}}{P_{t+1}}+\beta E_{t} \mu_{t+1}(1-\alpha)\right]\left(i_{t}^{L}-i_{t}^{L, n}\right)+\beta E_{t} \mu_{t+1}(1-\alpha)\left[i_{t}^{L}-i_{t+1}^{L, n}\right]=0 \\
-\frac{\lambda_{t}}{P_{t}}+\beta E_{t} \frac{\lambda_{t+1}}{P_{t+1}}\left(1+i_{t}^{L, n}\right)-\beta E_{t} \mu_{t+1}(1-\alpha)[\underbrace{i_{t+1}^{L, n}-i_{t}^{L, n}}_{\Delta i_{t+1}^{L, n}}]=0 \\
\frac{\lambda_{t}}{P_{t}}=\beta E_{t} \frac{\lambda_{t+1}}{P_{t+1}}\left(1+i_{t}^{L, n}\right)-\beta E_{t} \mu_{t+1}(1-\alpha) \Delta i_{t+1}^{L, n}
\end{gathered}
$$




$$
1=\beta E_{t}\left\{\left(\frac{C_{t}}{C_{t+1}}\right)^{-\sigma} \frac{P_{t}}{P_{t+1}}\left[\left(1+i_{t}^{L, n}\right)-\mu_{t+1}(1-\alpha) \Delta i_{t+1}^{L, n}\right]\right\}
$$

sendo $\Delta i_{t+1}^{L, n}=i_{t+1}^{L, n}-i_{t}^{L, n}$.

A equação de Euler (3.4) relaciona o fator intertemporal de desconto, $\left(C_{t} / C_{t+1}\right)^{-\sigma} P_{t} / P_{t+1}$, com a taxa de juros básica. De forma análoga, a equação de Euler (3.6) relaciona o fator de desconto intertemporal com a taxa de juros de longo prazo dos títulos recém emitidos. A grande diferença é que esta é corrigida por mudanças na expectativa, $\Delta i_{t+1}^{L, n}$, enquanto aquela não. A correção é ponderada pelo multiplicador de Lagrange $\mu_{t}$ que segue o processo definido pela equação (3.5).

Intuitivamente, o termo $\mu_{t+1} \Delta i_{t+1}^{L, n}$ na equação (3.6) é a perda de capital no período $t+1$ devido a aumentos na taxa de juros de longo prazo. Esse é o efeito riqueza da transmissão da política monetária. Ele reduz o incentivo a investir nos títulos de longo prazo no período corrente e, consequentemente, a taxa de longo prazo é maior que a taxa de juros de curto prazo para o agente ser indiferente entre os dois títulos. Os valores de Steady State de todas as taxas de juros são iguais.

\subsubsection{Equações da Firma}

O problema de ótimo da firma é igual ao problema da firma no modelo canônico e não será apresentado em detalhes aqui. A dinâmica de preços agregados segue:

$$
1=\left[\theta \pi_{t}^{\epsilon-1}+(1-\theta)\left(\frac{P_{t}^{*}}{P_{t}}\right)^{1-\epsilon}\right]
$$

onde $\theta$ é a probabilidade de reajuste do contrato de preço, $\pi_{t}$ é a taxa de inflação, $\epsilon$ é calibrado de forma às firmas terem um mark-up de $20 \%$ e $P_{t}^{*} / P_{t}$ é a razão entre os preços recém ajustados e o índice de preço na economia.

As condições de ótimo da firma são:

$$
\frac{P_{t}^{*}}{P_{t}}=\mu \frac{Z_{2, t}}{Z_{1, t}}
$$


sendo

$$
\begin{gathered}
Z_{1, t}=C_{t}^{1-\sigma}+\beta \theta E_{t} \pi_{t+1}^{\epsilon-1} Z_{1, t+1} \\
Z_{2, t}=C_{t}^{1-\sigma} m c_{t}+\beta \theta E_{t} \pi_{t+1}^{\epsilon} Z_{2, t+1}
\end{gathered}
$$

onde $\mu$ é a taxa de mark-up, $Z_{2, t}$ e $Z_{1, t}$ são duas variáveis auxiliares criadas para facilitar escrever o problema da firma recursivamente e $m c_{t}$ é o custo marginal da firma, que é dado pela equação:

$$
m c_{t}=\frac{W_{t}}{P_{t}}
$$

sendo $W_{t} / P_{t}$ o salário real.

\subsubsection{Autoridade Fiscal e Monetária}

Nesta seção, será usada uma regra fiscal exatamente igual à usada por Krause e Moyen $(2016)^{3}$ :

$$
\hat{T}_{t}=\rho_{T} \hat{T_{t-1}}+\phi_{b}\left(\hat{b_{t}^{L}}+\hat{b_{t}}\right)+s_{t}
$$

onde $\hat{T}_{t}$ é o desvio do imposto lump-sum do seu valor de Steady State, $\hat{T}_{t} \equiv T_{t}-\bar{T}_{t}, \hat{b}_{t}^{L}$ é o desvio do estoque real de título de longo prazo do seu valor de Steady State, $\hat{b_{t}^{L}} \equiv b_{t}^{L}-\overline{b_{t}^{L}}, \hat{b_{t}}$ é o desvio do estoque real de título de curto prazo do seu valor de Steady State, $\hat{b}_{t} \equiv b_{t}-\bar{b}_{t}$, e $s_{t}$ é um choque fiscal com desvio padrão $\sigma_{s}$.

A restrição orçamentária do governo é:

$$
T_{t}+\frac{B_{t}}{P_{t}}+\frac{B_{t}^{L, n}}{P_{t}}=g+\left(1+i_{t-1}\right) \frac{B_{t-1}}{P_{t}}+\left(\alpha+i_{t-1}^{L}\right) \frac{B_{t-1}^{L}}{P_{t}}
$$

onde $g$ é uma constante de gasto público.

A autoridade monetária segue uma regra de política monetária da forma:

$$
i_{t}=\left(1-\rho_{i}\right) \bar{i}+\rho_{i} i_{t-1}+\phi_{\pi}\left(\pi_{t}-1\right)+v_{t}
$$

3 Os autores usam uma tributação distorciva no mercado de trabalho. Nesta seção, optou-se, para simplificar a análise, pelo uso de um imposto lump-sum. Posteriormente, a hipótese de taxação distorciva é testada. 
onde $i_{t}$ é a taxa de juros controlada pela autoridade monetária e que remunera os títulos de um período, $\bar{i}$ é o valor de Steady-State da taxa de juros, $\pi_{t}$ é a taxa de inflação e $v_{t}$ é um choque de política monetária com desvio padrão $\sigma_{v}$.

\subsubsection{Equilíbrio}

A demanda agregada de bens exige que o produto seja igual ao consumo das famílias mais o consumo do governo:

$$
Y_{t}=C_{t}+g
$$

A condição de market clearing do mercado de trabalho é:

$$
\Delta_{p, t} Y_{t}=A N_{t}
$$

sendo $\Delta_{p, t}$ o coeficiente de dispersão de preços, cuja movimento é dado pela equação:

$$
\Delta_{p, t}=\theta \pi_{t}^{\epsilon} \Delta_{p, t-1}+(1-\theta)\left[\frac{P_{t}^{*}}{P_{t}}\right]^{-\epsilon}
$$

O equilíbrio do modelo é determinado pelos processos estacionários $i_{t}, i_{t}^{L}, i_{t}^{L, n}, C_{t}$, $\pi_{t}, W_{t} / P_{t}, N_{t}, P_{t}^{*} / P_{t}, Z_{1, t}, Z_{2, t}, m c_{t}, T_{t}, B_{t} / P_{t}, B_{t}^{L} / P_{t}, B_{t}^{L, n} / P_{t}, Y_{t}, \Delta_{p, t}$ e $\mu_{t}$ satisfazendo as relações (3.1), (3.2), (3.3), (3.4), (3.5), (3.6), (3.7), (3.8), (3.9), (3.10), (3.11), (3.12), (3.13), (3.14), (3.15), (3.16) e (3.17) e pelos processos estocásticos $v_{t}$ e $s_{t}$. Para encontrar equilíbrio, é necessária mais uma restrição, que será $B_{t} / P_{t}=0$

O objetivo deste trabalho é estudar como a maturidade influencia na dinâmica da economia. A restrição, $B_{t} / P_{t}=0$, foi escolhida de forma a permitir os agentes suavizarem consumo apenas com os títulos de longo prazo, o que permite focar melhor a análise nos mecanismos de transmissão de choques dos títulos de longo prazo.

\subsubsection{Calibração e Simulação}

Em comparação com o modelo canônico do capítulo 2 - cujos parâmetros foram apresentados na tabela 1 - o único parâmetro adicionado ao modelo foi o parâmetro $\alpha$. Ele, além de governar a probabilidade dos títulos maturarem, controla também a maturidade 
média da dívida, sendo essa igual a $1 / \alpha$. A dívida brasileira possui uma maturidade média de 4,57 anos, segundo a Secretaria do Tesouro Nacional (STN) ${ }^{4}$. O valor de $\alpha$ foi então calibrado em 0,055. Os parâmetros utilizados estão apresentados na tabela 2

Tabela 2 - Calibração para o modelo com estrutura recursiva

\begin{tabular}{|c|c|c|c|}
\hline Simbolo & Valores & Descrição & Fonte \\
\hline \multicolumn{4}{|c|}{ Razões } \\
\hline$S_{g}$ & $22,20 \%$ & Razão Governo Produto & IBGE \\
\hline$S_{b}$ & $36,81 \%$ & Razão Dívida Produto & IBGE \\
\hline \multicolumn{4}{|c|}{ Parâmetros de Preferências e de Tecnologia } \\
\hline$\alpha$ & 0,055 & Probabilidade do título maturar & STN \\
\hline$\beta$ & 0,989 & Coeficiente de desconto intertemporal & Castro et al. (2015) \\
\hline$\sigma$ & 1,3 & Elasticidade de substituição intertemporal & Castro et al. (2015) \\
\hline$\varphi$ & 1 & Elasticidade da oferta de trabalho de Frisch & Castro et al. (2015) \\
\hline$\epsilon$ & 6 & Mark-up de $20 \%$ & Krause e Moyen (2016) \\
\hline \multicolumn{4}{|c|}{ Parâmetros de Rigidez } \\
\hline$\theta$ & 0,67 & Proporção de firmas reajustando preços & Krause e Moyen (2016) \\
\hline \multicolumn{4}{|c|}{ Parâmetros da Regra Fiscal, da Monetária e da Restrição Orçamentária do Governo } \\
\hline$\phi_{b}$ & 0,02 & Resposta da tributação a desvios da dívida & Castro et al. (2015) \\
\hline$\phi_{\pi}$ & 2,43 & Coeficiente de Taylor & Castro et al. (2015) \\
\hline$\rho_{T}$ & 0,8 & Coeficiente auto-regressivo da regra fiscal & Castro et al. (2015) \\
\hline$\rho_{R}$ & 0,79 & Coeficiente auto-regressivo da regra monetária & Castro et al. (2015) \\
\hline$g$ & 0,24 & Gastos do governo & IBGE \\
\hline \multicolumn{4}{|c|}{ Coeficientes dos Choques Exógenos } \\
\hline$\sigma_{v}$ & 0,32 & Desvio padrão do choque monetário $\left(v_{t}\right)$ & Castro et al. (2015) \\
\hline$\sigma_{s}$ & 1,73 & Desvio padrão do choque monetário $\left(s_{t}\right)$ & Castro et al. (2015) \\
\hline
\end{tabular}

Fonte: Elaboração própria.

A figura 3 apresenta as funções de resposta a impulso de algumas variáveis escolhidas após ocorrer um choque de um desvio padrão na taxa de juros básica da economia. O modelo com a calibração apresentada na tabela 2 está representado por uma linha contínua preta. O choque na taxa básica demora alguns períodos para se dissipar, principalmente devido ao coeficiente regressivo presente na equação (3.14). Já o impacto na taxa de juros de longo prazo e o na taxa dos juros dos títulos recém emitidos são nulos. Posteriormente, a relação entre juros de longo prazo e juros de curto prazo - taxa básica de juros, será

4 Dado calibrado de acordo com o valor da série de prazo médio do estoque do total da dívida pública federal em dezembro de 2015. 
explorada melhor. A dívida aumenta levemente e a tributação não é impactada.

Figura 3 - Função de resposta a impulso para o modelo com maturidade recursiva quando ocorre um choque na taxa de juros básica


Elaboração própria

A figura 4 apresenta as funções de resposta a impulso de mais algumas variáveis. Pode-se ver que um choque de um desvio padrão na taxa de juros possui o efeito contracionista no produto, no consumo, no salário real e na taxa de inflação. O modelo está de acordo com evidências empíricas e com a literatura.

Para fazer o exercício de comparação, também se calibrou o modelo com o dobro da maturidade, $\alpha=0,027$, e outro com metade da maturidade, $\alpha=0,109$. A figura 3 e a figura 4 também apresentam as funções de resposta a impulso para esses modelos, sendo o primeiro representado por uma linha tracejada cinza escuro e o segundo por uma linha pontilhada cinza claro. É claro como a maturidade da dívida não tem impacto neste 
Figura 4 - Função de resposta a impulso para o modelo com maturidade recursiva quando ocorre um choque na taxa de juros básica
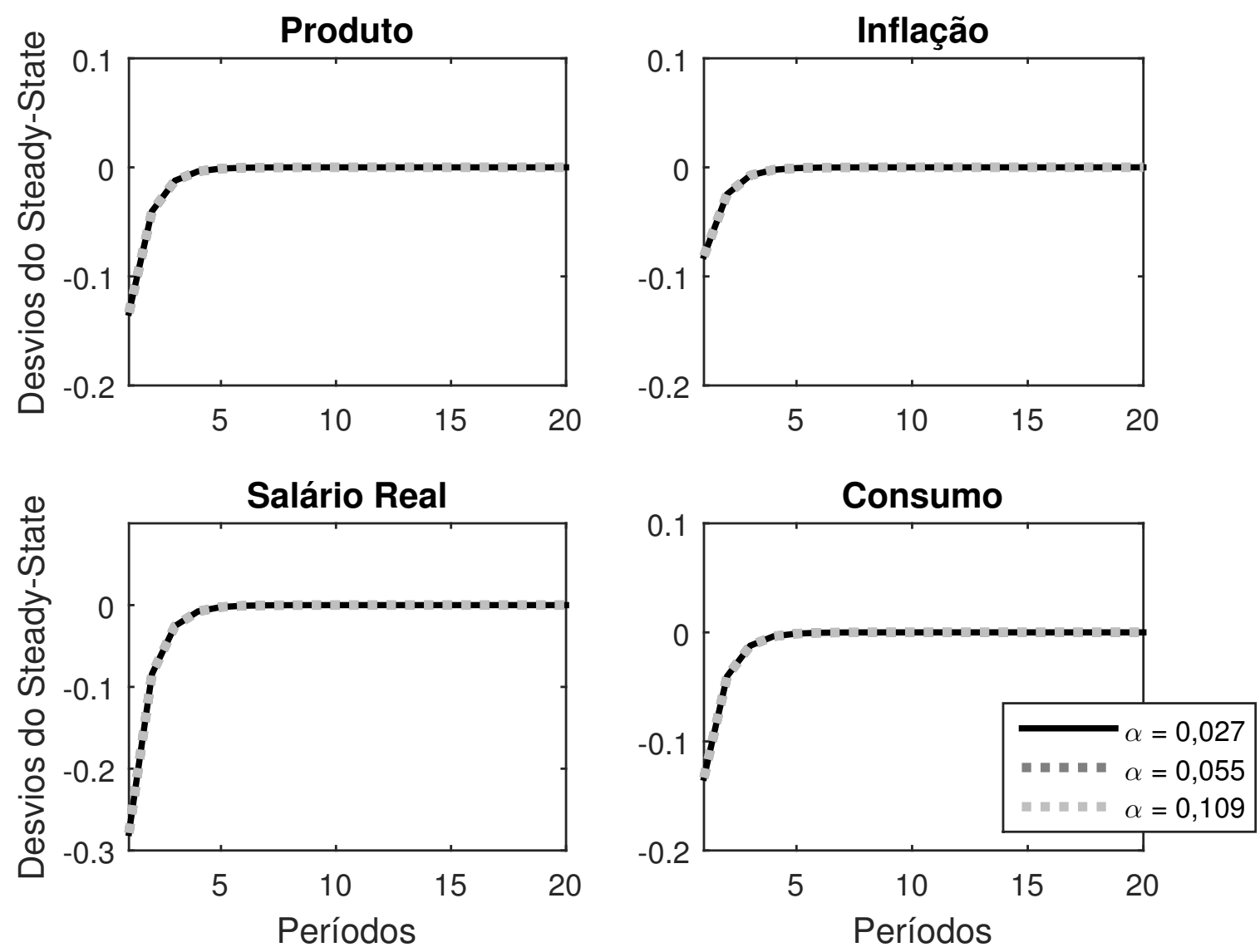

Elaboração própria

modelo.

As funções de resposta a impulso do modelo após a ocorrência do choque fiscal são apresentadas na figura 5. Após o choque, a tributação aumenta em um primeiro momento e depois volta lentamente ao nível de Steady-State. O aumento da tributação leva a uma diminuição dos estoques da dívida, tanto o estoque da dívida de longo prazo quanto o estoque da dívida recém emitida. A dívida possui o papel de amortecer choques na economia. O impacto do choque fiscal na taxa básica de juros, na taxa de juros de longo prazo, na taxa de juros de emissão, no produto e na inflação é nulo. Além disso, variações na maturidade da dívida não influenciam no modelo. 
Figura 5 - Função de resposta a impulso para o modelo com maturidade recursiva quando ocorre um choque fiscal
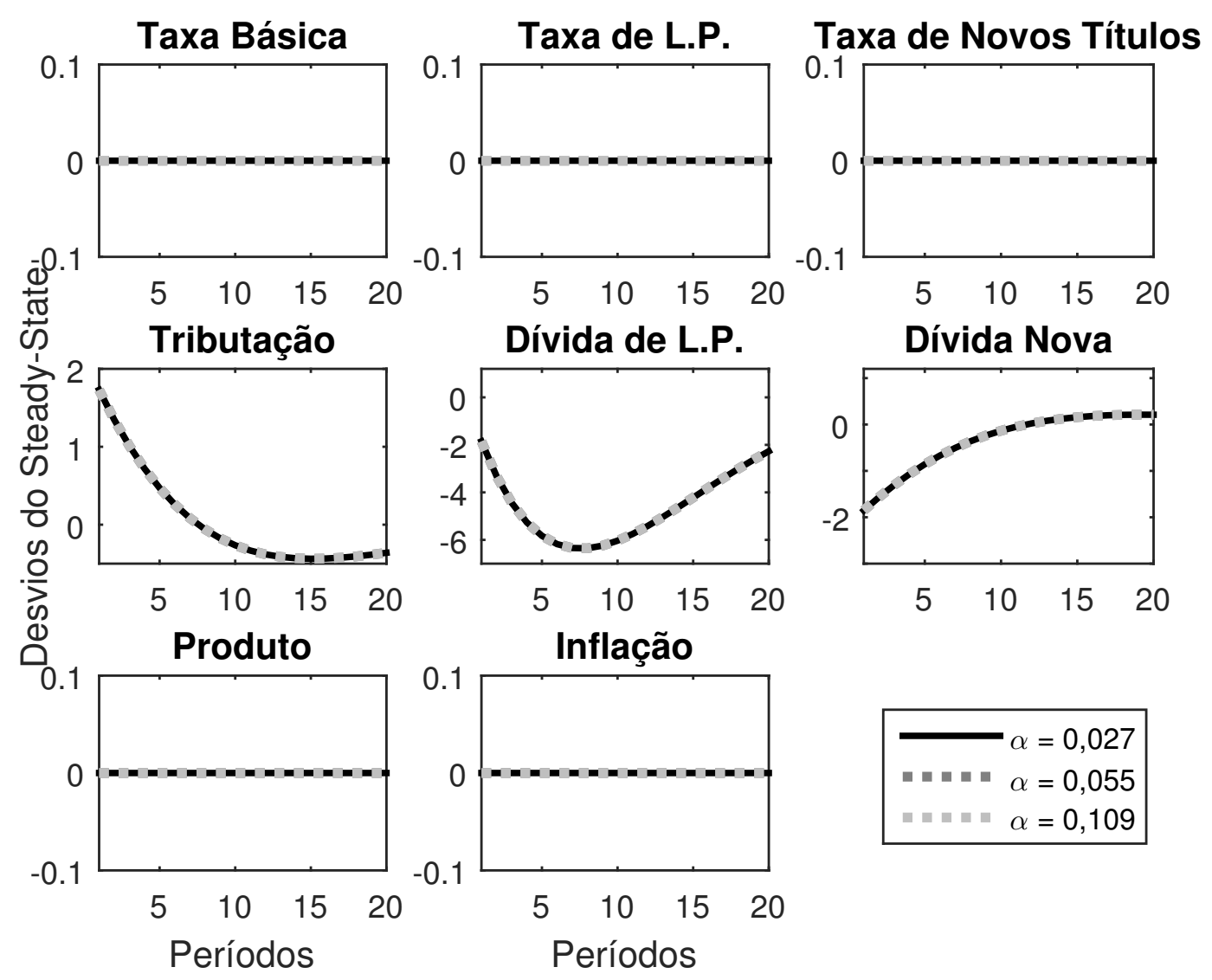

$$
\begin{array}{r}
\alpha=0,027 \\
\alpha=0,055 \\
\alpha=0,109
\end{array}
$$

Elaboração própria 


\subsubsection{Relação entre Taxas de Juros}

Para entender melhor como as taxas de juros estão conectadas no modelo, usou-se as equações (3.4) e (3.6) log linearizadas. Simplificando as equações e substituindo uma na outra, encontra-se a relação $i_{t}^{L, n}=\alpha^{n} i_{t}+\left(1-\alpha^{n}\right) i_{t+1}^{L, n}$. Essa relação pode ser resolvida iterando para frente.

$$
i_{t}^{L, n}=\alpha^{n} \sum_{s=0}^{\infty}\left(1-\alpha^{n}\right)^{s} E_{t} i_{t+s}
$$

sendo $\alpha^{n} \equiv \alpha+\bar{i} /(1+\bar{i})$. A relação mostra que a taxa de juros de longo prazo de emissão é uma soma ponderada das taxas de juros esperadas de curto prazo, com peso declinando a uma taxa de $\left(1-\alpha^{n}\right)^{s}$.

Também é conveniente entender como a taxa média de longo prazo responde à taxa de juros de longo prazo de emissão. Como o modelo possui uma estrutura recursiva, a taxa de juros média de longo prazo é uma média ponderada das taxas de emissão passadas. Essa relação é clara log linearizando as equações (3.1) e (3.2). Simplificando-as e substituindo uma na outra, encontra-se a relação $i_{t}^{L}=(1-\alpha) i_{t-1}^{L}+\alpha E_{t} i_{t}^{L, n}$. Escrevendo recursivamente a equação:

$$
i_{t}^{L}=\alpha \sum_{s=0}^{\infty}(1-\alpha)^{s} i_{t-s}^{L, n}
$$

ou seja, a taxa de juros média de longo prazo é uma média ponderada das taxas de emissão de longo prazo passadas, com ponderação $(1-\alpha)^{s}$ decrescendo em $s$. Por essa equação fica claro porque a taxa de juros média de longo prazo não responde ao choque na figura 3.

\subsection{Modificação do Modelo}

Pastore (1996) é o primeiro autor a argumentar que um título pós-fixado tem impacto negativo na eficácia da política monetária - a existência de um título pós-fixado obstruiria o canal riqueza de transmissão da política monetária. A literatura nacional discutindo o tema é grande, mas não se sabe de nenhum trabalho que o analisa usando um modelo DSGE. Esta seção procura contribuir com a literatura nacional introduzindo 
títulos pós-fixados no modelo de Krause e Moyen (2016). A estrutura recursiva da dívida pública será modificada para permitir dois títulos de longo prazo, ambos maturando com a mesma probabilidade $\alpha$. O estoque de títulos de longo prazo, $B_{t}^{L}$, é composto por títulos pós-fixados, $B_{t}^{P O S}$, e pré-fixados, $B_{t}^{P R E}$ :

$$
\begin{gathered}
B_{t}^{L}=B_{t}^{P O S}+B_{t}^{P R E} \\
B_{t}^{L, n}=B_{t}^{P O S, n}+B_{t}^{P R E, n}
\end{gathered}
$$

Os novos títulos modificam a equação que determina a taxa de juros média de longo prazo, equação (3.2). Partindo da mesma definição de taxa média de longo prazo como uma média ponderada:

$$
i_{t}^{L}=\frac{B_{t}^{L, n}}{B_{t}^{L}} i_{t}^{L, n}+(1-\alpha) \frac{B_{t-1}^{L, n}}{B_{t}^{L}} i_{t-1}^{L, n}+(1-\alpha)^{2} \frac{B_{t-2}^{L, n}}{B_{t}^{L}} i_{t-2}^{L, n}+\ldots
$$

Pode-se separar os títulos de longo prazo em títulos pós-fixados e em títulos pré-fixados usando a definição de composição dos estoques, equações (3.18) e (3.19):

$$
\begin{aligned}
i_{t}^{L}=\frac{B_{t}^{P O S, n}}{B_{t}^{L}} i_{t}+\frac{B_{t}^{P R E, n}}{B_{t}^{L}} i_{t}^{P R E, n}+(1-\alpha)\left[\frac{B_{t-1}^{P O S, n}}{B_{t}^{L}} i_{t}+\frac{B_{t-1}^{P R E, n}}{B_{t}^{L}} i_{t-1}^{P R E, n}\right]+ \\
(1-\alpha)^{2}\left[\frac{B_{t-2}^{P O S, n}}{B_{t}^{L}} i_{t}+\frac{B_{t-2}^{P R E, n}}{B_{t}^{L}} i_{t-2}^{P R E, n}\right]+\ldots
\end{aligned}
$$

Observe que, ao separar os títulos pré-fixados e pós-fixados, deve-se também modificar a taxa de juros incidente em cada um dos tipos. Os títulos pós fixados, $B_{t-i}^{P O S, n} \forall i \in$ $\mathbb{N}$, são remunerados pela taxa de juros básica do período atual, $i_{t}$, e os títulos pré-fixados, $B_{t-i}^{P R E, n} \forall i \in \mathbb{N}$, são remunerados pela taxa de emissão do período da emissão, $i_{t-i}^{P R E, n}$. O peso da taxa de juros de um título previamente emitido na taxa de juros média de longo prazo depende da fração desses títulos que ainda resta no estoque total de títulos de longo prazo. Essa equação também pode ser escrita de uma forma recursiva:

$$
\begin{aligned}
i_{t}^{L}=\frac{B_{t}^{P O S}}{B_{t}^{L}} i_{t}+\frac{B_{t}^{P R E}}{B_{t}^{L}} i_{t}^{P R E, n}+(1-\alpha) \frac{B_{t-1}^{P O S}}{B_{t}^{L}}\left(i_{t-1}^{L}-i_{t-1}\right)+ & \\
& (1-\alpha) \frac{B_{t-1}^{P R E}}{B_{t}^{L}}\left(i_{t-1}^{L}-i_{t}^{P R E, n}\right)
\end{aligned}
$$


Intuitivamente, a taxa de juros de longo prazo é igual à soma das remunerações dos títulos pós-fixados e dos pré-fixados, ambas ponderadas pela participação relativa na dívida, mais o diferencial no período anterior entre os juros de longo prazo e a taxa de juros básica da economia e mais o diferencial entre os juros de longo prazo no período anterior e a taxa de juros atual de emissão de títulos pré-fixados. Ambos diferenciais são ponderados pela participação relativa na dívida ${ }^{5}$. A definição da taxa de juros média da seção anterior, equação (3.2), não é recuperável da nova equação que define a taxa de juros média, equação (3.20).

Os dois novos títulos também possuem equações de movimento do estoque:

$$
\begin{aligned}
& B_{t}^{P O S}=(1-\alpha) B_{t-1}^{P O S}+B_{t}^{P O S, n} \\
& B_{t}^{P R E}=(1-\alpha) B_{t-1}^{P R E}+B_{t}^{P R E, n}
\end{aligned}
$$

\subsubsection{Consumidor}

O problema do consumidor é maximizar sua utilidade sujeito à restrição orçamentária, à equação de movimento do estoque de títulos, (3.1), à equação que determina a taxa média de juros dos títulos de longo prazo, (3.20), às equações de composição dos estoques dos títulos de longo prazo, (3.18) e (3.19), e às equações de movimentos dos títulos pós e pré fixados, (3.21) e (3.22):

$$
\max E_{0} \sum_{t=0}^{\infty} \beta^{t}\left(\frac{C_{t}^{1-\sigma}}{1-\sigma}-\frac{N_{t}^{1+\varphi}}{1+\varphi}\right)
$$

5 Quando, a dívida é exclusivamente composta por títulos pré fixados, $B^{P O S}=0$, a equação (3.20) pode ser simplificada e é igual, como seria de se esperar, à equação (3.2). Quando a dívida é puramente pós-fixada, $B^{P R E}=0$, encontra-se a equação:

$$
\left(i_{t}^{L}-i_{t}\right) B_{t}^{L}=(1-\alpha)\left(i_{t-1}^{L}-i_{t-1}\right) B_{t-1}^{L}
$$

Para analisar a equação acima, suponha que $\left(i_{t}^{L}-i_{t}\right)$ seja constante. . Como todos os títulos de longo prazo são pós fixados, não é uma hipótese irrealista. A equação acima ficará igual a $B_{t}^{L}=(1-\alpha) B_{t-1}^{L}$. Como $0<(1-\alpha)<1$, tem-se, recursivamente, que $B_{t}^{L}=1 / \alpha B_{0}^{L}$. 
sujeitos a

$$
\begin{aligned}
& \frac{B_{t}}{P_{t}}+\frac{B_{t}^{L, n}}{P_{t}}+C_{t}=\left(1+i_{t-1}\right) \frac{B_{t-1}}{P_{t}}+\left(\alpha+i_{t-1}^{l}\right) \frac{B_{t-1}^{L}}{P_{t}}+\frac{W_{t}}{P_{t}} N_{t}+Z_{t}+T_{t} \\
& B_{t}^{L}=(1-\alpha) B_{t-1}^{L}+B_{t}^{L, n} \\
& i_{t}^{L}=\frac{B_{t}^{P O S}}{B_{t}^{L}} i_{t}+\frac{B_{t}^{P R E}}{B_{t}^{L}} i_{t}^{P R E, n}+(1-\alpha) \frac{B_{t-1}^{P O S}}{B_{t}^{L}}\left(i_{t-1}^{L}-i_{t-1}\right)+(1-\alpha) \frac{B_{t-1}^{P R E}}{B_{t}^{L}}\left(i_{t-1}^{L}-i_{t}^{P R E, n}\right) \\
& B_{t}^{L}=B_{t}^{P O S}+B_{t}^{P R E} \\
& B_{t}^{L, n}=B_{t}^{P O S, n}+B_{t}^{P R E, n} \\
& B_{t}^{P O S}=(1-\alpha) B_{t-1}^{P O S}+B_{t}^{P O S, n} \\
& B_{t}^{P R E}=(1-\alpha) B_{t-1}^{P R E}+B_{t}^{P R E, n}
\end{aligned}
$$

A forma mais fácil de resolver o problema é substituir as equações de composição, (3.18) e (3.19), em todas as outras restrições. Em seguida, substitui-se as equações de movimentos dos títulos pós e pré fixados, (3.21) e (3.22), nas restrições restantes. O problema do consumidor passa a ser maximizar:

$$
\max E_{0} \sum_{t=0}^{\infty} \beta^{t}\left(\frac{C_{t}^{1-\sigma}}{1-\sigma}-\frac{N_{t}^{1+\varphi}}{1+\varphi}\right)
$$

sujeito à restrição orçamentária modificada

$$
\begin{aligned}
& C_{t}+\frac{B_{t}}{P_{t}}+\frac{\left(B_{t}^{P O S}-(1-\alpha) B_{t-1}^{P O S}\right)+\left(B_{t}^{P R E}-(1-\alpha) B_{t-1}^{P R E}\right)}{P_{t}} \\
& =\left(1+i_{t-1}\right) \frac{B_{t-1}}{P_{t}}+\left(\alpha+i_{t-1}^{L}\right) \frac{B_{t-1}^{P R E}}{P_{t}}+\left(\alpha+i_{t-1}^{L}\right) \frac{B_{t-1}^{P O S}}{P_{t}}+\frac{W_{t}}{P_{t}} N_{t}+Z_{t}+T_{t}
\end{aligned}
$$

e à equação da taxa média de juros do estoque de dívida de longo prazo:

$$
\begin{aligned}
\left(i_{t}^{L}-i_{t}\right) B_{t}^{P O S}+\left(i_{t}^{L}-i_{t}^{P R E, n}\right) B_{t}^{P R E}= & (1-\alpha)\left(i_{t-1}^{L}-i_{t-1}\right) B_{t-1}^{P O S} \\
& +(1-\alpha)\left(i_{t-1}^{L}-i_{t}^{P R E, n}\right) B_{t-1}^{P R E}
\end{aligned}
$$

O primeiro resultado interessante do modelo ${ }^{6}$ fica evidente olhando as condições de ótimo resultantes do processo de otimização. A equação de Euler para o título pós-fixado possui uma Euler igual ao título de um período - equação (3.4), ou seja, comportam-se como o título de menor prazo possível. Já o título pré-fixado comporta-se igual ao título pré-fixado do modelo de Krause e Moyen (2016) - equações (3.5) e (3.6). As equações 
encontradas foram:

$$
\begin{gathered}
1=\beta E_{t}\left\{\left(\frac{C_{t}}{C_{t+1}}\right)^{-\sigma} \frac{P_{t}}{P_{t+1}}\left[1+i_{t}\right]\right\} \\
1=\beta E_{t}\left\{\left(\frac{C_{t}}{C_{t+1}}\right)^{-\sigma} \frac{P_{t}}{P_{t+1}}\left[1+i_{t}^{L, n}-\mu_{t+1}(1-\alpha) \Delta i_{t+1}^{P R E, n}\right]\right\} \\
\mu_{t}=\beta E_{t}\left\{\left(\frac{C_{t}}{C_{t+1}}\right)^{-\sigma} \frac{P_{t}}{P_{t+1}}\left[1+(1-\alpha) \mu_{t+1}\right]\right\}
\end{gathered}
$$

\subsubsection{Resto do Modelo e Equilíbrio}

O restante do modelo é igual ao modelo canônico, apresentado no capítulo 2, e ao restante do modelo da seção 3.1. O sistema de equações formadas pelas equações (3.1), (3.18), (3.19), (3.20), (3.21) e (3.22) são linearmente dependentes, o que impossibilita a resolução do modelo. Como forma de resolver o problema, as novas equações de movimento não foram adicionadas - pois são redundantes - e a quantidade de um dos novos títulos foi fixada, de forma que $B_{t}^{i} / P_{t}=\bar{B}^{i} / P, \forall i \in[P R E, P O S]$.

O equilíbrio do modelo é determinado pelos processos estacionários $i_{t}, i_{t}^{L}, i_{t}^{P R E, n}$, $C_{t}, \pi_{t}, W_{t} / P_{t}, N_{t}, P_{t}^{*} / P_{t}, Z_{1, t}, Z_{2, t}, m c_{t}, T_{t}, B_{t} / P_{t}, B_{t}^{L} / P_{t}, Y_{t}, \Delta_{p, t}, \mu_{t}, B_{t}^{P O S}, B_{t}^{P R E}, B_{t}^{P O S, n} \mathrm{e}$ $B_{t}^{P R E, n}$ satisfazendo as relações (3.1), (3.3), (3.4), (3.5), (3.6), (3.7), (3.8), (3.9), (3.10), (3.11), (3.12), (3.13), (3.14), (3.15), (3.16), (3.17), (3.18), (3.19) e (3.20) e pelos processos estocásticos $v_{t}$ e $s_{t}$. Para encontrar equilíbrio, são necessárias mais três restrições, que serão $B_{t} / P_{t}=0, B_{t}^{i} / P_{t}=\bar{B}^{i} / P, \forall i \in[P R E, P O S]$ e $B_{t}^{i, n} / P_{t}=B^{i, n} / P, \forall i \in[P R E, P O S]$. Dado que a última restrição permite duas calibrações, $i=P R E$ ou $i=P O S$, serão feitas duas simulações.

Assim como na seção 3.1.4, usou-se a restrição $B_{t} / P_{t}=0$, já que essa permite uma maior focalização da análise nos mecanismos de transmissão de choques dos títulos de longo prazo. Já a restrição de fixar um dos títulos de longo prazo, o título pré-fixado ou o título pós fixado, também é escolhida por permitir entender melhor os mecanismos do modelo. Espera-se que o ajuste feito exclusivamente pelos títulos pós fixados seja diferente do ajuste feito exclusivamente pelos títulos pré fixados. 


\subsubsection{Calibrações}

Para calibrar a quantidade de título pós-fixado, usou-se o percentual da Dívida Pública Mobiliária Federal interna que possui rentabilidade vinculada à taxa SELIC. O dado foi coletado no site da Secretaria do Tesouro Nacional. Em dezembro de 2015, o percentual estava em $24,01 \%$.

Com o intuito de comparar as duas possíveis calibrações da modificação proposta ao modelo com o modelo estilizado de Krause e Moyen (2016), as funções de resposta a impulso dos três foram apresentadas simultaneamente. Nas figuras 6, 7, 8, 9 e 10 a calibração com o valor da dívida pós fixada constante, $B_{t}^{P O S} / P_{t}=B^{P \overline{S S}} / P$ e $B_{t}^{P O S, n} / P_{t}=B^{P O \bar{S}, n} / P$, é representada pela linha contínua preta, a calibração com o valor da dívida pré fixada constante, $B_{t}^{P R E} / P_{t}=B^{\bar{P} R E} / P$ e $B_{t}^{P R E, n} / P_{t}=B^{P \bar{R} E, n} / P$, é representada pela linha tracejada cinza escuro e as funções de resposta a impulso do modelo sem modificação é representada por linhas pontilhadas cinza claro.

Na figura 6, são apresentadas as funções de resposta a impulso para a taxa básica de juros, para a taxa de juros média de longo prazo, para a taxa de juros de emissão de novos títulos, para a alíquota de tributação, para o estoque de dívida de longo prazo e para o estoque de dívida recém emitida. A forma de calibrar o modelo modificado não impacta nas funções de resposta a impulso, resultado que se mantém para todas as outras variáveis analisadas. Somente a taxa de juros média de longo prazo apresenta comportamento diferente, sendo que essa passou a responder ao choque monetário. 
Figura 6 - Funções de resposta a impulso para o modelo modificado quando ocorre um choque na taxa de juros básica
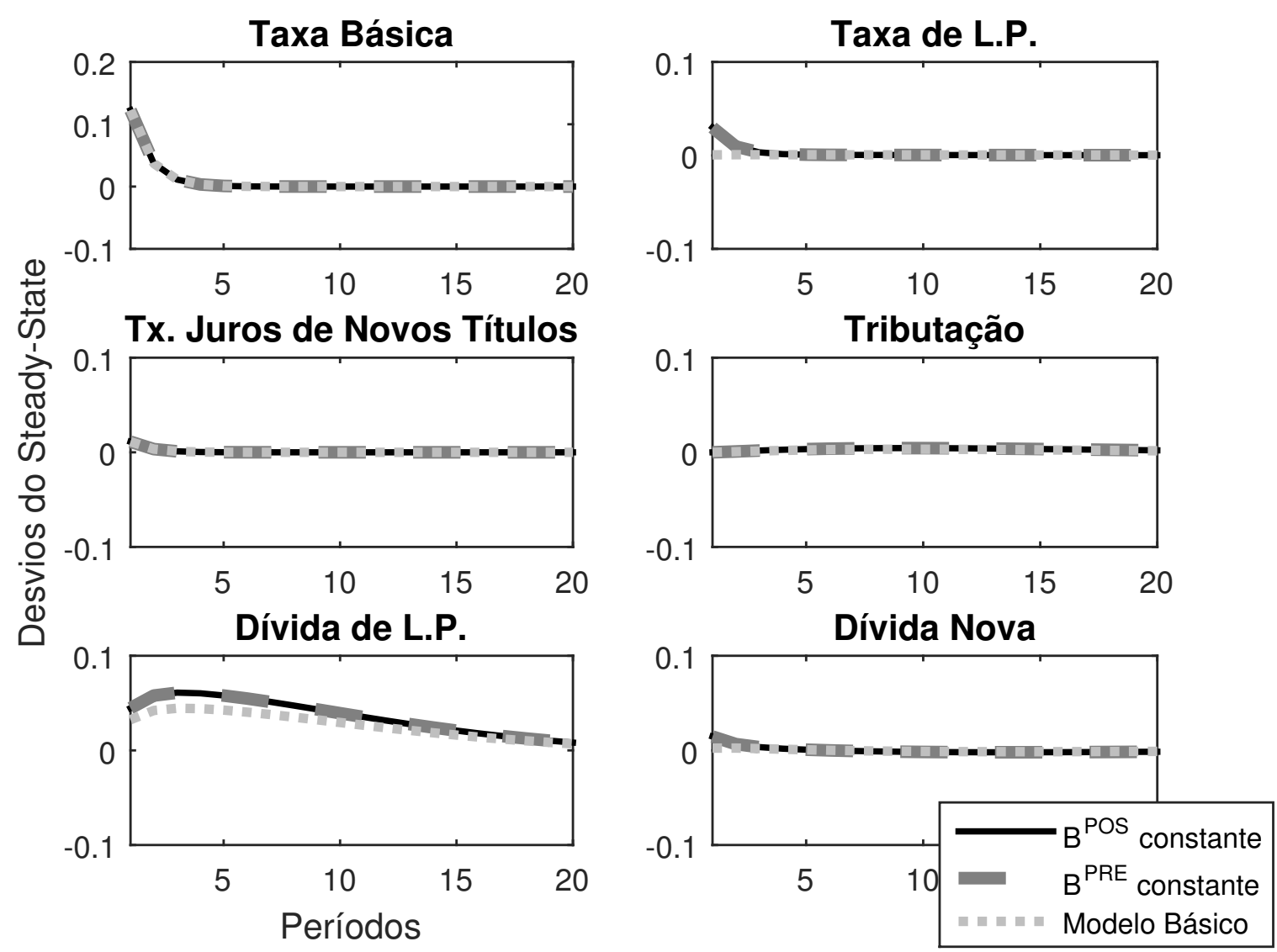

Elaboração própria

Na figura 7, são apresentadas as funções de resposta a impulso para o produto, a inflação, a taxa de salário real e o consumo. Para essas variáveis, a forma de calibrar o modelo modificado não impacta nas funções de resposta a impulso, sendo essas idênticas ao modelo sem modificação. 
Figura 7 - Funções de resposta a impulso para o modelo modificado quando ocorre um choque na taxa de juros básica
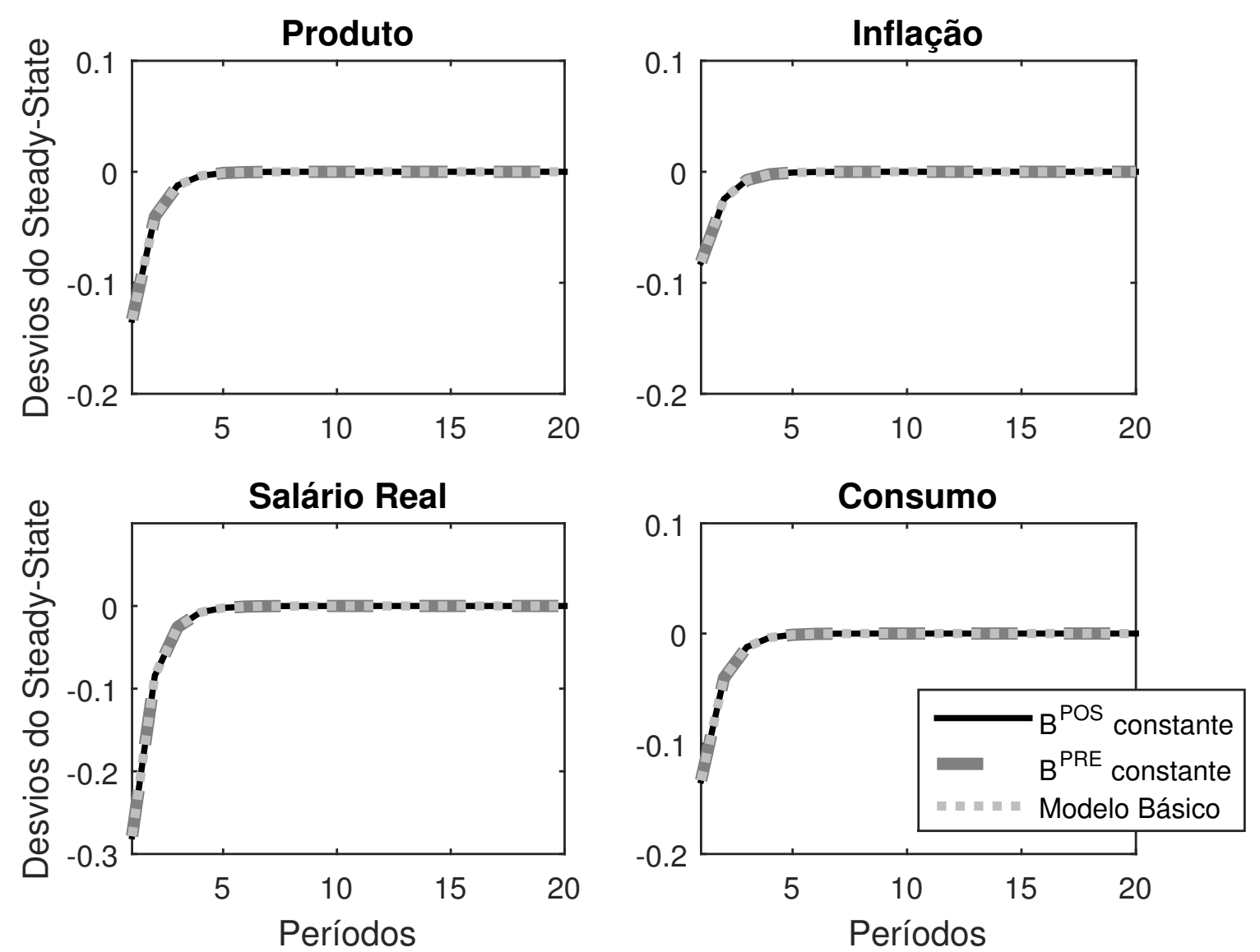

Elaboração própria

Na figura 8, são apresentadas as funções de resposta a impulso para o estoque de dívida pré-fixada e para a dívida pré-fixada recém emitida quando a dívida pós fixada é constante, representadas pela linha contínua preta, e as funções de resposta a impulso para o estoque de dívida pós fixada e para a dívida pós fixada recém emitida quando a dívida pré fixada é constante, representadas pela linha tracejada cinza escuro. É claro que não há diferença de dinâmica entre os dois modelos. 
Figura 8 - Funções de resposta a impulso para duas calibrações do modelo modificado quando ocorre um choque na taxa de juros básica

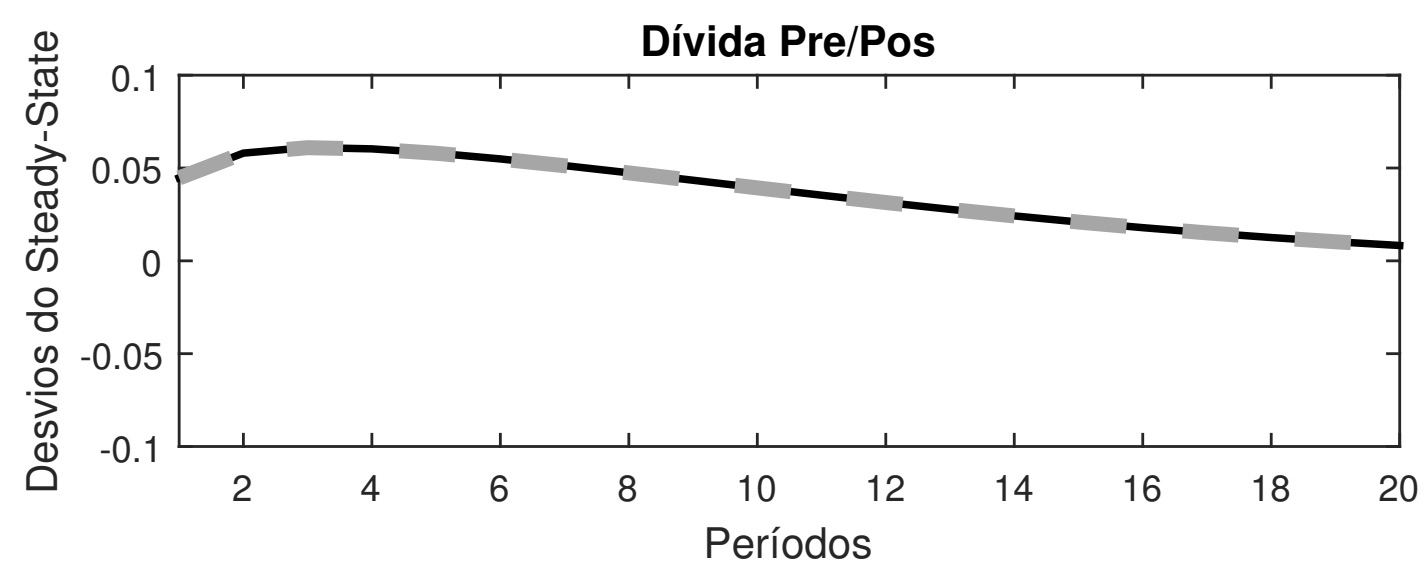

Dívida Pre/Pos Nova

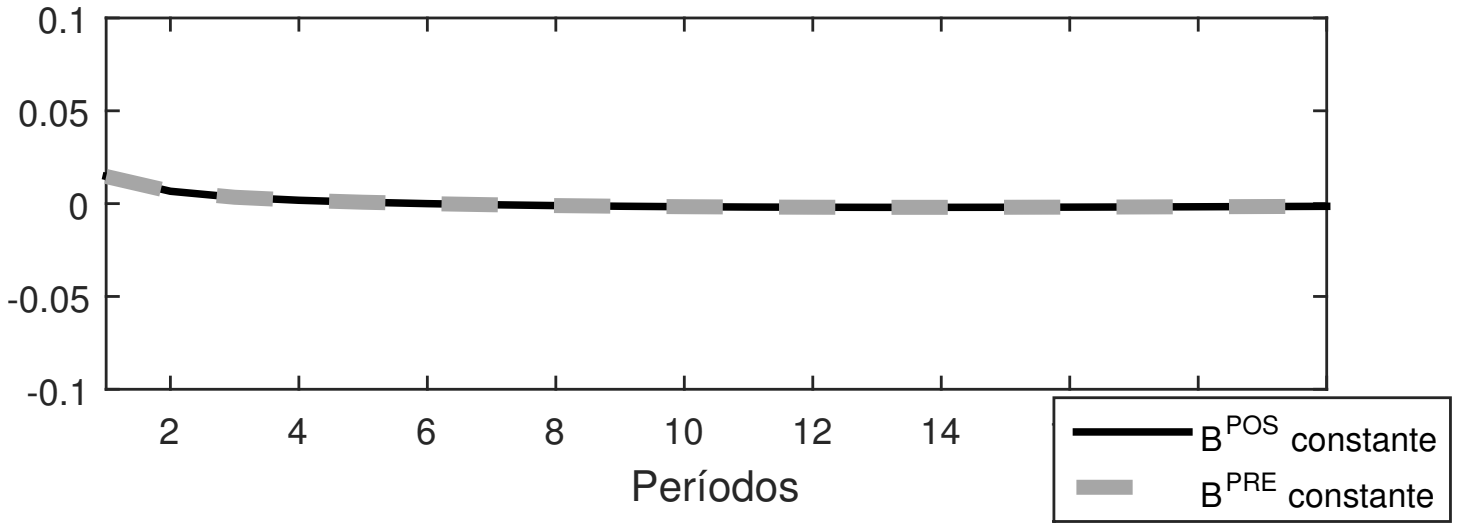

Elaboração própria

Outras proporções de dívida foram testadas em diferentes calibrações, mas nenhuma apresentou resultado diferente do acima apresentado. A estrutura modificada de títulos públicos não impacta na dinâmica do modelo. Mudanças na maturidade também não impactam na dinâmica da economia e os gráficos apresentando as funções de resposta a impulso foram omitidos.

As funções de resposta a impulso para o modelo modificado após a ocorrência de um choque fiscal estão na figura 9. As funções de resposta a impulso do modelo sem modificação também são apresentadas para exercício de comparação. A tributação aumenta na mesma magnitude do choque fiscal o que leva a uma diminuição do estoque de dívida de longo prazo e de dívida recém emitida. Na medida em que a tributação vai diminuindo, a 
Figura 9 - Funções de resposta a impulso para o modelo modificado quando ocorre um choque fiscal
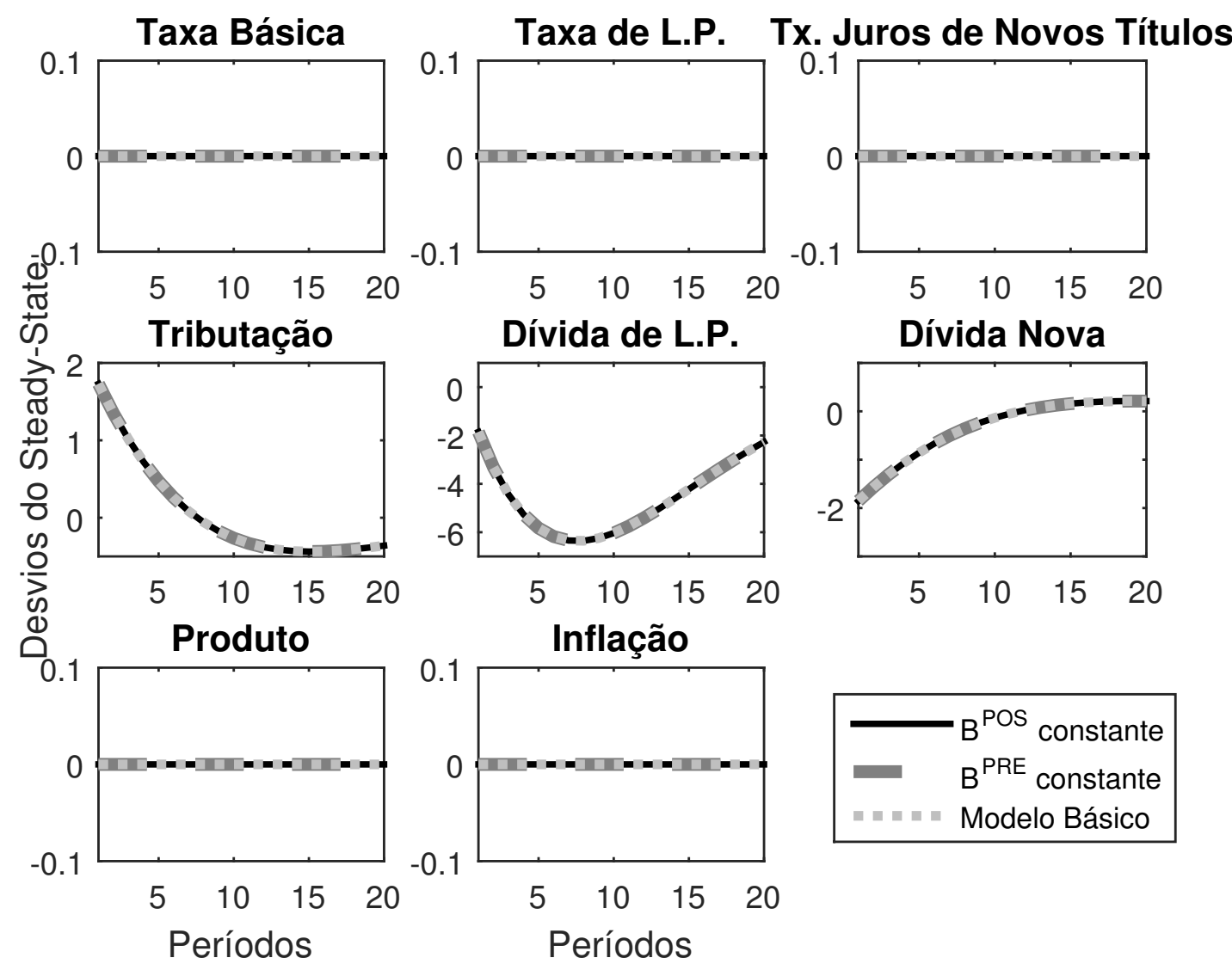

Elaboração própria 
dívida vai aumentando e ambas retornam ao valor de Steady-State. Assim como na figura 5, vemos que o papel da dívida pública no modelo é amortecer choques. O impacto na taxa básica de juros, na taxa de juros de longo prazo, na taxa de juros de emissão, no produto e na inflação é nulo. O efeito na dinâmica do modelo da adição do título pós-fixado também é nulo.

Na figura 10, apresentam-se funções de resposta a impulso para as duas calibrações possíveis do modelo modificado. Observa-se que o comportamento do estoque de dívida pós-fixada quando a dívida pré-fixada é constante é igual ao comportamento do estoque de dívida pré-fixada quando a dívida pós-fixada é constante. As figuras 9 e 10 deixam claro como a estrutura modificada de títulos públicos não impacta na dinâmica do modelo.

Figura 10 - Funções de resposta a impulso para duas calibrações do modelo modificado quando ocorre um choque fiscal



Dívida Pre/Pos Nova

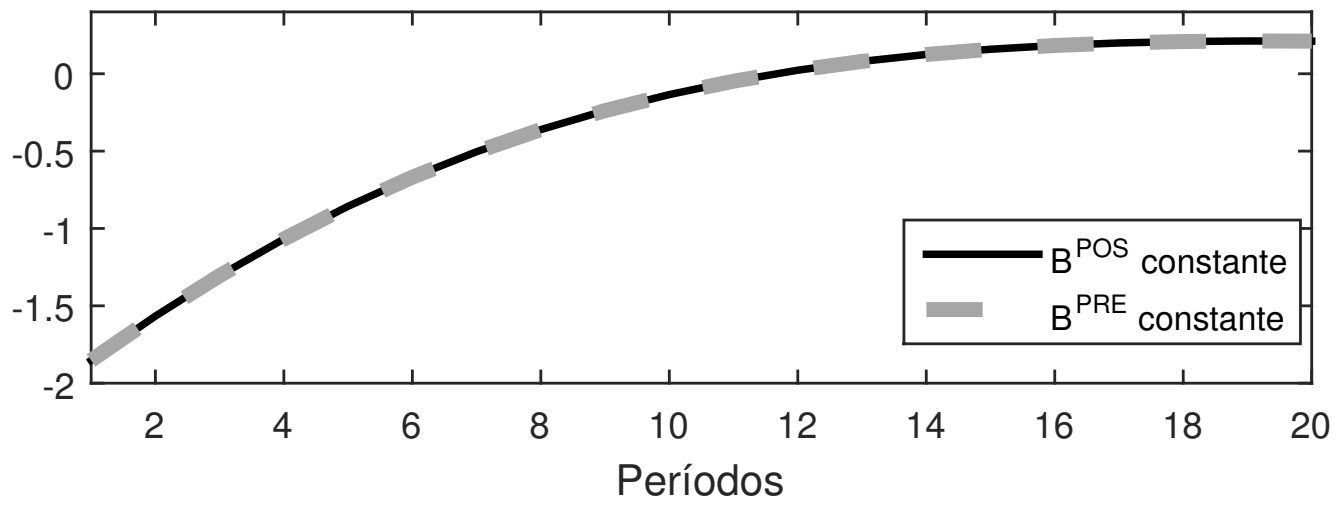

Elaboração própria 


\subsection{Imposto Distorcivo}

Uma maneira de tornar o tamanho do governo mais relevante é adicionando tributação distorciva (BARRO, 1999). Diferentes estruturas de maturidade implicam em diferentes necessidades de financiamento do governo quando ocorre variações na taxa de juros. Uma estrutura que demande maior financiamento, quando há tributação distorciva no mercado de trabalho, possivelmente levará a uma dinâmica diferente no modelo.

A adição de um imposto distorcivo, $\tau_{t}$, altera algumas equações do modelo, mais especificamente a equação (3.3) passa a ser:

$$
N_{t}^{\varphi} C_{t}^{\sigma}=\left(1-\tau_{t}\right) \frac{W_{t}}{P_{t}}
$$

a equação (3.12):

$$
\tau_{t}-\bar{\tau}=\rho_{\tau}\left(\tau_{t-1}-\bar{\tau}\right)+\phi_{b}\left(\hat{b_{t}^{L}}+\hat{b_{t}}\right)
$$

e a equação (3.13):

$$
\tau_{t} \frac{W_{t}}{P_{t}} N_{t}+\frac{B_{t}}{P_{t}}+\frac{B_{t}^{L, n}}{P_{t}}=g+\left(1+i_{t-1}\right) \frac{B_{t-1}}{P_{t}}+\left(\alpha+i_{t-1}^{L}\right) \frac{B_{t-1}^{L}}{P_{t}}
$$

A figura 11 e a figura 12 apesentam comparações entre as funções de resposta a impulso quando ocorre um choque na taxa básica de juros do modelo apresentado na seção 3.1 deste capítulo, linha contínua preta, com as funções de resposta a impulso para o mesmo modelo, mas com tributação distorciva no mercado de trabalho, linha tracejada cinza. Na figura 11, a diferença mais marcante entre os modelos acontece no comportamento da dívida de longo prazo, que é muito mais acentuado no modelo com tributação distorciva. O movimento da tributação é pequeno em ambos os modelos. Na figura 12, o comportamento das variáveis é bem semelhante nos dois modelos. 
Figura 11 - Comparação entre funções de resposta a impulso do modelo com maturidade recursiva sem e com tributação distorciva quando ocorre um choque na taxa básica de juros


Elaboração própria 
Figura 12 - Comparação entre funções de resposta a impulso do modelo com maturidade recursiva sem e com tributação distorciva quando ocorre um choque na taxa básica de juros
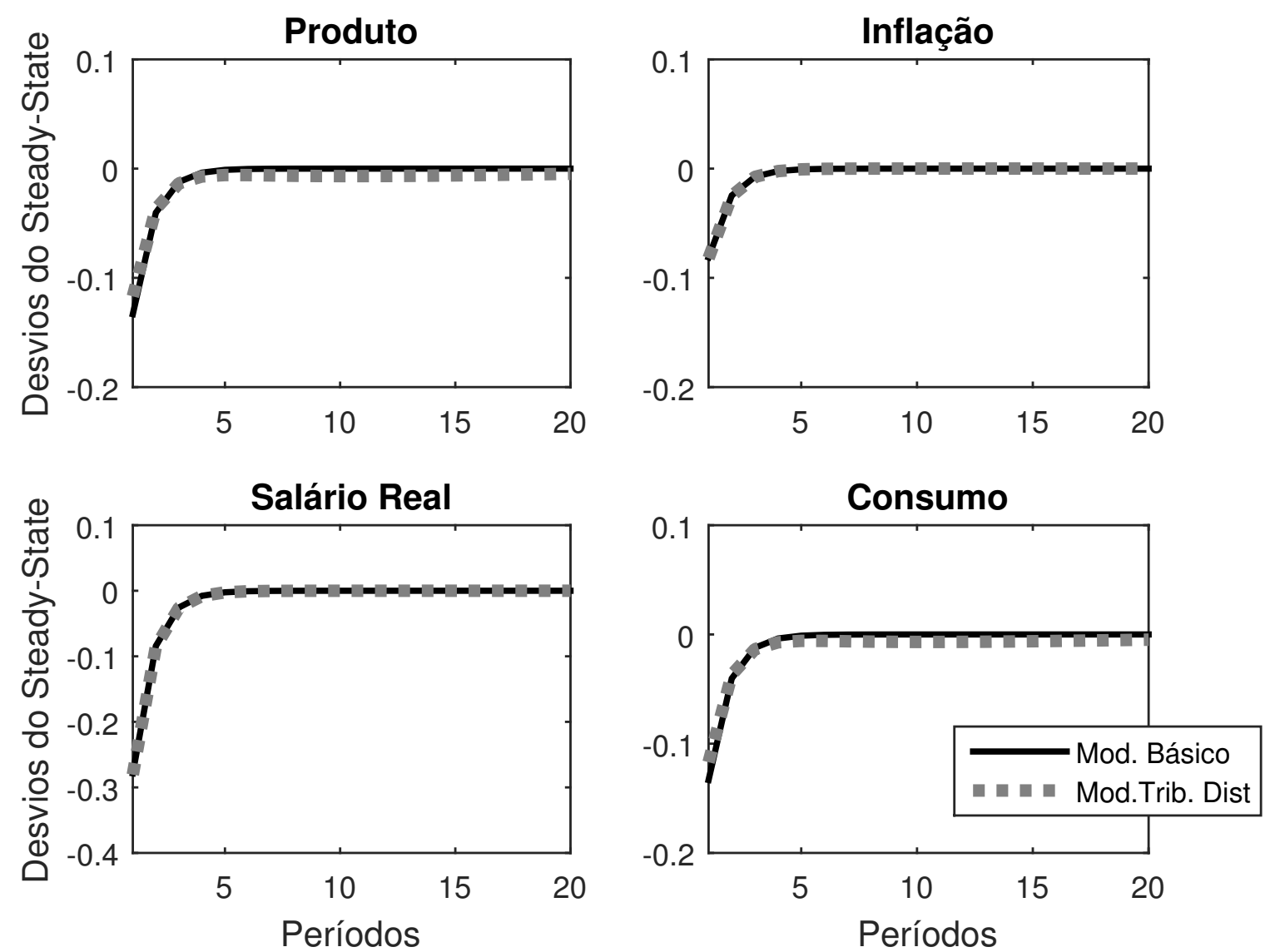

Elaboração própria

A figura 13 apresenta as funções de resposta a impulso para duas versões do modelo com maturidade recursiva, uma sem tributação distorciva e outra com, após a ocorrência do choque fiscal. A tributação aumenta em um primeiro momento e vai lentamente retornando ao valor de Steady-State. Tanto a dívida de longo prazo, quanto a dívida recém emitida, diminuem em um primeiro momento e depois retornam ao nível de Steady-State. Vale atentar que, no modelo básico, é a dívida que absorve toda a nova tributação diminuindo o estoque. No modelo com tributação distorciva, o impacto do aumento da tributação na dívida é menor. Isso porque a tributação distorciva diminui o produto e aumenta a inflação, levando a uma resposta da taxa básica de juros. 

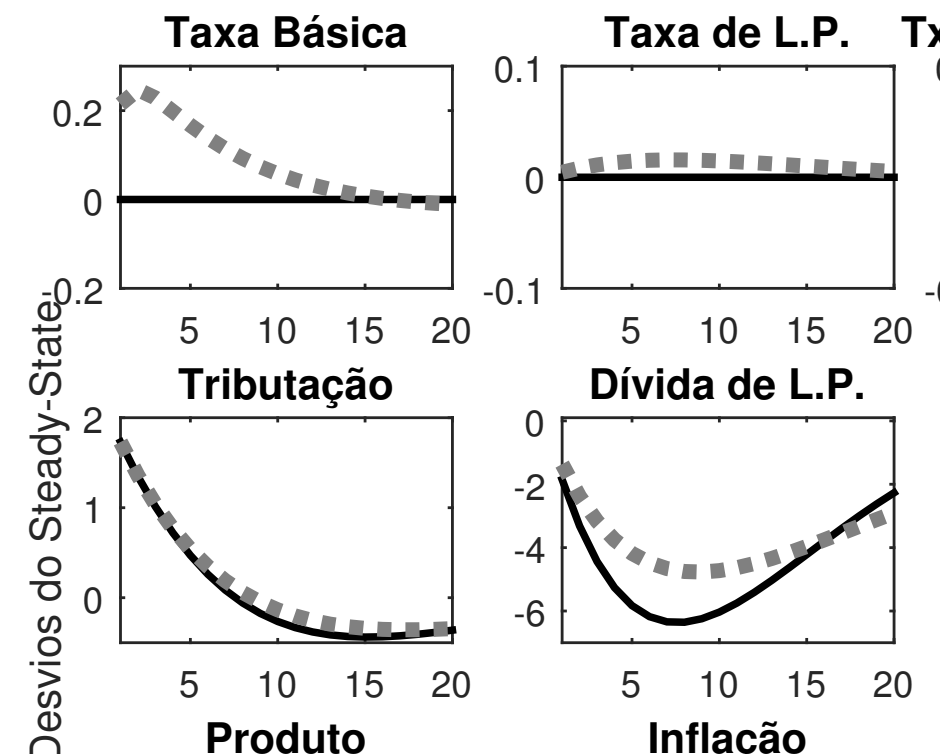

\section{Tx. Juros de Novos Títulos}
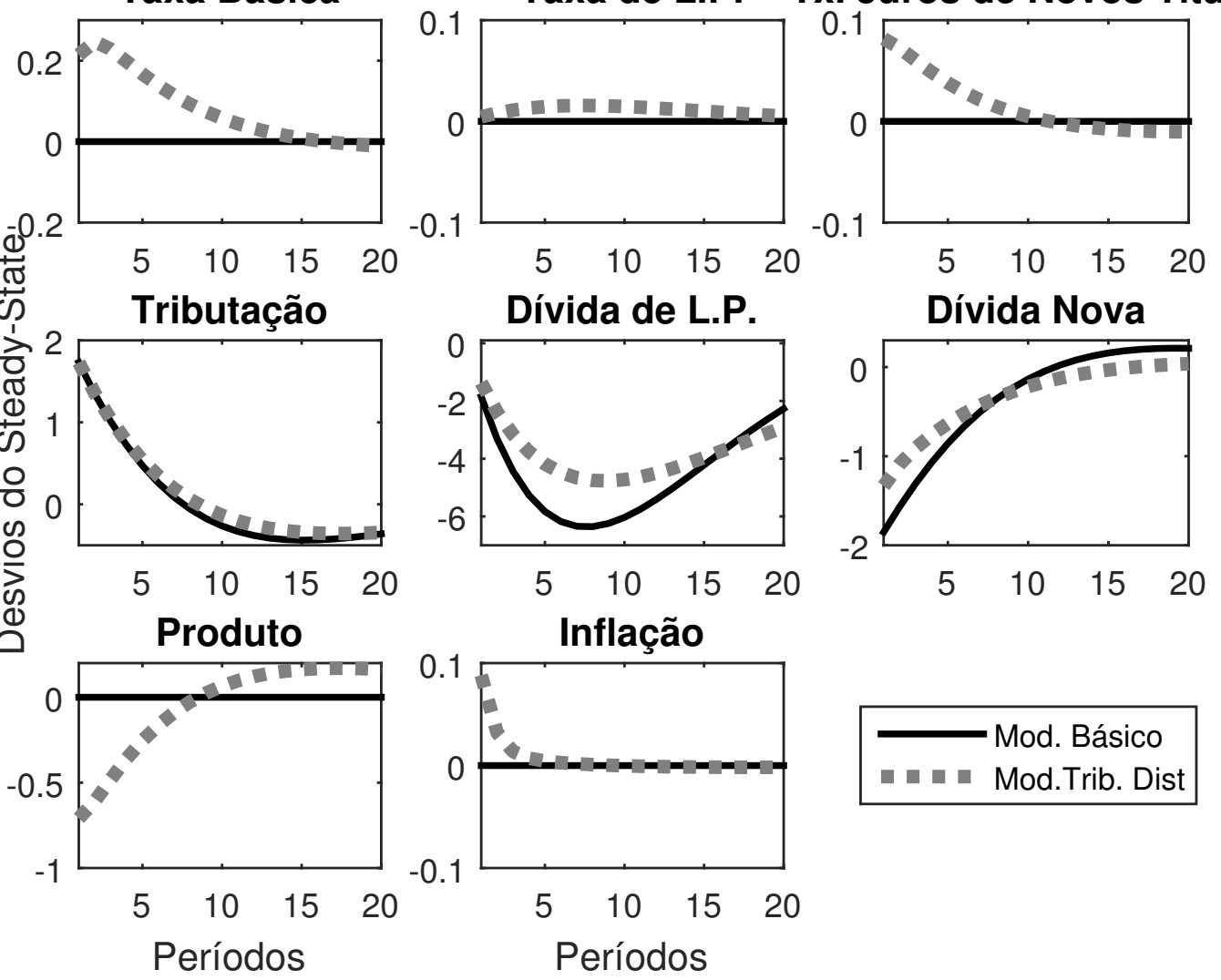

Elaboração própria 
É pertinente também comparar o modelo com a estrutura de juros especificada como no modelo de Krause e Moyen (2016) com o modelo cuja estrutura de juros foi modificada para permitir um título pós fixado. As figuras 14, 15 e 16 comparam as funções de resposta a impulso após um choque na taxa básica de juros para os dois modelos, lembrando que o segundo modelo possui duas formas de ser calibrado. O modelo estilizado de Krause e Moyen (2016) é representado por uma linha contínua preta, a calibração do modelo modificado em que a dívida pós-fixada é constante é representada pela linha tracejada cinza escuro e a calibração do modelo modificado em que a dívida pré-fixada é constante é representada pela linha pontilhada cinza claro.

Na figura 14, é claro como as dinâmicas entre as duas formas de calibração são idênticas, não alterando em nada as funções de resposta a impulso. A única diferença do modelo modificado é uma alteração na função de resposta a impulso da taxa média de longo prazo, que aumenta com o choque na taxa de juros e, no caso do modelo sem modificação, fica constante. Na calibração com dívida pré-fixada constante, a dívida de longo prazo aumenta um pouco mais. 
Figura 14 - Comparação entre funções de resposta a impulso a um choque na taxa básica de juros do modelo modificado sem e com tributação distorciva


Elaboração própria

Na figura 15, todas as funções resposta a impulso são idênticas, ou seja, a modificação da estrutura da dívida pública em nada altera o comportamento das variáveis produto, consumo, salário real e inflação. 
Figura 15 - Comparação entre funções de resposta a impulso a um choque na taxa básica de juros do modelo modificado sem e com tributação distorciva
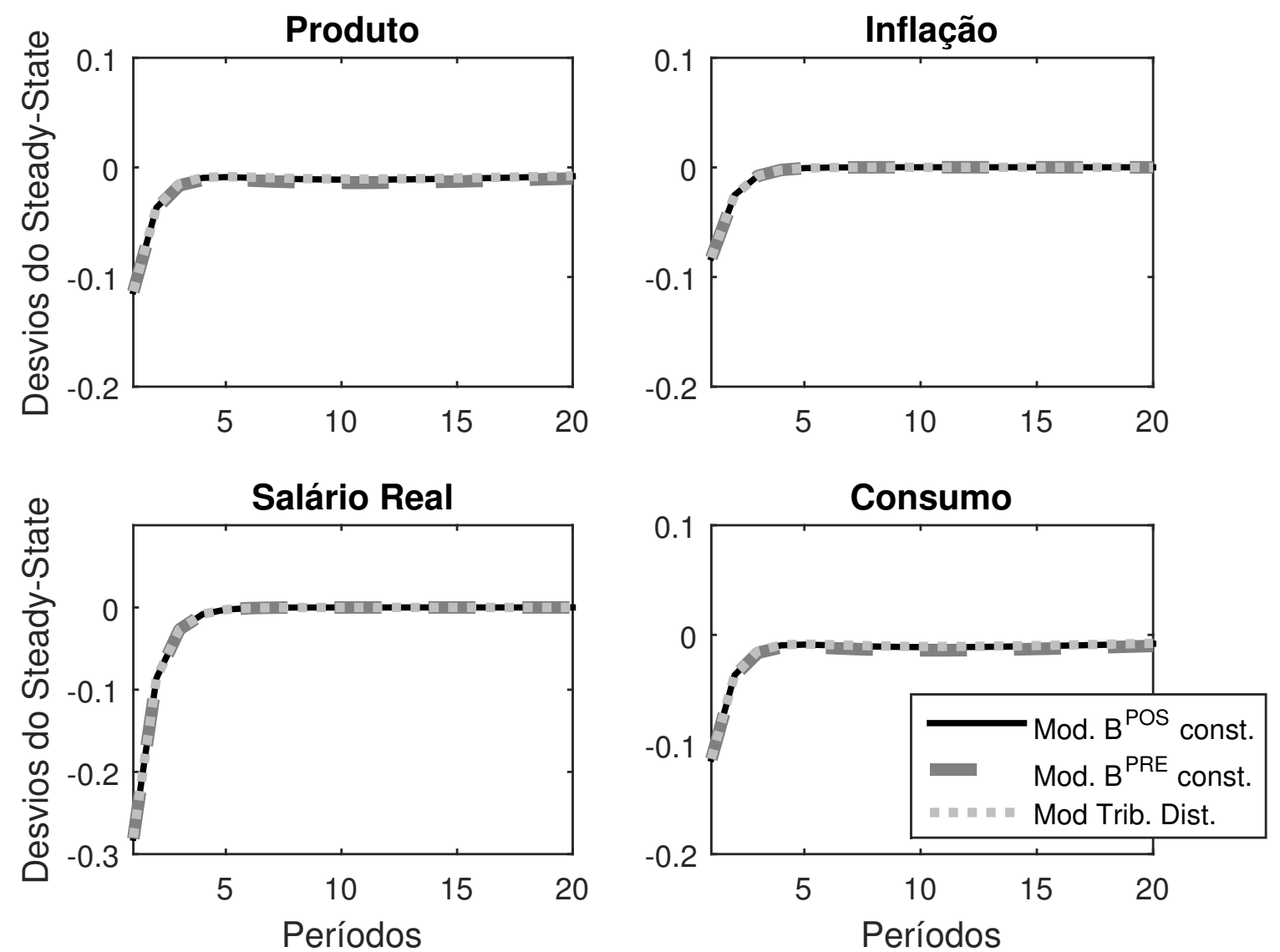

Elaboração própria

A figura 16 mostra que, quando se afasta da equivalência ricardiana utilizando-se de impostos distorcivos no mercado de trabalho, a flexibilização da estrutura da dívida passa a apresentar uma dinâmica diferente. Quando ocorre um choque monetário e a dívida pré-fixada está constante (pós-fixada constante), o estoque da dívida pós-fixada (pré-fixada) de longo prazo aumenta e a emissão de novos títulos pós-fixados (pré-fixados) aumenta, mas logo volta ao valor de Steady-State. O interessante a se notar é que emite-se mais dívida pós-fixada do que pré-fixada. 
Figura 16 - Funções de resposta a impulso a um choque na taxa básica de juros para duas calibrações do modelo modificado com tributação distorciva
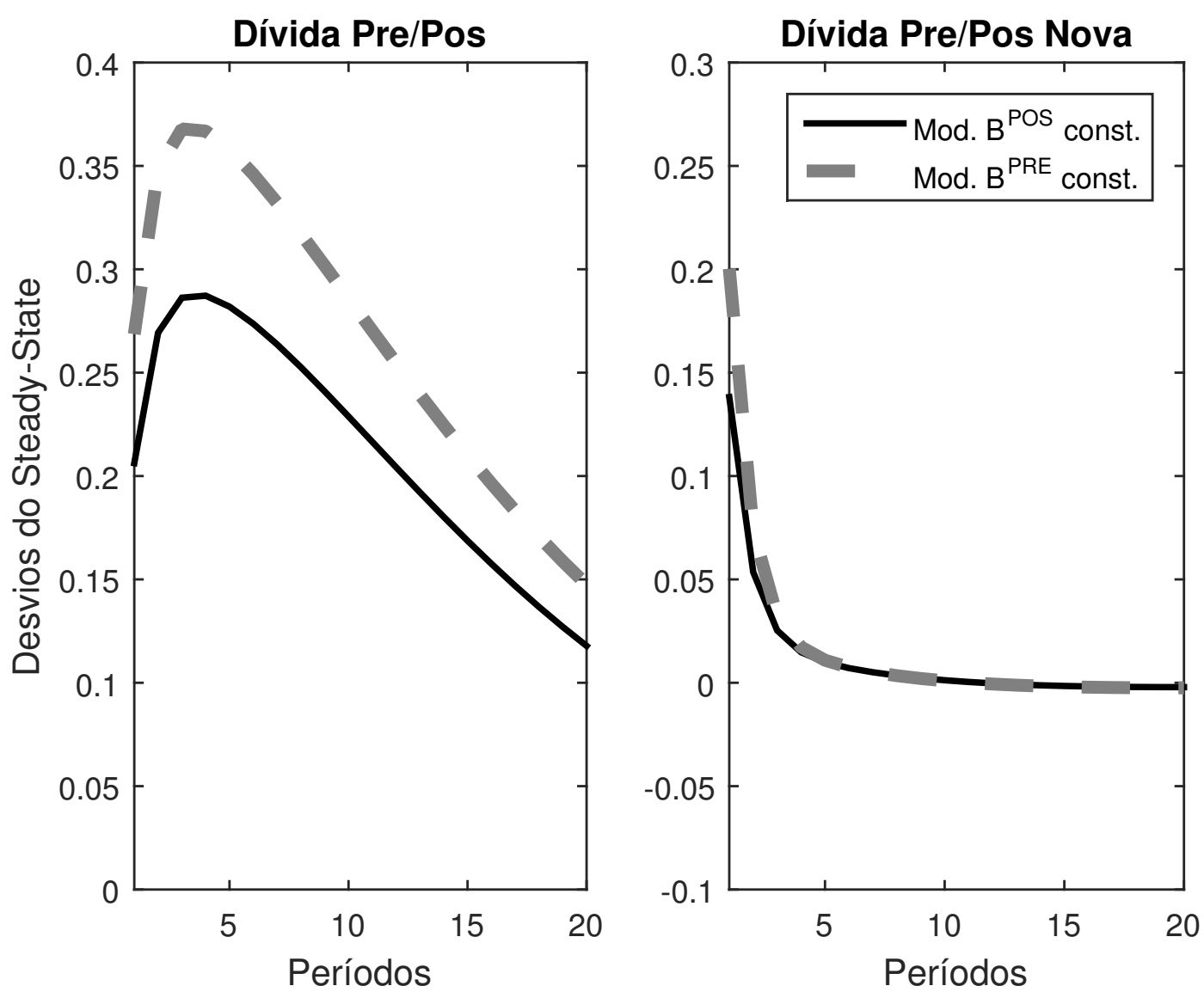

Elaboração própria

As funções de resposta a impulso após a ocorrência de um choque fiscal para duas calibrações do modelo modificado com tributação distorciva e para o modelo sem a modificação da estrutura da dívida, mas ainda com tributação distorciva são apresentadas na figura 17. O impacto da modificação em tributação, taxa básica de juros, taxa de juros de novos títulos, produto e inflação é nulo, mas o impacto na taxa de juros de longo prazo e na dívida de longo prazo é significante. O comportamento modelo com a dívida pós fixada constante é bem semelhante ao comportamento modelo sem a modificação, uma vez que o ajuste está sendo feito apenas por títulos pré-fixado. Quando existe o título pós-fixado, o funcionamento da economia é diferente. O aumento da taxa de juros de longo prazo é mais significativo e a queda no estoque de longo prazo é menor. 
Figura 17 - Comparação entre funções de resposta a impulso do modelo modificado sem e com tributação distorciva quando ocorre um choque fiscal

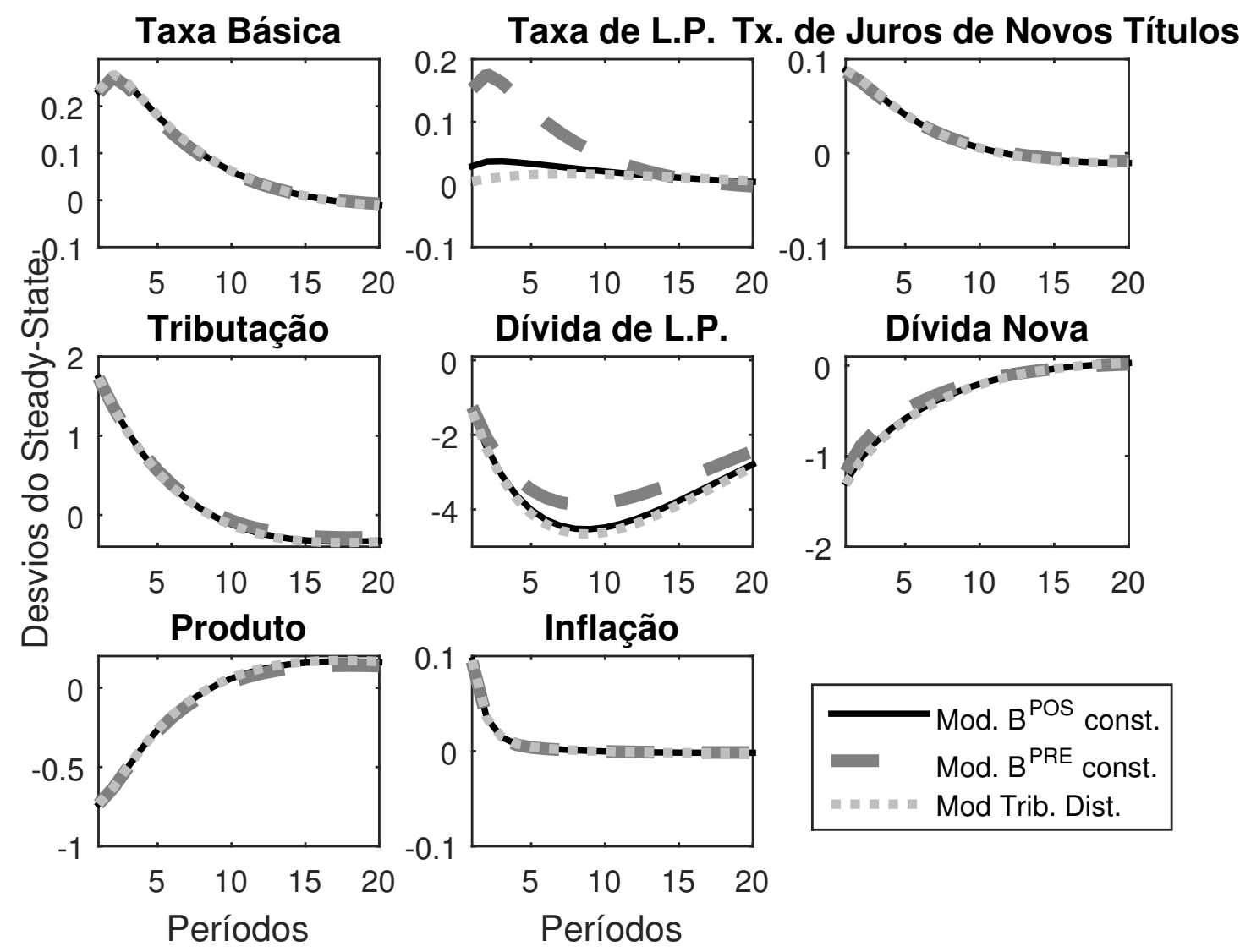

Elaboração própria 
As figuras 18 e 19 apresentam as funções de resposta a impulso para três calibrações diferentes do modelo com tributação distorciva. O parâmetro $\alpha$ - parâmetro que controla a maturidade da dívida pública - foi calibrado com os valores de 0,027, 0,055 e 0,109. O primeiro valor corresponde a uma maturidade igual ao dobro da maturidade da dívida pública brasileira, o segundo a um valor igual à maturidade da dívida pública brasileira e o terceiro a um valor igual à metade da dívida pública brasileira.

Na figura 18, estão as funções de resposta a impulso quando ocorre um choque na taxa básica de juros. Mudanças na maturidade afetam apenas a taxa de juros de emissão de novos títulos e a taxa de juros de longo prazo. Quanto mais longa a maturidade, ou seja, menor o parâmetro $\alpha$, menor o impacto do choque na taxa de juros de longo prazo e na taxa de juros de emissão de novos títulos. 
Figura 18 - Funções de resposta a impulso do modelo com tributação distorciva após um choque na taxa básica de juros para diferentes maturidades

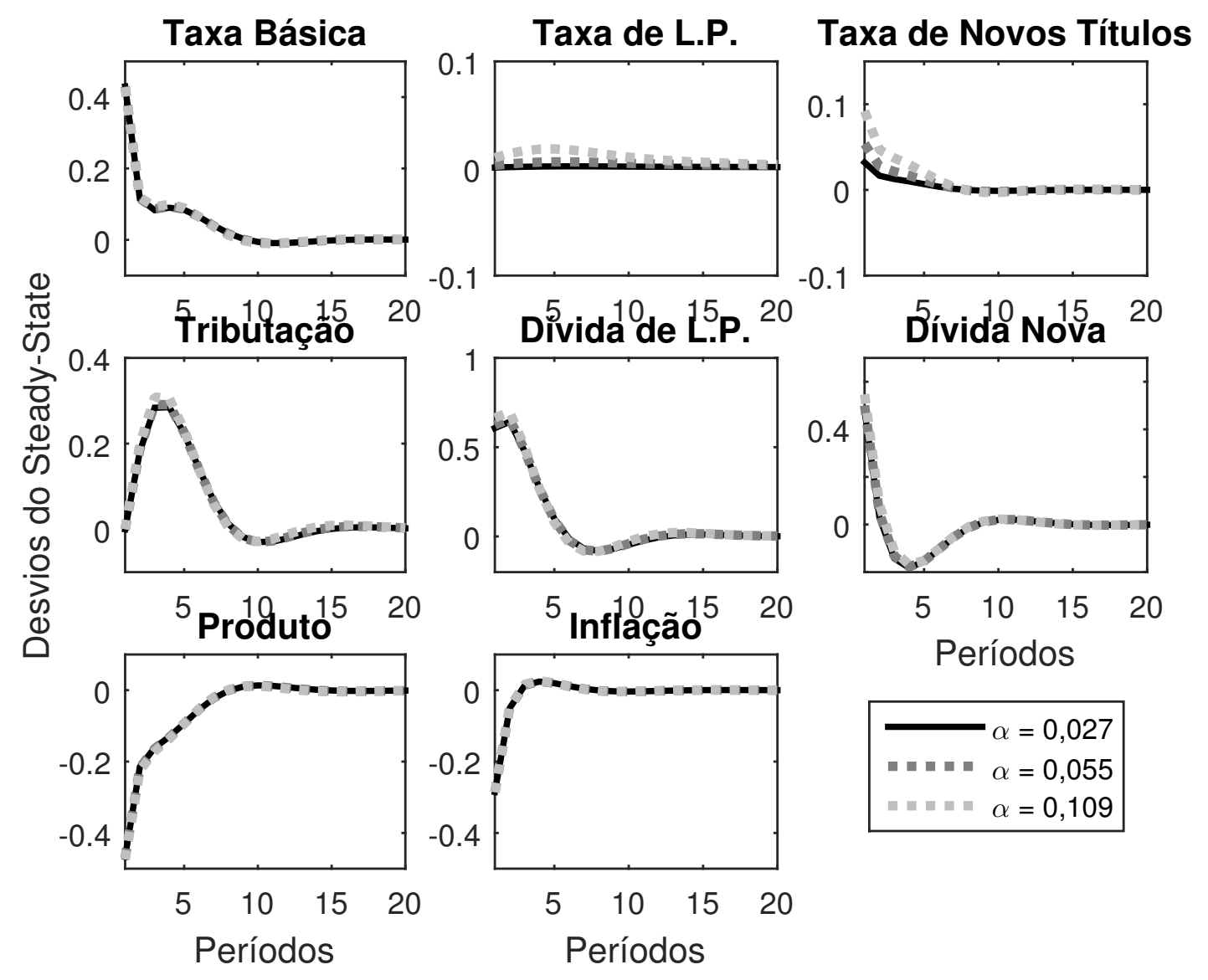

Elaboração própria 
Na figura 19, estão as funções de resposta a impulso quando ocorre um choque fiscal. Novamente, mudanças na maturidade afetam apenas a taxa de juros de emissão de novos títulos e a taxa de juros de longo prazo. Quanto mais longa a maturidade, ou seja, menor o parâmetro $\alpha$, menor o impacto do choque na taxa de juros de longo prazo e na taxa de juros de emissão de novos títulos. 
Figura 19 - Funções de resposta a impulso do modelo com tributação distorciva após um choque fiscal para diferentes maturidades
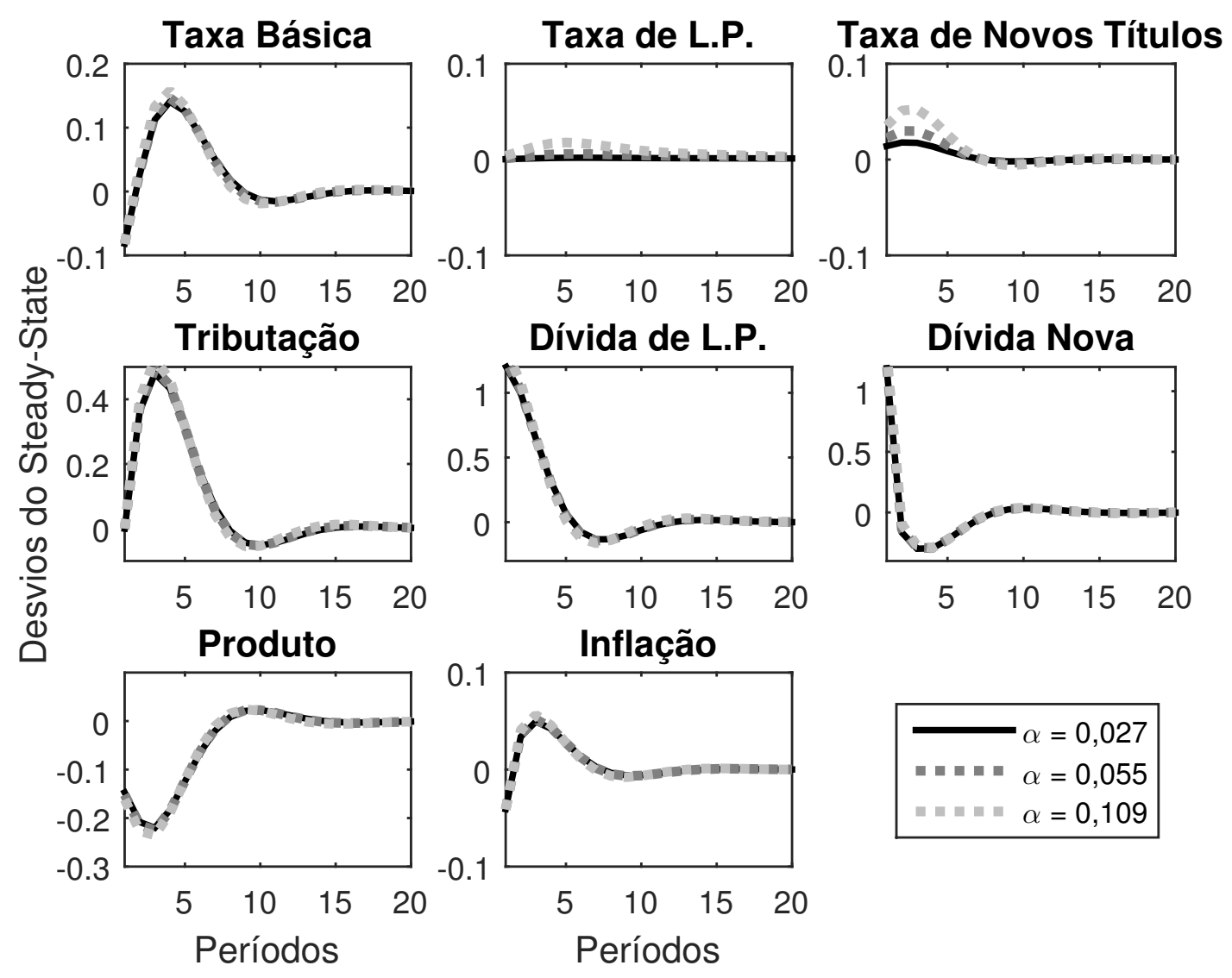

Elaboração própria 


\subsection{Agentes Não Ricardianos}

Por último, são introduzidos agentes rule-of-thumb ao modelo. Uma parcela $\gamma$ da população é composta por agentes que não maximizam intertemporalmente a utilidade, possivelmente por imperfeições no mercado de crédito. A fonte dessa imperfeição de mercado não é uma questão investigada por este trabalho. O consumo e quantidade de trabalho ofertada pelos agentes rule-of-thumb são representados, respectivamente, por $C_{t}^{r}$ e $N_{t}^{r}$. Seguindo a mesma notação, o consumo e quantidade de trabalho ofertada pelos agentes ricardianos são representados, respectivamente, por $C_{t}^{o}$ e $N_{t}^{o}$. Um agente rule-of-thumb possui a função de utilidade de um período:

$$
\left(\frac{C_{t}^{r 1-\sigma}}{1-\sigma}-\frac{N_{t}^{r 1+\varphi}}{1+\varphi}\right)
$$

e estão sujeitos a restrição orçamentária, que é, exatamente, a renda líquida de impostos ${ }^{7}$. É essa relação que define o nível de consumo a cada período:

$$
C_{t}^{r}=\left(1-\tau_{t}\right) \frac{W_{t}}{P_{t}} N_{t}^{r}
$$

Como o mercado de trabalho é competitivo, os agentes rule-of-thumb possuem a função de oferta de trabalho:

$$
N_{t}^{r \varphi} C_{t}^{r \sigma}=\left(1-\tau_{t}\right) \frac{W_{t}}{P_{t}}
$$

\subsubsection{Agregação}

A agregação é dada pela média ponderadas dos indivíduos:

$$
C_{t}=\gamma C_{t}^{o}+(1-\gamma) C_{t}^{r}
$$

$\mathrm{e}$

$$
N_{t}=\gamma N_{t}^{o}+(1-\gamma) N_{t}^{r}
$$

sendo $C_{t}^{o}$ o consumo dos agentes otimizadores e $C_{t}^{r}$ o consumo dos agentes rule-of-thumb. A notação é análoga para a quantidade de trabalho.

$\overline{7}$ Supõe-se que a parcela da renda tributada, $\tau_{t}$, é a mesma para todos os agentes. 


\subsubsection{Calibração e Simulação}

O parâmetro $\gamma$ pode ser pensado como a parcela do consumo dos agentes rule of thumb no consumo total. Seguindo a calibração de Castro et al. (2015), o valor do parâmetro é igual ao número do agentes que recebem até 2,5 salários mínimos segundo a Pesquisa Nacional por Amostra de Domicílios (PNAD). O valor é de 0,40.

A figura 20 apresenta as funções de resposta do modelo com taxação distorciva e com agentes não ricardianos e do modelo com taxação distorciva, sendo as primeiras representadas pelas linhas contínuas pretas e as segundas pelas linhas tracejadas cinzas escuros. Observa-se que os modelos possuem funções de resposta a impulso semelhantes para todas as variáveis. A modificação da estrutura da dívida pública, novamente, só apresentou efeito na taxa de juros de longo prazo e os gráficos comparando as funções de resposta a impulso foram omitidos. 


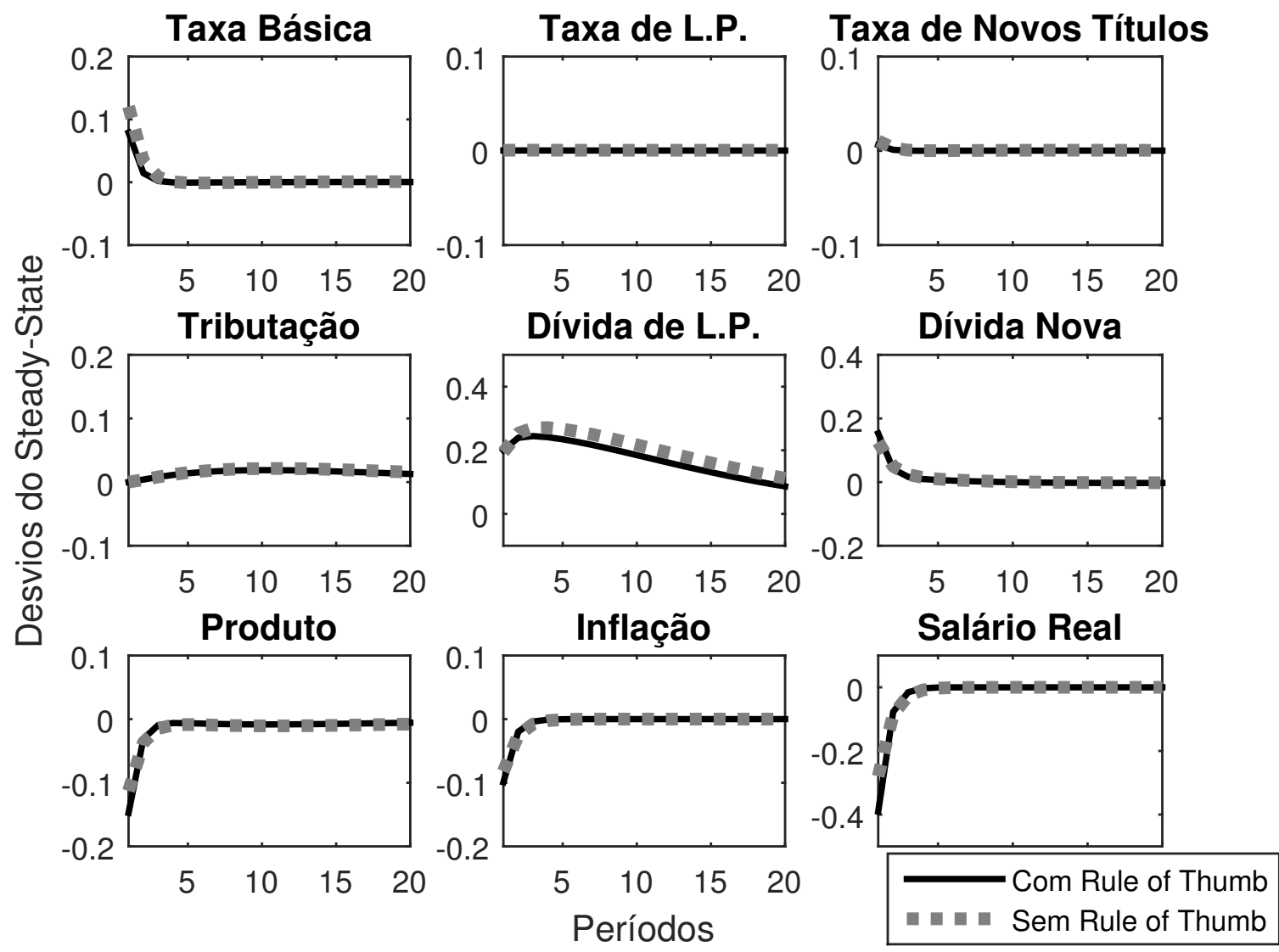

Elaboração própria 
Na figura 21, observa-se que a dinâmica após o choque fiscal é semelhante para todas as variáveis, com exceção da taxa básica de juros. Essa aumenta mais acentuadamente no modelo sem agentes rule of thumb. Em ambos os modelos, o choque fiscal leva a uma contração do produto, resultado encontrado também por Galí, López-Salido e Vallés (2007). Os autores encontram que choques fiscais em modelos com agentes rule of thumb e com preços rígidos são expansionistas no produto. 

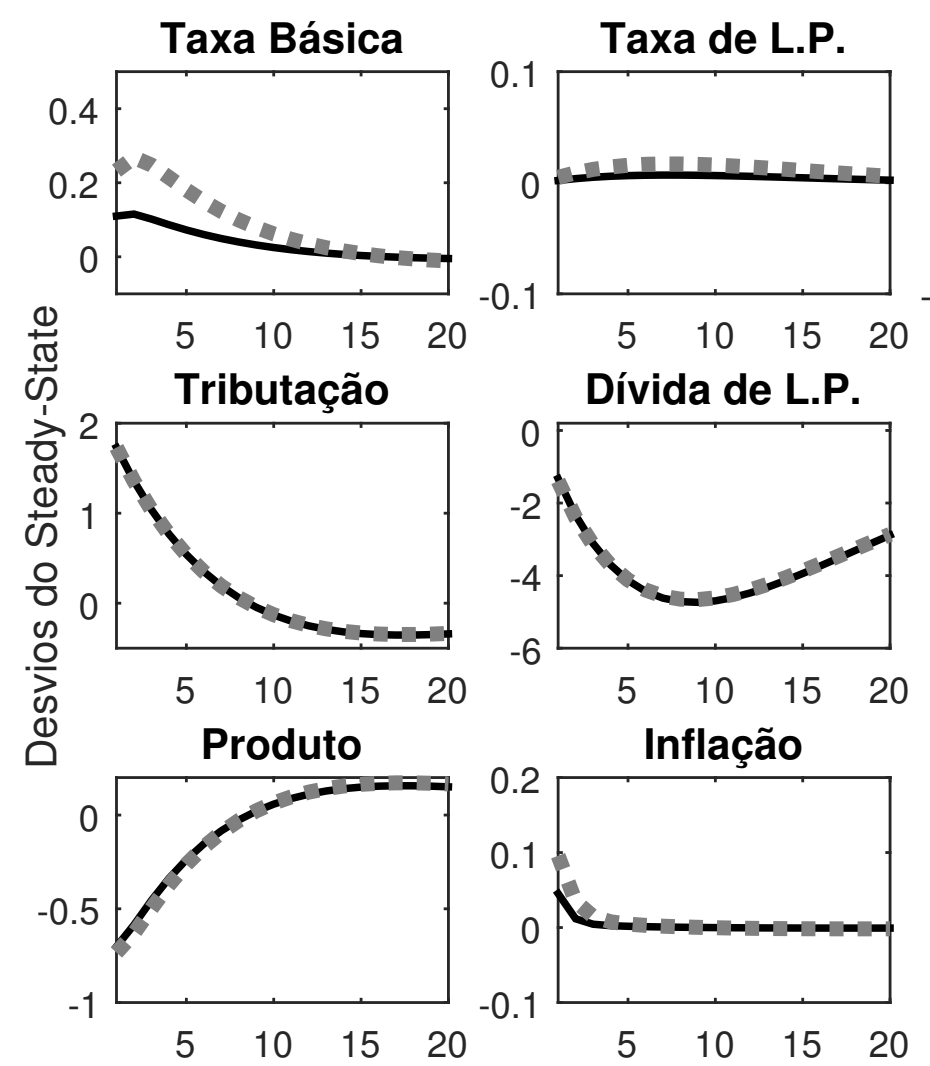

\section{Taxa de Novos Títulos}

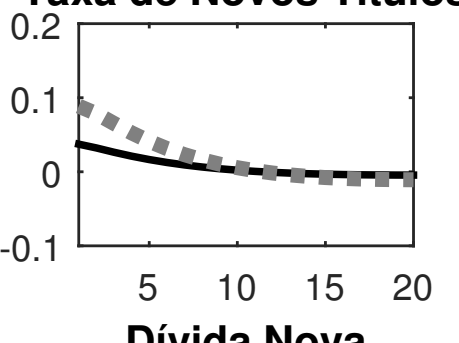

Dívida de L.P.

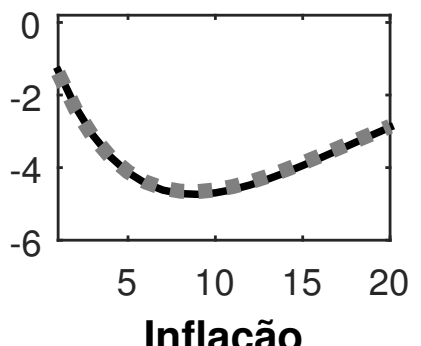

Dívida Nova
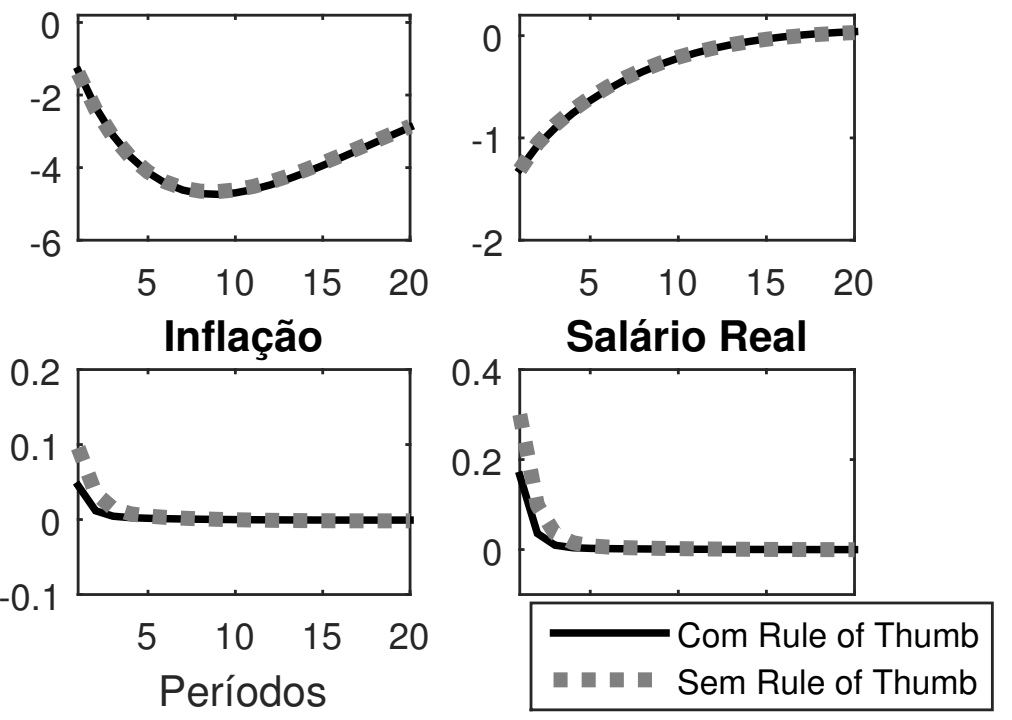

Elaboração própria 


\subsection{Conclusão}

Na seção 3.1, foi apresentada uma versão estilizada do modelo de Krause e Moyen (2016). Os autores introduzem maturidade da dívida pública em um modelo DSGE através de uma estrutura recursiva. É possível ver um canal de impacto da maturidade no modelo, mais especificamente o canal de efeito riqueza encontrado na equação de Euler do título de longo prazo, equação (3.6). As figuras 3 e 4 apresentam funções de resposta a impulso para um modelo com maturidade da dívida semelhante à brasileira, para um com o dobro da maturidade brasileira e para um com metade da maturidade brasileira. As funções de resposta a impulso são idênticas para os diferentes casos de maturidade, levando a concluir que a maturidade da dívida pública não possui impacto na dinâmica do modelo apresentado.

Usando a experiência brasileira e a discussão existente na literatura nacional sobre títulos pós-fixados como motivações, generalizou-se a estrutura da dívida de longo prazo para permitir a existência de um título pós fixado. Essa modificação, apresentada na seção 3.2, também não apresentou impacto ao modelo. Vale ressaltar que o único efeito da modificação foi na taxa de juros de longo prazo, que passou a responder a mudanças da taxa de juros básica da economia. O argumento de Pastore (1996) não se mantém no modelo desenvolvido. Mudanças na maturidade continuam não impactando na dinâmica da economia.

Outras características foram introduzidas ao modelo, como tributação distorciva - seção 3.3 - e agentes rule-of-thumb - seção 3.4. A tributação distorciva é a quem mais altera a dinâmica do modelo, principalmente para as variáveis dívida pública e alíquota de tributação. Mesmo nos modelos mais complexos, mudanças no parâmetro de maturidade da dívida continuam não impactando na dinâmica.

Em todas as versões do modelo, a ocorrência de choques fiscais aumenta a tributação e diminui o estoque da dívida de longo prazo. A dívida sofre variações com o papel de amortecer choques na economia - algo em linha com a literatura de tributação ótima. A tributação distorce o mercado de trabalho, o choque fiscal passa a ter efeitos contracionistas 
no produto e passa a elevar a inflação e, consequentemente, a taxa básica de juros. A adição de um título pós-fixado teve efeito na taxa de juros de longo prazo, que passou a responder contemporaneamente a mudanças na taxa básica de juros. Quando combina-se a adição do novo título com impostos distorcivos no mercado de trabalho, pode-se observar como o ajuste acontece diferente quando feito exclusivamente através de títulos pós-fixados e quando feito exclusivamente através de títulos pré-fixados. A taxa de juros média de longo prazo é mais volátil quando o estoque de dívida pré-fixada é constante. 


\section{Modelo com Perpetual Youth}

Este capítulo introduz maturidade da dívida pública de uma maneira diferente à utilizada no capítulo 3. Será usada a maneira proposta por Woodford (2001). Além da modelagem diferente da maturidade, optou-se também por se afastar da ideia de agentes representativos. Modelos DSGE que não utilizam esse tipo de agentes permitem um maior papel para a dívida pública, uma vez que eles não implicam em equivalência ricardina.

Diferente do modelo do capítulo anterior, em que o agente representativo vive infinitamente, neste os agentes enfrentam uma probabilidade de morrer. Essa estrutura é baseada no modelo de Chadha e Nolan (2003) e Piergallini (2006), uma versão em tempo discreto dos modelos de Blanchard (1985) e Yaari (1965). Nisticò (2012) utiliza esse tipo de modelo para analisar mercado acionário e Ganelli (2005) e Giorgio e Nisticò (2007) o utilizam para analisar uma economia aberta. Ao introduzir a possibilidade de morrer, o consumo dos agentes passa a depender do estoque de riqueza, aqui formada por títulos de curto e longo prazos. Optou-se por um modelo que permitia o consumo depender da riqueza do indivíduo, principalmente porque essa hipótese está presente no modelo de Pastore (1996).

\subsection{Lado da Demanda}

A diferença do modelo está no lado da demanda. Suponha que os consumidores possuam utilidades idênticas e que possuam uma probabilidade $\xi$ de morrer a cada período. Na economia, não há crescimento populacional. Mantém-se a hipótese de um contínuo de produtos, $C_{t}(i)$ com $i \in[0,1]$. A elasticidade de substituição é representada por $\epsilon$ e o contínuo de bens é agregado em um índice de consumo, $C_{t}$, pelo agregador de DixitStiglitz. Um agente que nasceu no período $s$, maximiza no período $t$ a seguinte utilidade intertemporal:

$$
E_{t} \sum_{t=0}^{\infty} \beta^{t}(1-\xi)^{t}\left[{\frac{C_{s, t}}{1-\sigma}}^{1-\sigma}-{\frac{N_{s, t}}{1+\varphi}}^{1+\varphi}\right]
$$


sujeito à restrição orçamentária ${ }^{1}$ :

$$
P_{t} C_{s, t}+Q_{t}^{S} B_{s, t}^{S}+Q_{t}^{M} B_{s, t}^{M} \leq \frac{1}{1-\xi} B_{s, t-1}^{S}+\frac{1}{1-\xi}\left(1+\rho Q_{t}^{M}\right) B_{s, t-1}^{M}+W_{t} N_{s, t}+Z_{s, t}-T_{t}
$$

sendo $C_{s, t}$ a cesta de consumo no período $t$ do agente nascido no período $s, N_{s, t}$ a quantidade de horas trabalhadas, $Q_{t}^{S}$ o preço do título de curto prazo (de um período), $B_{s, t}^{S}, Q_{t}^{M}$ o preço do título de longo prazo, $B_{s, t-1}^{M}$, $W_{t}$ é o salário ofertado ao indivíduo, $Z_{s, t}$ é o lucro das firmas e $T_{s, t}$ é um imposto lump-sum.

O título de longo prazo é introduzido conforme Woodford (2001), que o define como perpetuidades com cupons que decaem exponencialmente. Um título emitido na data t paga $\rho^{k-1}$ na data $t+k, \operatorname{com} k>1$ e $\rho \in[0,1]$, sendo o decaimento do cupom calibrável de acordo com a maturidade média do portfólio. Observe que, quando $\rho=1$, o título se assemelha a um "consol" e, quando $\rho=0$, o título se assemelha a um título de um período. A duração média do título é dada por $(1-\beta \rho)^{-1}$.

As equações de ótimo encontradas são:

$$
\begin{gathered}
Q_{t}^{S}=\beta E_{t}\left\{\left(\frac{C_{s, t+1}}{C_{s, t}}\right)^{-\sigma} \frac{P_{t}}{P_{t+1}}\right\} \\
\frac{W_{t}}{P_{t}}=C_{s, t}^{\sigma} N_{s, t}^{\varphi} \\
Q_{t}^{M}=\beta E_{t}\left\{\left(\frac{C_{s, t+1}}{C_{s, t}}\right)^{-\sigma} \frac{P_{t}}{P_{t+1}}\left(1+\rho Q_{t+1}^{M}\right)\right\}
\end{gathered}
$$

Das equações de ótimo, tem-se a equação de arbritagem entre as taxas de juros:

$$
Q_{t}^{M}=E_{t} Q_{t}^{S}\left(1+\rho Q_{t+1}^{M}\right)
$$

Definindo $Q_{t}^{S} \equiv 1 / R_{t}$, é possível definir o fator intertemporal de desconto entre o período $t$ e $t+1$ :

$$
\Lambda_{t, t+1}(s) \equiv \beta E_{t}\left[\frac{C_{s, t}}{C_{s, t+1}} \frac{P_{t}}{P_{t+1}}\right]=\frac{1}{R_{t}}
$$

1 O mercado perfeito de seguros herda a renda dos indivíduos que morreram e a redistribui entre os indivíduos restantes. Como resultado, a indústria de seguros possui lucro zero e o retorno de um contrato de seguro é dado por 1/(1- $\xi$ ). Para mais detalhes, ver Blanchard (1985) 
e o fator intertemporal de desconto entre o período $t$ e $t+T$

$$
\Lambda_{t, T}(s) \equiv \prod_{i=0}^{T} \Lambda_{t+i-1, t+i}(s)=\prod_{i=0}^{T} \frac{1}{R_{t+i}}
$$

\subsection{Riqueza}

Assim como Chadha e Nolan (2003) e Piergallini (2006), define-se a riqueza financeira do indivíduo $s$ no começo do período $t, \Omega_{s, t}$, como:

$$
\Omega_{s, t}=\frac{1}{1-\xi} B_{s, t-1}^{S}+\frac{1}{1-\xi}\left(1+\rho Q_{t}^{M}\right) B_{s, t-1}^{M}
$$

Reescrevendo a restrição orçamentária, encontra-se:

$$
\Omega_{s, t}=Q_{t}^{S}(1-\xi) E_{t} \Omega_{s, t+1}+P_{t} C_{s, t}-W_{t} N_{s, t}-Z_{s, t}+T_{t}
$$

Usando a condição de Non-Ponzi Game ${ }^{2}$, a equação de ótimo do consumo individual e interando restrição orçamentária, encontra-se o consumo como função de toda renda:

$$
P_{t} C_{s, t}=\Psi\left[\Omega_{s, t}+E_{t} \sum_{i=0}^{\infty} \Lambda_{t, t+i}(s)(1-\xi)^{i} \Upsilon_{s, t+i}\right]
$$

sendo $\Psi \equiv(1-\beta(1-\xi))$ e $\Upsilon_{s, t+i} \equiv W_{t+i} N_{s, t+i}+Z_{s, t+i}-T_{t+i}$.

\subsection{Agregação}

É necessário para resolver o modelo, agregar as coortes de forma a encontrar o consumo agregado. O tamanho da coorte, $t$ períodos após o nascimento, é dado por:

$$
\xi(1-\xi)^{t}
$$

O tamanho da coorte decresce monotonicamente, sendo que a soma de todas coortes

$2 \quad$ A condição de Non-Ponzi Game é:

$$
\lim _{T \rightarrow \infty}(1-\xi)^{T} E_{t} \Lambda_{t, T}(s) \Omega_{s, t+T}=0
$$


é igual a unidade, ou seja:

$$
\xi \sum_{j=-\infty}^{t}(1-\xi)^{t-j}=1
$$

A agregação do modelo é, consequentemente, direta. Seja $X_{t}$ a variável agregada, sua agregação é a soma de todas as coortes ponderando pelo respectivo peso na economia:

$$
X_{t}=\sum_{s=-\infty}^{t} \xi(1-\xi)^{t-s} X_{s, t}
$$

A restrição orçamentária e a oferta de trabalho agregada são respectivamente:

$$
\begin{gathered}
Q_{t}^{S} B_{t}^{S}+Q_{t}^{M} B_{t}^{M} \leq B_{t-1}^{S}+\left(1+\rho Q_{t}^{M}\right) B_{t-1}^{M}+W_{t} N_{t}+Z_{t}-T_{t}-P_{t} C_{t} \\
\frac{W_{t}}{P_{t}}=C_{t}^{\sigma} N_{t}^{\varphi}
\end{gathered}
$$

Rearranjando os termos da equação de consumo agregado, após agregação, encontrase uma equação de Euler para o consumo ${ }^{3}$ :

$$
E_{t} P_{t+1} C_{t+1}=\beta \frac{P_{t} C_{t}}{Q_{t}^{S}}-\frac{\xi}{1-\xi} \Psi E_{t}\left[B_{t}^{S}+\left(1+\rho Q_{t+1}^{M}\right) B_{t}^{M}\right]
$$

Observe que, quando a probabilidade de morrer é nula, $\xi=0$, a equação de Euler passa a ser igual à equação de Euler encontrada no capítulo 2 e no capítulo 3. O segundo termo do lado esquerdo é o resultado do efeito riqueza no consumo do indivíduo. Usando a equação de paridade dos preços dos títulos, acha-se a Euler para o outro título:

$$
E_{t} P_{t+1} C_{t+1}=\beta P_{t} C_{t} \frac{\left(1+\rho Q_{t+1}^{M}\right)}{Q_{t}^{M}}-\frac{\xi}{1-\xi} \Psi E_{t}\left[B_{t}^{S}+\left(1+\rho Q_{t+1}^{M}\right) B_{t}^{M}\right]
$$

\subsection{Firma}

O problema de ótimo da firma é igual ao problema do capítulo 2. A dinâmica de preços agregados segue:

$$
1=\left[\theta \pi_{t}^{\epsilon-1}+(1-\theta)\left(\frac{P_{t}^{*}}{P_{t}}\right)^{1-\epsilon}\right]
$$

3 Contas no apêndice B 
onde $\theta$ é a probabilidade de reajuste do contrato de preço, $\pi_{t}$ é a taxa de inflação, $\epsilon$ é calibrado de forma às firmas terem um mark-up de $20 \%$ e $P_{t}^{*} / P_{t}$ é a razão entre os preços recém ajustados e o índice de preço na economia.

As condições de ótimo da firma são:

$$
\frac{P_{t}^{*}}{P_{t}}=\mu \frac{Z_{2, t}}{Z_{1, t}}
$$

sendo

$$
\begin{gathered}
Z_{1, t}=C_{t}^{1-\sigma}+\beta \theta E_{t} \pi_{t+1}^{\epsilon-1} Z_{1, t+1} \\
Z_{2, t}=C_{t}^{1-\sigma} m c_{t}+\beta \theta E_{t} \pi_{t+1}^{\epsilon} Z_{2, t+1}
\end{gathered}
$$

onde $\mu$ é a taxa de mark-up, $Z_{2, t}$ e $Z_{1, t}$ são duas variáveis auxiliares criadas para facilitar escrever o problema da firma recursivamente e $m c_{t}$ é o custo marginal da firma, que é dado pela equação:

$$
m c_{t}=\frac{W_{t}}{P_{t}}
$$

sendo $W_{t} / P_{t}$ é o salário real.

\subsection{Autoridade Fiscal e Monetária}

Neste trabalho, decidiu-se usar uma regra fiscal da forma:

$$
\hat{T}_{t}=\rho_{T} \hat{T_{t-1}}+\phi_{b} \frac{\hat{\Omega_{t+1}}}{P_{t}}+s_{t}
$$

onde $\hat{\Omega}_{t}$ é desvio do estoque de riqueza do seu valor de Steady State, sendo o valor do estoque de riqueza definido como $\Omega_{t} \equiv B_{t}^{S} / P_{t}+\left(1+\rho Q_{t+1}^{M}\right) B_{t}^{M} / P_{t} . \hat{T}_{t}$ é o desvio do imposto lump-sum do seu valor de Steady State, $\hat{T}_{t} \equiv T_{t}-\bar{T}_{t}$, e $s_{t}$ é um choque fiscal com desvio padrão $\sigma_{s}$.

Também é necessário adicionar a restrição orçamentária do governo:

$$
T_{t}+Q_{t}^{S} \frac{B_{t}^{S}}{P_{t}}+Q_{t}^{M} \frac{B_{t}^{M}}{P_{t}}=\frac{B_{t-1}^{S}}{P_{t}}+\left(1+\rho Q_{t}^{M}\right) \frac{B_{t-1}^{M}}{P_{t}}+g
$$


onde $g$ é uma constante de gasto público.

Por último, para acabar de caracterizar o governo, a regra de política monetária é:

$$
\left(R_{t}\right)=\left(1-\rho_{R}\right) \bar{R}+\rho_{R} R_{t-1}+\phi_{\pi}\left(\pi_{t}-1\right)+v_{t}
$$

onde $R_{t}$ é a taxa de juros controlada pela autoridade monetária e definida como $Q_{t}^{S}=1 / R_{t}$, $\bar{R}_{t}$ é o valor de Steady-State, $\pi_{t}$ é a taxa de inflação e $v_{t}$ é um choque estocástico com desvio padrão $\sigma_{v}$.

\subsection{Equilíbrio}

A demanda agregada de bens exige que o produto seja igual ao consumo das famílias mais o consumo do governo:

$$
Y_{t}=C_{t}+g
$$

Usando a função de produção de cada firma, a condição de market clearing do mercado de trabalho, a demanda individual de cada firma e definindo $\Delta_{p, t} \equiv \int_{0}^{1}\left[P_{t}(i) / P_{t}\right]^{-\epsilon}$ como o coeficiente de dispersão de preços, chega-se à equação:

$$
\Delta_{p, t} Y_{t}=A N_{t}
$$

sendo o movimento de $\Delta_{p, t}$ dado por:

$$
\Delta_{p, t}=\theta \pi_{t}^{\epsilon} \Delta_{p, t-1}+(1-\theta)\left[\frac{P_{t}^{*}}{P_{t}}\right]^{-\epsilon}
$$

O equilíbrio do modelo é determinado pelos processos estacionários $Q_{t}^{S}, Q_{t}^{M}, C_{t}$, $\pi_{t}, W_{t} / P_{t}, N_{t}, P_{t}^{*} / P_{t}, Z_{1, t}, Z_{2, t}, m c_{t}, T_{t}, B_{t}^{S} / P_{t}, B_{t}^{M} / P_{t}, Y_{t}$ e $\Delta_{p, t}$ satisfazendo as relações (4.1), (4.2), (4.3), (4.4), (4.5), (4.6), (4.7), (4.8), (4.9), (4.10), (4.11), (4.12), (4.13) е (4.14) e pelo processo estocástico $v_{t}$ e $s_{t}$. Para encontrar o equilíbrio, é necessária mais uma restrição, que será $B_{t} / P_{t}=0$.

Assim como no capítulo 3, a restrição $B_{t} / P_{t}=0$ foi usada. Ela permite os agentes suavizarem consumo apenas com os títulos de longo prazo, o que permite focar melhor a análise nos mecanismos de transmissão de choques dos títulos de longo prazo. 


\subsection{Calibração e Simulação}

A probabilidade do agente morrer, $\xi$, foi calibrada para ser igual a 0,015 , valor usado por Piergallini $(2006)^{4}$. O parâmetro $\rho$ foi calibrado usando três valores, 0,7583 , 0,8847 e 0,9479 . Os três valores implicam maturidade da dívida de 4 períodos ( 1 anos), 8 períodos ( 2 anos) e 16 períodos ( 4 anos) e são representados, respectivamente, por uma linha contínua preta, uma linha tracejada cinza escuro e uma linha pontilhada cinza claro. Os parâmetros usados no modelo estão apresentados na tabela 3.

Tabela 3 - Calibração para o modelo com Perpetual Youth

\begin{tabular}{|c|c|c|c|}
\hline Simbolo & Valores & Descrição & Fonte \\
\hline \multicolumn{4}{|c|}{ Razões } \\
\hline$S_{g}$ & $22,20 \%$ & Razão Governo Produto & IBGE \\
\hline$S_{b}$ & $36,81 \%$ & Razão Dívida Produto & IBGE \\
\hline \multicolumn{4}{|c|}{ Parâmetros de Preferências e de Tecnologia } \\
\hline$\xi$ & 0,015 & Probabilidade do agente morrer & Piergallini (2006) \\
\hline$\beta$ & 0,989 & Coeficiente de desconto intertemporal & Castro et al. (2015) \\
\hline$\sigma$ & 1,3 & Elasticidade de substituição intertemporal & Castro et al. (2015) \\
\hline$\varphi$ & 1 & Elasticidade da oferta de trabalho de Frisch & Castro et al. (2015) \\
\hline$\epsilon$ & 6 & Mark-up de $20 \%$ & Krause e Moyen (2016) \\
\hline \multicolumn{4}{|c|}{ Parâmetros de Rigidez } \\
\hline$\theta$ & 0,67 & Proporção de firmas reajustando preços & Krause e Moyen (2016) \\
\hline \multicolumn{4}{|c|}{ Parâmetros da Regra Fiscal, da Monetária e da Restrição Orçamentária do Governo } \\
\hline$\phi_{b}$ & 0,02 & Resposta da tributação a desvios da dívida & Castro et al. (2015) \\
\hline$\phi_{\pi}$ & 2,43 & Coeficiente de Taylor & Castro et al. (2015) \\
\hline$\rho_{T}$ & 0,8 & Coeficiente auto-regressivo da regra fiscal & Castro et al. (2015) \\
\hline$\rho_{R}$ & 0,79 & Coeficiente auto-regressivo da regra monetária & Castro et al. (2015) \\
\hline$g$ & 0,24 & Gastos do governo & IBGE \\
\hline \multicolumn{4}{|c|}{ Coeficientes dos Choques Exógenos } \\
\hline$\sigma_{v}$ & 0,32 & Desvio padrão do choque monetário $\left(v_{t}\right)$ & Castro et al. (2015) \\
\hline$\sigma_{s}$ & 1,73 & Desvio padrão do choque monetário $\left(s_{t}\right)$ & Castro et al. (2015) \\
\hline
\end{tabular}

Fonte: Elaboração própria.

A figura 22 apresenta as funções de resposta a impulso de variáveis selecionadas a um choque de um desvio padrão da taxa básica de juros, $\left(R_{t}\right)$. Como era se se esperar, ao aumentar a taxa básica de juros, o preço do título de curto prazo e o preço do título de

4 Com o parâmetro calibrado, a expectativa de vida do agente é $1 / \xi$, ou seja, 66,67 anos. 
longo prazo diminuem. Também de forma esperada, a inflação, o salário real, o consumo, o produto e o número de horas trabalhadas diminuem. A quantidade de dívida e imposto lump-sum ficam estáveis. Também fica evidente na figura que a maturidade da dívida não tem impacto nas variáveis consumo, produto e inflação. 
Figura 22 - Funções de resposta a impulso para o modelo com Perpetual Youth quando ocorre um choque na taxa de juros básica

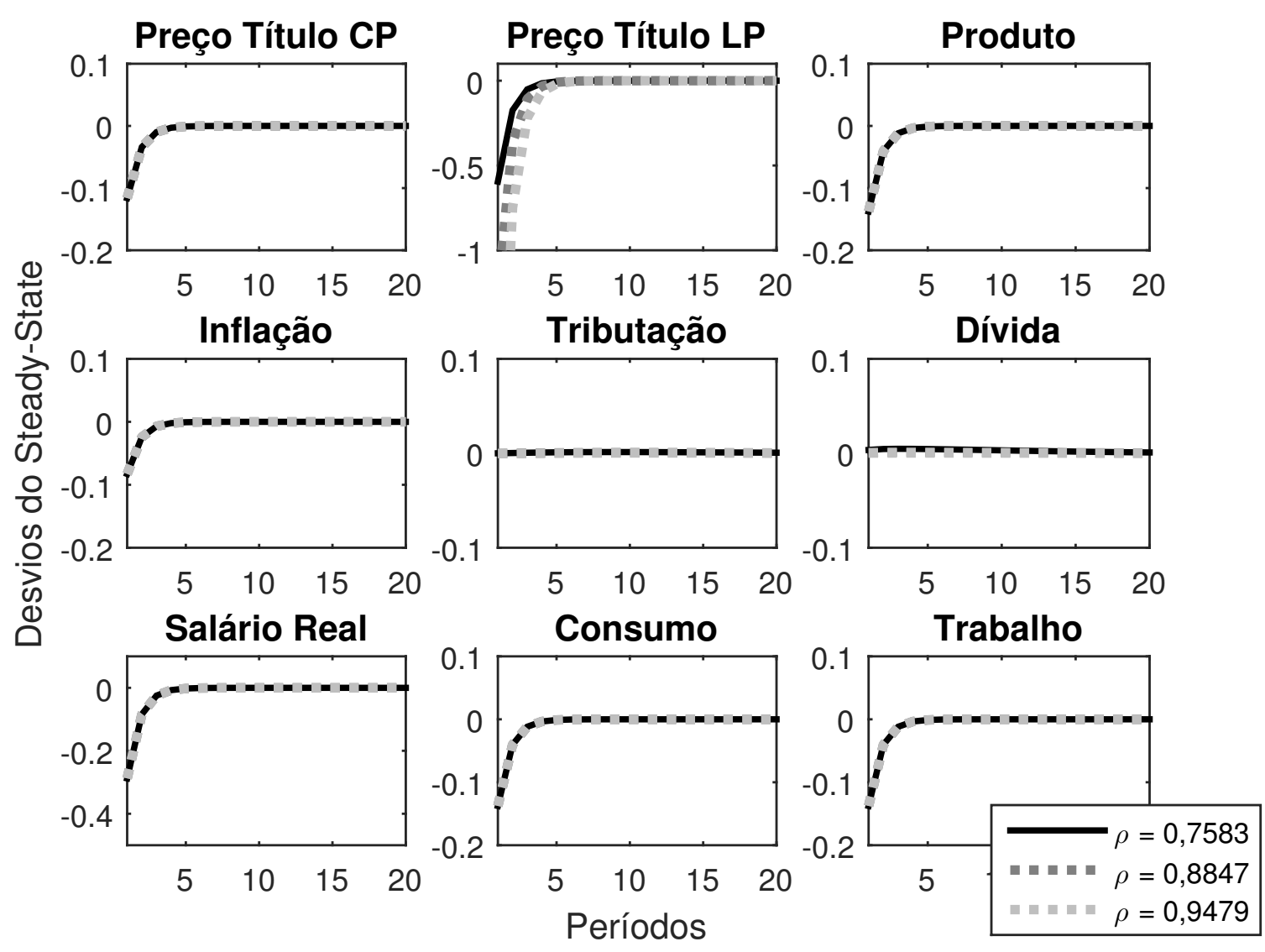

Elaboração própria 
Para entender melhor como está funcionando o modelo, é necessário analisar como o Steady State das variáveis está mudando com alterações de $\rho$, o parâmetro que controla a maturidade. No modelo, o estoque de dívida de longo prazo em valor real é dado por $B_{t}^{M} / P_{t}$ e o preço do título é dado por $\left(1+\rho Q_{t}^{M}\right)$. Calibrou-se o modelo para que a dívida de Steady State seja igual a $36,81 \%$ do produto, ou seja:

$$
\frac{\left(1+\rho \overline{Q^{M}}\right) \frac{\overline{B^{M}}}{P}}{Y}=s_{b}=0,3681
$$

Na figura 23, fica claro como o modelo está se comportando. A quantidade de título decai linearmente com o aumento de $\rho$, sendo acompanhada para um aumento exponencial do preço do título. Ao calcular o valor do estoque de títulos, acha-se a constante usada na calibração.

Figura 23 - Steady-State para diferentes $\rho$
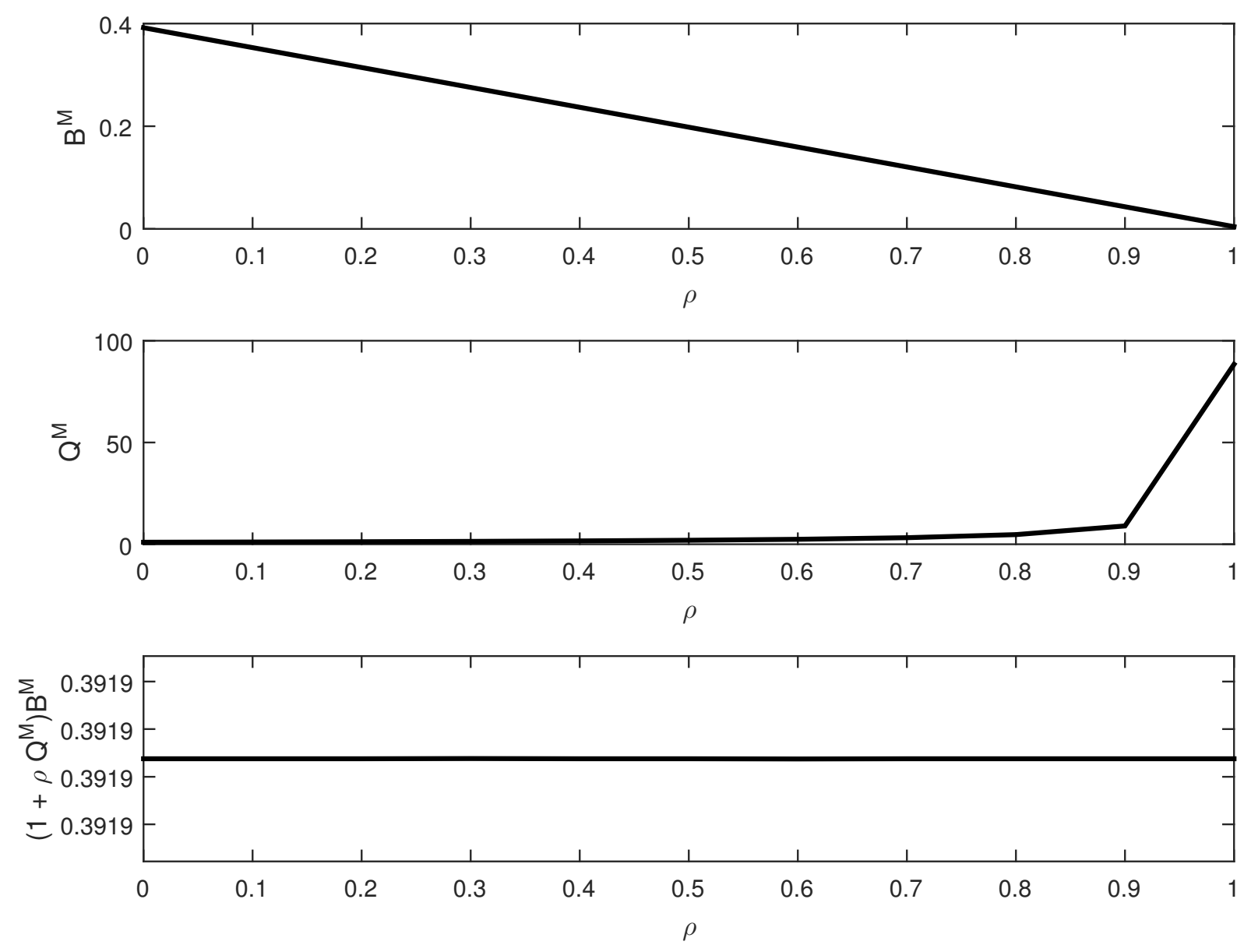

Elaboração própria 
Por último, a figura 24 apresenta os gráficos das funções de impulso a resposta quando acontece um choque fiscal para as variáveis preço do título de curto prazo, preço do título de longo prazo, produto, inflação, tributação lump-sum e estoque de dívida. O impacto do choque fiscal é nulo em todas as variáveis, exceto para o estoque da dívida pública, para a tributação e para o preço do título. Quando ocorre o choque, a tributação aumenta e a dívida diminui. O preço da dívida pública aumenta para equilibrar a razão dívida produto. O papel da dívida pública em amortecer choques que ocorrem na economia foi extensamente abordado pela literatura de tributação ótima. O impacto de variações na maturidade é exclusivamente no estoque da dívida e no preço do título, sendo que, quanto maior a maturidade, menor é a variação na dívida, mas maior é a variação no preço do título.

Figura 24 - Funções de resposta a impulso para o modelo com Perpetual Youth quando ocorre um choque fiscal
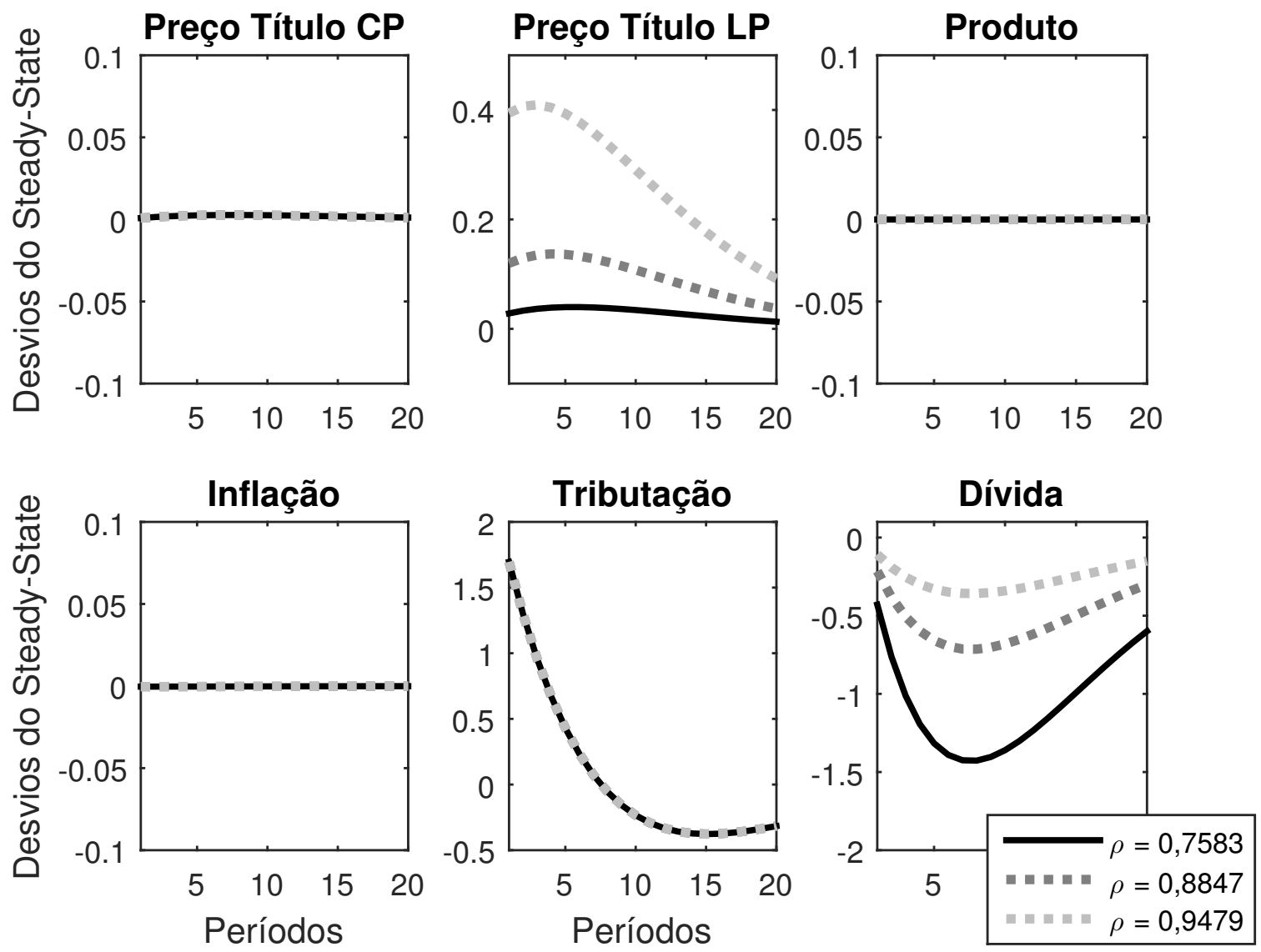

Elaboração própria 


\subsection{Imposto Distorcivo}

Nesta seção, será introduzido um imposto distorcivo, uma maneira de tornar mais relevante o governo - pelo menos com impacto na dinâmica da economia. Supõe-se que o governo taxa uma parcela $\tau_{t}$ da renda do trabalho. A equação (4.2) passa a ser:

$$
\left(1-\tau_{t}\right) \frac{W_{t}}{P_{t}}=C_{t}^{\sigma} N_{t}^{\varphi}
$$

A regra fiscal, equação (4.9), passa a ser:

$$
\tau_{t}-\bar{\tau}=\rho_{\tau}\left(\tau_{t-1}-\bar{\tau}\right)+\phi_{b}\left\{\omega_{t}-\bar{\omega}\right\}+s_{t}
$$

onde $\omega_{t} \equiv B_{t}^{S} / P_{t}+\left(1+\rho Q_{t+1}^{M}\right) B_{t}^{M} / P_{t}$ é o endividamento real. A restrição orçamentária do governo, equação (4.10), passa a ser escrita como:

$$
\tau_{t} \frac{W_{t}}{P_{t}} N_{t}+Q_{t}^{S} \frac{B_{t}^{S}}{P_{t}}+Q_{t}^{M} \frac{B_{t}^{M}}{P_{t}}=\frac{B_{t-1}^{S}}{P_{t}}+\left(1+\rho Q_{t}^{M}\right) \frac{B_{t-1}^{M}}{P_{t}}+g
$$

onde $g$ é uma constante de gasto público.

\subsubsection{Simulação}

A figura 25 apresenta funções de resposta a impulso de um conjunto de variáveis selecionadas para três calibrações do modelo com Perpetual Youth e com tributação distorciva. Na figura, a linha contínua preta representa o modelo com o parâmetro $\rho$ calibrado com 0,7583, ou seja, com maturidade da dívida de 1 ano. A linha tracejada cinza escuro representa o modelo com o parâmetro $\rho$ calibrado com 0,8847 (maturidade de 2 anos) e, por último, a linha pontilhada cinza claro representa o modelo calibrado com o parâmetro $\rho$ calibrado com 0,9479 (maturidade de 4 anos). É evidente na figura como o parâmetro de maturidade altera apenas o preço do título de longo prazo e minimamente o estoque da dívida de longo prazo. O impacto nas outras variáveis é nulo. 
Figura 25 - Funções de resposta a impulso para três calibrações do modelo com Perpetual Youth e com tributação distorciva quando ocorre um choque na taxa de juros básica

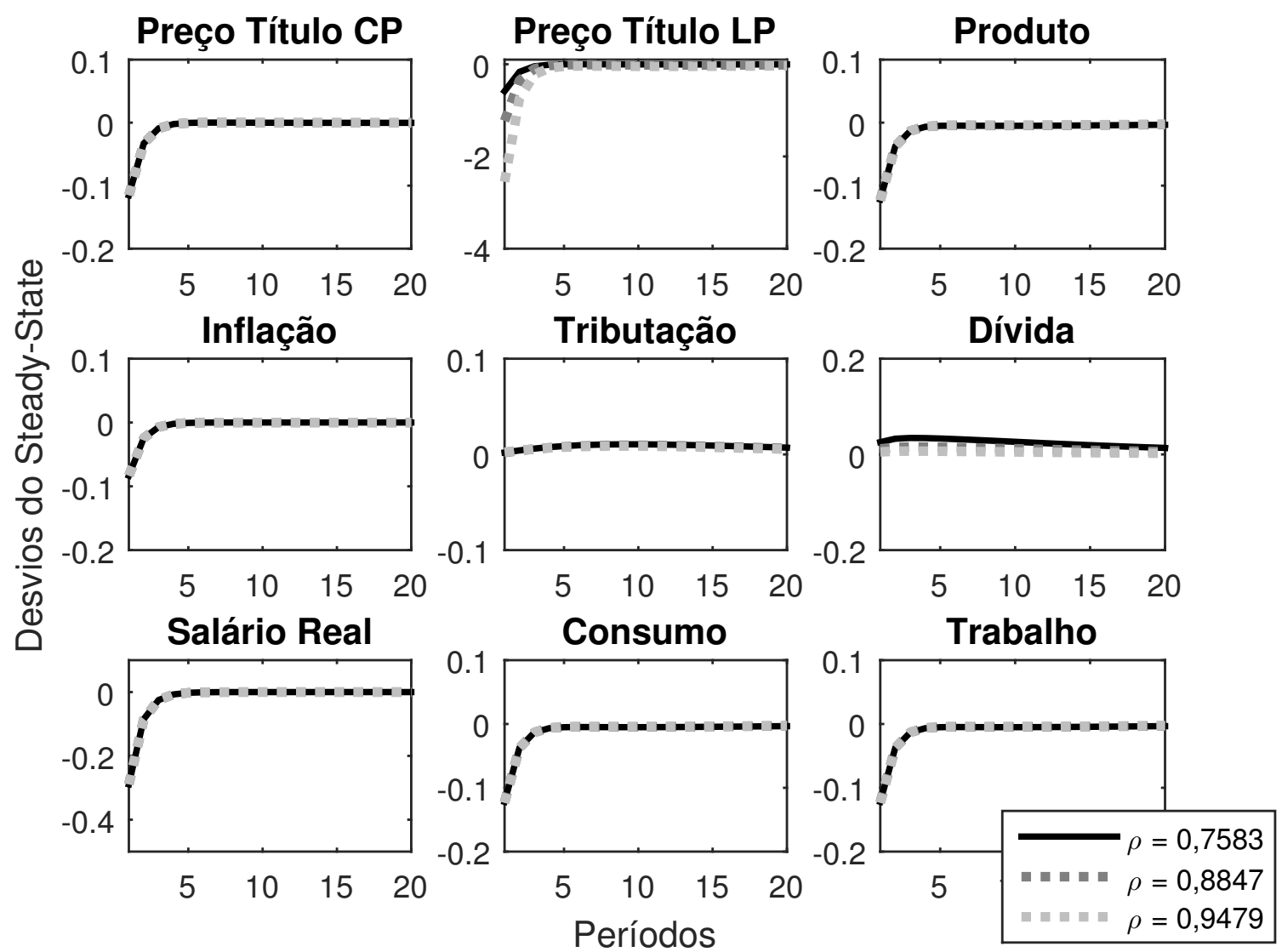

Elaboração própria 
As funções de resposta a impulso após a ocorrência do choque fiscal para o modelo com distorção no mercado de trabalho estão apresentadas na figura 26. O choque aumenta a alíquota de tributação e diminui o estoque da dívida e o preço do título de longo prazo. Como, no modelo, o imposto distorce o mercado de trabalho, o número de horas trabalhadas, o produto e o consumo caem. O salário real aumenta e é um resultado inesperado. O resultado é diferente do encontrado pela literatura empírica de política fiscal, mais especificamente Perotti (2007) e Galí, López-Salido e Vallés (2007). O choque fiscal impacta consideravelmente no preço do título de longo prazo. A figura também permite observar que, quanto maior a maturidade, menor é a variação na dívida para absorver o choque. O ajuste acontece no preço do título de longo prazo, ou seja, quanto maior a maturidade, maior a variação do preço do título quando acontece um choque fiscal. 
Figura 26 - Funções de resposta a impulso para três calibrações do modelo com Perpetual Youth e com tributação distorciva quando ocorre um choque fiscal


Elaboração própria 


\subsection{Conclusão}

Neste capítulo, foi desenvolvido um modelo DSGE com duas características marcantes que o distingue do modelo desenvolvido no capítulo 2: maturidade da dívida pública, modelada de acordo com Woodford (2001), e agentes não ricardianos, a la Blanchard (1985). Quando ocorre um choque monetário, a maturidade da dívida pública impacta, exclusivamente, na tributação, no estoque da dívida e no preço do título de longo prazo, mas a magnitude da diferença é mínima. Esse efeito é ampliado com a introdução do imposto distorcivo. O impacto da maturidade da dívida nas variáveis consumo, produto e inflação é nulo.

Quando ocorre um choque fiscal, a tributação aumenta e o estoque da dívida diminui. O preço do título de longo prazo aumenta com a queda do estoque da dívida. Sem imposto distorcivo, o preço do título de curto prazo, o produto e a inflação não são afetados pelo choque fiscal, evidenciando a validade da Equivalência Ricardiana no modelo. Com o imposto distorcivo, o choque fiscal continua afetando negativamente o preço da dívida de longo prazo e o estoque de dívida e passa a afetar negativamente o produto, o consumo, o trabalho e o preço do título de curto prazo. O salário real e a inflação aumentam momentaneamente. Vale atentar que a maturidade impacta na quantidade de dívida que é necessária emitir para absorver o choque - quanto maior a maturidade, menor é a variação da dívida que é necessária emitir. 


\section{Conclusão}

Procurou-se neste trabalho analisar qual o impacto da maturidade da dívida pública no comportamento da economia e na execução da política monetária. Para isso, desenvolveu-se três modelos de DSGE. O primeiro, apresentado no capítulo 2 tinha apenas o objetivo de padronizar a notação e de apresentar resultados comuns aos modelos que seriam desenvolvidos nos próximos capítulos.

No capítulo 3, a maturidade da dívida foi introduzida ao modelo canônico usando uma estrutura recursiva e que foi proposta por Krause e Moyen (2016). Na seção 3.1, fica claro qual seria o possível canal de impacto da maturidade no modelo - canal riqueza da dívida pública - na equação de Euler do título de longo prazo, equação (3.6). As figuras 3 e 4 levam a concluir que a maturidade da dívida pública não possui impacto na dinâmica do modelo apresentado.

Usando o caso brasileiro como motivação, procurou-se na seção 3.2 generalizar a estrutura do modelo da seção 3.1 para permitir a existência de um título com remuneração semelhante a um título pós-fixado. O argumento contra a existência das LFTs, o título pós-fixado nacional, foi primeiramente apontado por Pastore (1996). O autor argumenta que esse título enfraqueceria o canal riqueza na transmissão da política monetária. Essa modificação também não apresentou impacto ao modelo. A única diferença foi que a taxa de juros de longo prazo passou a responder a mudanças da taxa de juros básica. Mudanças na maturidade continuam não impactando na dinâmica da economia. Outras características foram introduzidas ao modelo, como tributação distorciva - seção 3.3 - e agentes rule-of-thumb - seção 3.4.

Choques fiscais aumentam a tributação e diminuem os estoques dos mais variados tipos de dívida, ficando claro o papel que esses possuem em amortecer choques na economia. A literatura de tributação ótima também argumenta que o papel da dívida pública é absorver choques na economia. A tributação distorciva leva o choque fiscal a ter efeitos contracionistas no produto e a elevar a inflação e a taxa básica de juros. Quando combina-se a adição do novo título com impostos distorcivos no mercado de trabalho, pode-se observar 
como o ajuste acontece diferente quando feito exclusivamente através de títulos pós-fixados e quando feito exclusivamente através de títulos pré-fixados.

No capítulo 4, os agentes enfrentam uma probabilidade de morrer à la Blanchard (1985). A estrutura é baseada nos modelos de Chadha e Nolan (2003) e Piergallini (2006). A forma de introduzir a maturidade da dívida pública foi proposta por Woodford (2001), sendo a dívida de longo prazo uma perpetuidade que para cupons com decaimento exponencial. No modelo, a maturidade da dívida pública impacta, exclusivamente, na tributação, no estoque da dívida e no preço do título de longo prazo, mas a magnitude da diferença é mínima. Esse efeito é ampliado com a introdução do imposto distorcivo. O impacto da maturidade da dívida nas variáveis consumo, produto e inflação é nulo.

Quando ocorre um choque fiscal, observa-se o papel da dívida pública de absorver choques na economia, resultado também encontrado pela literatura de tributação ótima. A tributação aumenta logo após a ocorrência do choque e o estoque da dívida diminui. O impacto da maturidade está na quantidade de dívida para absorver o choque - quanto maior a maturidade, menor é a variação no estoque da dívida. 


\section{Referências}

AIYAGARI, S. R.; MARCET, A.; SARGENT, T. J.; SEPPÄLÄ, J. Optimal taxation without state-contingent debt. Journal of Political Economy, v. 110, n. 6, p. 1220-1254, 2002.

ALFARO, L.; KANCZUK, F. Nominal versus indexed debt: A quantitative horse race. Journal of International Money and Finance, v. 29, n. 8, p. 1706-1726, 2010.

ANGELETOS, G. Fiscal policy with noncontingent debt and the optimal maturity structure. Quarterly Journal of Economics, v. 117, n. 3, p. 1105-1131, 2002.

ARIDA, P. As letras financeiras do tesouro em seu vigésimo aniversário. In: BACHA, E.; FILHO, L. C. O. (Ed.). Mercado de capitais e dívida pública. Rio de Janeiro: Contracapa, 2006 .

ARIDA, P.; BACHA, E.; Lara Resende, A. Credit, interest, and jurisdictional uncertainty: conjectures on the case of Brazil. In: GIAVAZZI, F.; GOLDFAJN, I.; HERRERA, S. (Ed.). Inflation targeting, debt, and the Brazilian experience, 1999 to 2003. Mass: MIT Press, 2005. p. 265-293.

BARRO, R. J. Are government bonds net wealth? Journal of Political Economy, v. 82, n. 6 , p. 1095-1117, 1974.

BARRO, R. J. On the determination of the public debt. The Journal of Political Economy, v. 87 , n. 5 , p. $940-971,1979$.

BARRO, R. J. Notes on optimal debt management. Journal of Applied Economics, v. 2, n. 2, p. 281-289, 1999.

BENIGNO, P.; WOODFORD, M. Optimal monetary and fiscal policy: A linear-quadratic approach. In: NBER Macroeconomics Annual 2003, Volume 18. Mass: The MIT Press, 2004. p. 271-364.

BERNANKE, B. S.; GERTLER, M. Inside the black box: The credit channel of monetary policy transmission. The Journal of Economic Perspectives, n. 4, p. 27-48, 1995.

BLANCHARD, O. J. Debt, deficits, and finite horizons. The Journal of Political Economy, v. 93, n. 2 , p. 223-247, 1985.

BUCHANAN, J. M. Barro on the ricardian equivalence theorem. Journal of Political Economy, v. 84, n. 2, p. 337-342, 1976.

BUERA, F.; NICOLINI, J. P. Optimal maturity of government debt without state contingent bonds. Journal of Monetary Economics, v. 51, n. 3, p. 531-554, 2004.

CALVO, G. A. Staggered prices in a utility-maximizing framework. Journal of Monetary Economics, v. 12, n. 3, p. 383-398, 1983.

CARNEIRO, D. D. Letras financeiras do tesouro e normalidade financeira: haverá um "peso problem". In: BACHA, E.; FILHO, L. C. O. (Ed.). Mercado de capitais e dívida pública. Rio de Janeiro: Contracapa, 2006. 
CARVALHO, B.; GOLDFAJN, I.; PAMES, B. O que fazer com as letras financeiras do tesouro? Estimando o custo de sua redução. In: BACHA, E.; FILHO, L. C. O. (Ed.). Mercado de capitais e dívida pública. Rio de Janeiro: Contracapa, 2006.

CASTRO, M. R. D.; GOUVEA, S. N.; MINELlA, A.; SANTOS, R.; SOUZA-SOBRINHO, N. F. SAMBA: Stochastic analytical model with a Bayesian approach. Brazilian Review of Econometrics, v. 35, n. 2, 2015.

CHADHA, J. S.; NOLAN, C. On the interaction of monetary and fiscal policy. Dynamic Macroeconomic Analysis: Theory and Policy in General Equilibrium, Cambridge University Press, p. 243, 2003.

CHAMLEY, C. Optimal taxation of capital income in general equilibrium with infinite lives. Econometrica, v. 54, n. 3, p. 607-622, 1986.

CHRISTIANO, L. J.; FITZGERALD, T. J. Understanding the fiscal theory of the price level. [S.l.], 2000.

DIAMOND, P. A. National debt in a neoclassical growth model. The American Economic Review, v. 55, n. 5, p. 1126-1150, 1965.

DIVINO, J. A.; Silva Junior, R. L. S. Public debt composition and monetary policy. Anais do XXXV Encontro Brasileiro de Econometria, v. 1, p. 1-28, 2013.

EUSEPI, S.; PRESTON, B. Fiscal foundations of inflation: Imperfect knowledge. Trabalho não publicado, 2014.

FARAGLIA, E.; MARCET, A.; OIKONOMOU, R.; SCOTT, A. The impact of debt levels and debt maturity on inflation. The Economic Journal, v. 123, n. 566, p. F164-F192, 2013.

FARAGLIA, E.; MARCET, A.; SCOTT, A. In search of a theory of debt management. Journal of Monetary Economics, v. 57, n. 7, p. 821-836, 2010.

FAVERO, C. A.; GIAVAZZI, F. Why are Brazil's interest rates so high? Bocconi, 2002.

GALI, J. Monetary Policy, Inflation, and the Business Cycle: An Introduction to the New Keynesian Framework and Its Applications. New Jersey: Princeton University Press, 2008.

GALÍ, J.; LÓPEZ-SALIDO, J. D.; VALLÉS, J. Understanding the effects of government spending on consumption. Journal of the European Economic Association, v. 5, n. 1, p. 227-270, 2007.

GANELLI, G. The new open economy macroeconomics of government debt. Journal of international Economics, v. 65, n. 1, p. 167-184, 2005.

GIORGIO, G. D.; NISTICÒ, S. Monetary policy and stock prices in an open economy. Journal of Money, Credit and Banking, v. 39, n. 8, p. 1947-1985, 2007.

GONÇALVES, F. M.; HOLLAND, M.; SPACOV, A. D. Can jurisdictional uncertainty and capital controls explain the high level of real interest rates in Brazil? evidence from panel data. Revista Brasileira de Economia, v. 61, n. 1, p. 49-75, 2007.

HALL, G. J.; SARGENT, T. J. Interest rate risk and other determinants of post-WWII US government debt/GDP dynamics. Mass, 2010. 
HILSCHER, J.; RAVIV, A.; REIS, R. Inflating away the public debt? an empirical assessment. Mass, 2014.

JUDD, K. L. Redistributive taxation in a simple perfect foresight model. Journal of public Economics, v. 28, n. 1, p. 59-83, 1985.

KRAUSE, M. U.; MOYEN, S. Public debt and changing inflation targets. American Economic Journal Macroeconomics, v. 8, 2016.

LEEPER, E. M.; ZHOU, X. Inflation's role in optimal monetary-fiscal policy. Mass, 2013.

LETTAU, M.; LUDVIGSON, S. Consumption, aggregate wealth, and expected stock returns. Journal of Finance, v. 56, n. 3, p. 815-849, 2001.

LOYO, E. Política monetária e alongamento da dívida pública. In: BACHA, E.; FILHO, L. C. O. (Ed.). Mercado de capitais e dívida pública. Rio de Janeiro: Contracapa, 2006.

LUCAS, R. E.; STOKEY, N. L. Optimal fiscal and monetary policy in an economy without capital. Journal of Monetary Economics, v. 12, n. 1, p. 55-93, 1983.

LUDVIGSON, S. C.; STEINDEL, C.; LETTAU, M. Monetary policy transmission through the consumption-wealth channel. Economic Policy Review, p. 117-133, 2002.

MINELLA, A.; SOUZA-SOBRINHO, N. Monetary channels in Brazil through the lens of a semi-structural model. Central Bank of Brazil, Working Paper Series, n. 181, 2009.

MISHKIN, F. Symposium on the monetary transmission mechanism. Journal of Economic Perspectives, v. 9, n. 4, p. 3-10, 1995.

MODIGLIANI, F. Long-run implications of alternative fiscal policies and the burden of the national debt. The Economic Journal, v. 71, n. 284, p. 730-755, 1961.

MONACELLI, T.; PEROTTI, R. Fiscal policy, wealth effects, and markups. Mass, 2008.

MUINHOS, M. K.; NAKANE, M. Comparing equilibrium real interest rates: different approaches to measure Brazilian rates. Banco Central do Brasil, Discussion paper, v. 101, 2006.

NISTICÒ, S. Monetary policy and stock-price dynamics in a DSGE framework. Journal of Macroeconomics, v. 34, n. 1, p. 126-146, 2012.

PASTORE, A. C. Por que a política monetária perde eficácia? Revista Brasileira de Economia, v. 50, n. 3, p. 281-311, 1996.

PEROTTI, R. In search of the transmission mechanism of fiscal policy. Mass, 2007.

PIERGALLINI, A. Real balance effects and monetary policy. Economic Inquiry, v. 44, n. 3, p. 497-511, 2006.

RAMEY, V. A. Can government purchases stimulate the economy? Journal of Economic Literature, v. 49, n. 3, p. 673-685, 2011.

RAMSEY, F. P. A contribution to the theory of taxation. The Economic Journal, v. 37, n. 145, p. 47-61, 1927. 
RESENDE, A. L. Em defesa dos títulos de indexação financeira. In: BACHA, E.; FILHO, L. C. O. (Ed.). Mercado de capitais e dívida pública. Rio de Janeiro: Contracapa, 2006.

ROLEY, V. V. A theory of federal debt management. The American Economic Review, v. 69, n. 5, p. 915-926, 1979.

SCHMITT-GROHÉ, S.; URIBE, M. Optimal simple and implementable monetary and fiscal rules. Journal of Monetary Economics, v. 54, n. 6, p. 1702-1725, 2007.

SEGURA-UBIERGO, M. A. The Puzzle of Brazil's High Interest Rates. Washington: International Monetary Fund, 2012.

SIMONSEN, M. H. Aspectos técnicos do Plano Collor. Revista Brasileira de Economia, v. 45, p. 113-128, 1991.

WOODFORD, M. Fiscal requirements for price stability. Journal of Money, Credit and Banking, v. 33, n. 3, p. 669-728, 2001.

WOODFORD, M. Macroeconomic analysis without the rational expectations hypothesis. Annual Review of Economics, v. 5, n. 1, p. 303-346, 2013.

YAARI, M. E. Uncertain lifetime, life insurance, and the theory of the consumer. The Review of Economic Studies, v. 32, n. 2, p. 137-150, 1965. 
Apêndices 



\section{APÊNDICE A - Modelo com Maturidade Recursiva}

\section{A.1 Calculo das Equações de Ótimo do Modelo Modificado}

O problema do consumidor é maximizar a função de utilidade:

$$
E_{0} \sum_{t=0}^{\infty} \beta^{t}\left(\frac{C_{t}^{1-\sigma}}{1-\sigma}-\frac{N_{t}^{1+\phi}}{1+\phi}\right)
$$

sujeito à restrição orçamentária modificada:

$$
\begin{aligned}
& C_{t}+\frac{B_{t}}{P_{t}}+\frac{\left(B_{t}^{P O S}-(1-\alpha) B_{t-1}^{P O S}\right)+\left(B_{t}^{P R E}-(1-\alpha) B_{t-1}^{P R E}\right)}{P_{t}} \\
& =\left(1+i_{t-1}\right) \frac{B_{t-1}}{P_{t}}+\left(\alpha+i_{t-1}^{L}\right) \frac{B_{t-1}^{P R E}}{P_{t}}+\left(\alpha+i_{t-1}^{L}\right) \frac{B_{t-1}^{P O S}}{P_{t}}+\frac{W_{t}}{P_{t}} N_{t}+Z_{t}+T_{t}
\end{aligned}
$$

e à equação da taxa média de juros do estoque de dívida de longo prazo:

$$
\begin{aligned}
\left(i_{t}^{L}-i_{t}\right) B_{t}^{P O S}+\left(i_{t}^{L}-i_{t}^{P R E, n}\right) B_{t}^{P R E}= & (1-\alpha)\left(i_{t-1}^{L}-i_{t-1}\right) B_{t-1}^{P O S} \\
& +(1-\alpha)\left(i_{t-1}^{L}-i_{t}^{P R E, n}\right) B_{t-1}^{P R E}
\end{aligned}
$$

Derivando para $C_{t}$, encontram-se a equação:

$$
\lambda_{t}=C_{t}^{-\sigma}
$$

Derivando para $N_{t}$ :

$$
N_{t}^{\phi}=\lambda_{t} \frac{W_{t}}{P_{t}}
$$

Encontrando a equação de oferta de trabalho:

$$
\frac{N_{t}^{\phi}}{C_{t}^{-\sigma}}=\frac{W_{t}}{P_{t}}
$$

Derivando para $B_{t}$, encontra-se:

$$
\frac{\lambda_{t}}{P_{t}}=E_{t} \beta \frac{\lambda_{t+1}}{P_{t+1}}\left[1+i_{t}\right]
$$

ou, simplificando:

$$
1=E_{t} \beta \frac{\lambda_{t+1}}{\lambda_{t}} \frac{P_{t}}{P_{t+1}}\left[1+i_{t}\right]
$$


Derivando para $B_{t}^{P O S}$ :

$$
\frac{\lambda_{t}}{P_{t}}+\beta E_{t} \frac{\lambda_{t+1}}{P_{t+1}}\left(1+i_{t}^{L}\right)-\mu_{t}\left(i_{t}^{L}-i_{t}\right)+\beta E_{t}(1-\alpha) \mu_{t+1}\left(i_{t}^{L}-i_{t}\right)=0
$$

Derivando para $B_{t}^{P R E}$ :

$-\frac{\lambda_{t}}{P_{t}}+E_{t} \beta \frac{\lambda_{t+1}}{P_{t+1}}\left(1+i_{t}^{L}\right)-\mu_{t}\left(i_{t}^{L}-i_{t}^{P R E, n}\right)+\beta(1-\alpha) E_{t} \mu_{t+1}\left(i_{t}^{L}-i_{t+1}^{P R E, n}\right)=0$

Derivando para $i_{t}^{L}$ :

$\beta E_{t} \frac{\lambda_{t+1}}{P_{t+1}}\left[B_{t}^{P O S}+B_{t}^{P R E}\right]-\mu_{t}\left[B_{t}^{P O S}+B_{t}^{P R E}\right]+\beta E_{t}(1-\alpha) \mu_{t+1}\left[B_{t}^{P O S}+B_{t}^{P R E}\right]=0$

Simplificando a derivada de $B_{t}^{P O S}$ e colocando $\left(i_{t}^{L}-i_{t}\right)$ em evidência:

$$
-\frac{\lambda_{t}}{P_{t}}+\beta E_{t} \frac{\lambda_{t+1}}{P_{t+1}}\left(1+i_{t}^{L}\right)-E_{t}\left(\mu_{t}-\beta(1-\alpha) E_{t} \mu_{t+1}\right)\left(i_{t}^{L}-i_{t}\right)=0
$$

usando o resultado da simplificação da derivada de $i_{t}^{L}$ :

$$
-\frac{\lambda_{t}}{P_{t}}+\beta E_{t} \frac{\lambda_{t+1}}{P_{t+1}}\left(1+i_{t}^{L}\right)-\beta E_{t} \frac{\lambda_{t+1}}{P_{t+1}}\left(i_{t}^{L}-i_{t}\right)=0
$$

simplificando encontramos uma equação idêntica a equação (3.4):

$$
1=\beta E_{t} \frac{\lambda_{t+1}}{\lambda_{t}} \frac{P_{t}}{P_{t+1}}\left(1+i_{t}\right)
$$

Simplificando a derivada de $B_{t}^{P R E}$ :

$$
-\frac{\lambda_{t}}{P_{t}}+\beta E_{t} \frac{\lambda_{t+1}}{P_{t+1}}\left(1+i_{t}^{L}\right)-\mu_{t}\left(i_{t}^{L}-i_{t}^{P R E, n}\right)+(1-\alpha) E_{t} \mu_{t+1}\left(i_{t}^{L}-i_{t+1}^{P R E, n}\right)=0
$$

rearranjando a equação

$$
\frac{\lambda_{t}}{P_{t}}=\beta E_{t} \frac{\lambda_{t+1}}{P_{t+1}}\left(1+i_{t}^{L}\right)-\mu_{t} i_{t}^{L}+\mu_{t} i_{t}^{P R E, n}+\beta E_{t}(1-\alpha) \mu_{t+1} i_{t}^{L}-\beta E_{t}(1-\alpha) \mu_{t+1} i_{t+1}^{P R E, n}
$$

colocando $i_{t}^{L}$ em evidência

$$
\left.\frac{\lambda_{t}}{P_{t}}=\beta E_{t} \frac{\lambda_{t+1}}{P_{t+1}}\left(1+i_{t}^{L}\right)-E_{t}\left(\mu_{t}-\beta(1-\alpha) \mu_{t+1}\right) i_{t}^{L}+\mu_{t} i_{t}^{P R E, n}-\beta E_{t}(1-\alpha) \mu_{t+1} i_{t+1}^{P R E, n}\right)
$$

usando o resultado da simplificação da derivada de $i_{t}^{L}$ :

$$
\begin{aligned}
\frac{\lambda_{t}}{P_{t}}= & \beta E_{t} \frac{\lambda_{t+1}}{P_{t+1}}\left(1+i_{t}^{L}\right)-\beta E_{t} \frac{\lambda_{t+1}}{P_{t+1}} i_{t}^{L}+E \\
& \left.-t\left(\beta \frac{\lambda_{t+1}}{P_{t+1}}+\beta(1-\alpha) \mu_{t+1}\right) i_{t}^{P R E, n}-\beta(1-\alpha) \mu_{t+1} i_{t+1}^{P R E, n}\right)
\end{aligned}
$$




$$
\frac{\lambda_{t}}{P_{t}}=\beta E_{t} \frac{\lambda_{t+1}}{P_{t+1}}\left(1-i_{t+1}^{P R E, n}\right)-\beta E_{t}(1-\alpha) \mu_{t+1}\left(i_{t+1}^{P R E, n}-i_{t}^{P R E, n}\right)
$$

Usando a normalização do multiplicador de Krause e Moyen (2016), a equação fica exatamente igual a equação (3.6):

$$
1=E_{t} \beta E_{t} \frac{\lambda_{t+1}}{\lambda_{t}} \frac{P_{t}}{P_{t+1}}\left[1+i_{t}^{L, n}-\mu_{t+1}(1-\alpha) \Delta i_{t+1}^{P R E, n}\right]
$$

Simplificando a derivada de $i_{t}^{L}$ e dividindo por $B_{t}^{P O S}+B_{t}^{P R E}$ :

$$
\beta E_{t} \frac{\lambda_{t+1}}{P_{t+1}}-\mu_{t}+\beta E_{t}(1-\alpha) \mu_{t+1}=0
$$

Usando a normalização do multiplicador de Krause e Moyen (2016), a equação fica exatamente igual a equação (3.5):

$$
\mu_{t}=\beta E_{t} \frac{\lambda_{t+1}}{\lambda_{t}} \frac{P_{t}}{P_{t+1}}\left(1+(1-\alpha) \mu_{t+1}\right)
$$





\section{APÊNDICE B - Modelo com perpetual youth}

\section{B.1 Consumo Agregado}

A equação de consumo como função da riqueza é:

$$
P_{t} C_{s, t}=\Psi\left[\Omega_{s, t}+E_{t} \sum_{i=0}^{\infty} \Lambda_{t, t+i}(s)(1-\xi)^{i} \Upsilon_{s, t+i}\right]
$$

sendo $\Psi \equiv(1-\beta(1-\xi))$ e $\Upsilon_{s, t+i} \equiv W_{t+i} N_{s, t+i}+Z_{s, t+i}-T_{t+i}$.

Essa equação pode ser agregada por coortes:

$$
P_{t} C_{t}=\Psi\left[\Omega_{t}+E_{t} \sum_{i=0}^{\infty} \Lambda_{t, t+i}(1-\xi)^{i} \Upsilon_{t+i}\right]
$$

sendo $\Upsilon_{t+i} \equiv W_{t+i} N_{t+i}+Z_{t+i}-T_{t+i}$. Subtraindo $P_{t+1} C_{t+1}$ de $P_{t} C_{t}$ tem-se:

$$
P_{t+1} C_{t+1}-P_{t} C_{t}=\Psi\left[\Omega_{t+1}-\Omega_{t}-\Upsilon_{t}+\left(1-(1-\xi) \Lambda_{t, t+1}\right) \sum_{i=0}^{\infty}(1-\xi)^{i} \Lambda_{t+1, t+1+i} \Upsilon_{t+1+i}\right]
$$

Reescrevendo a restrição orçamentária usando a definição de riqueza financeira agregada, tem-se:

$$
\Omega_{t}=P_{t} C_{t}+Q_{t}^{S} \Omega_{t+1}-\Upsilon_{t}
$$

Logo, pode se encontrar $\Omega_{t+1}-\Omega_{t}$ :

$$
\Omega_{t+1}-\Omega_{t}=\left(1-Q_{t}^{S}\right) \Omega_{t+1}-P_{t} C_{t}+\Upsilon_{t}
$$

Substituindo a equação (B.4) na equação (B.2), tem-se:

$$
P_{t+1} C_{t+1}-P_{t} C_{t}=\Psi\left[\Omega_{t+1}-\Omega_{t}-\Upsilon_{t}+\left(1-(1-\xi) \Lambda_{t, t+1}\right) \sum_{i=0}^{\infty}(1-\xi)^{i} \Lambda_{t+1, t+1+i} \Upsilon_{t+1+i}\right]
$$

e usando a equação (B.1) um período a frente:

$$
P_{t+1} C_{t+1}-P_{t} C_{t}=\Psi\left[\left(1-Q_{t}^{S}\right) \Omega_{t+1}-P_{t} C_{t}+\left(1-(1-\xi) \Lambda_{t, t+1}\right)\left[\frac{P_{t+1} C_{t+1}}{\Psi}-\Omega_{t+1}\right]\right.
$$

Com simplificações algébricas, acha-se a equação (4.3):

$$
E_{t} P_{t+1} C_{t+1}=\beta R_{t} P_{t} C_{t}-\frac{\xi}{1-\xi} \Psi E_{t} \Omega_{t+1}
$$

